\title{
Ilse Kunert
}

\section{J. U. Niemcewicz: \\ Śpiewy historyczne}

Geschichtsauffassung und -darstellung

Verlag Otto Sagner München · Berlin - Washington D.C.

Digitalisiert im Rahmen der Kooperation mit dem DFG-Projekt „Digi20“

der Bayerischen Staatsbibliothek, München. OCR-Bearbeitung und Erstellung des eBooks durch den Verlag Otto Sagner:

http://verlag.kubon-sagner.de

() bei Verlag Otto Sagner. Eine Verwertung oder Weitergabe der Texte und Abbildungen, insbesondere durch Vervielfältigung, ist ohne vorherige schriftliche Genehmigung des Verlages unzulässig.

«Verlag Otto Sagner» ist ein Imprint der Kubon \& Sagner GmbH. 


\section{SLAVISTIS CHE BEITRAGE}

Unter Mitwirkung von M. Braun, Göttingen - † P. Diels, München - J. Holthusen, Bochum - E. Koschmieder, München - W. Lettenbauer, Freiburg/Br. - J. Matl, Graz F. W. Neumann, Mainz - K.-H. Pollok, Regensburg - L. Sadnik-Aitzetmüller, Saarbrücken - J. Schütz, Erlangen

HERAUSGEGEBEN VON A. SCHMAUS, MONCHEN

Technische Redaktion: P. Rehder, München

Band 28 


\section{ILSE KUNERT}

J.U. NIEMCEWICZ: ŚPIEWY HISTORYCZNE GESCHICHTSAUFFASSUNG UND -DARSTELLUNG 
Copyright by Verlag Otto Sagner, München 1968

Abteilung der Fa. Kubon \& Sagner, München

Druck: Fa. W. u. I. M. Salzer

8 München 2, Schleißheimer Straße 20 


\section{Vorwort}

Diese Arbeit ist im Jahre 1955 von der Philosophischen Fakultät der Universität München als Dissertation angenommen worden. Da in der $\mathrm{Zwischenzeit} \mathrm{meines} \mathrm{Wissens}$ keine neuen Untersuchungen zu diesem Thema erschienen sind und auch die im Pamiętnik Literacki geführte und 1959 abgeschlossene Diskussion zwischen Maria Diuska und Kazimierz Budzyk über den polnischen Syllabotonismus keine Argumente gegen die hier - im Kapitel úber Metrum und Rhythmus - vertretene Meinung erbracht hat, glaubte ich, von einer Uberarbeitung der Dissertation absehen zu durfen.

Meinem verehrten Doktorvater Prof. Dr. Alo1s Schmaus möchte ich auch an dieser Stelle sehr herzlich dafür danken, dass er die Arbeit in der von inm begrundeten und herausgegebenen Reihe "Slavistische Beiträge" aufgenommen und inre Veröffentlichung auch finanziell unterstützt hat.

München, November 1967

Ilse Kunert 
$\underline{\text { Seite }}$

Einfuhrung :

1) Die wichtigstẹ geistigen Strömungen in Polen in der Zeit von 1795-1820

2) Niemcewicz - Leben und Werk

I. Die "Splewy Historyczne"
1) Gattung
$22-28$
2) Entstehung
$28-35$

II. Die Geschichte und ihre Darstellung
1) Der historische Gehalt
$36-62$
2) Die Quellen
$63-68$

III. Die sprachlichen und künstlerischen Mittel der Darstellung
1) Die Śplewy und ihr Verhältnis zur Ballade
$69-75$
2) Strophe, Reim, Metren und Rhythmus
$75-86$
3) Wortschatz, Syntax und rhetorische Figuren
$86-107$
4) Der Aufbau
$108-121$

Zusammenfassung

$122-129$

Li teraturverzeichnis 


\section{1) Die wicht1gsten geistigen Strömungen in Poken von $1795-1820$}

Eine Arbeit, die sich mit Julian Ursyn Niemcewicz (1757 1841) befasst, also einem Menschen und Dichter, dessen Wirken und Einfluss in die tragische leit der Tellungen und des Herzogtums und späteren Könlgrelches Warschau fällt, kann nicht ohne einen Ausblick auf die allgemeinen polnischen Verhältnisse dieser zeit verständlich werden. Denn wohl kaum eine andere Zeit in der Geschichte Polens hat inre Menschen 80 geformt und inren Bedurfnissen angepasst wie gerade diese Epoche.

jie durch die Tellungen erfolgte Zersplitterung Polens in einen preussischen, einen oesterreichischen und einen russ1schen Tell, zu dem sich se1t 1807 noch das Herzogtum Warschau gesellte, das dann 1815 in veränderter Gestalt von dem Königrelch Kongresspolen abgelöst wurde, macht die polit1sche Geschichte dieser zeit äusserst kompliziert und verwlckelt. Sie hat viele sowohl positive als auch negative Blemente aurzuweisen. Literarisch aber war sie elne Zeit der Wiedergeburt. Zu diesem Ergebnis ist die heutige Porschung ${ }^{2}$ im Gegensatz zu den alteren Literarhistorikern wie Chlebowski oder Chrzanowsk1 gekommen, welch letzterer die zäsur zwischen altpolnischer und neuer Ifteratur in die zeit der Teilungen verlegt, was schon in dem Titel seines Werkes "Historya Iiteratury Niepodległej Polski" (Geschichte der Ifteratur des unabhän-

1 The Cambridge History of Poland, Cambildge University Press 1951 . Tadeusz Mikulski, Literatura obwięcenia. In "O Sytuacj1 W Histori1 I1 teratury Polskiej", Krakbw 1953. Julian Rrzyzanowski; Historja Li teratury Polskiej, Warszawa 1953. 
gigen Polen) zum Ausdruck kommt. Diese Haltung der Literarhistoriker ist zu einem grossen Teil auch durch den literarischen Kampf der Klassizisten gegen die Romantiker und die Auffassungen der romantischen Schriftsteller selbst beeinflusst worden. Heute ist man zu der Uberzeugung gelangt, dass die Romantik selbst während einer langen Zeitspanne aus den Ideen und Strömungen der Aufklärung geschöpft habe, und zwar besonders die Warschauer und Wilnaer Romantiker, so dass eine derartige Trennung gewaltsam und damit fragwïrdig wäre. Auch kulturgeschichtliche Gesichtspunkte sprechen gegen die al te Auffassung, wie z.B. das Aufblühen des literarischen Lebens in der Epoche Stanislaw Augusts, das über die Teilungen hinweg auch in den ersten Jahren des 19. Jahrhunderts noch wirksam war. In den ersten Jahren nach dem Untergang des polnischen Staates war allerdings alles geistige und kulturelle Leben erstarrt. Aber allmählich erholte man sich wieder und begann, die Reformarbeit aus den letzten Regierungsjahren des konigs Stanisław fortzusetzen, und zwar mit verstärkter Energie. Kultur und Wissenschaften waren einzig und allein darauf ausgerichtet, das stagnierende geistige Leben wiederzuerwecken und dem einen ziele dienstbar zu machen: der Wiederherstellung eines polnischen Staates. Ein neuer Geist war erwacht. Vor den Teilungen hatte das Volk das Land mit dem Staate identifiziert, und somit bedeutete der zerfall des Staates für das polnische Volk auch den Untergang der Nation. Das 1797 in Paris entstandene Lied von Wybicki "Jeszce Polska nie zginęłan, die Nationalhyme der Polen, aber gab inm die freudige Gewissheit, dass die Nationalität den Zusammenbruch des Staates durchaus überleben kann, wenn es noch ein Volk gibt, das dieser Nationalität bewusst angehört. Dieser Glaube bemächtigte sich der ganzen Nation und murde zur Inspiration für die polnische Literatur, ausgedríckt von den Legionärsdichtern, die an den napoleonischen Kriegen teilgenommen hatten, und von den Warschauer "Klassizlsten". Daher war die 
Rolle, die die Literatur im Zeitalter nach den Teilungen in Polen spielte, weit grösser als in den anderen europäischen Staaten. Tarnowski formuliert die Begründung dafür folgendermassen: "Während bei anderen glücklicheren Völkern der Sinn des Volkes und seine Gefüle tausend Formen haben, in die sie sich ergiessen und in denen sie sich sammeln können, während sie sich in politischer Tätigkeit, im sozialen Fortschritt, in der Wissenschaft, im religiösen Leben, im wirtschaftichen Fortschritt kundtun können, haben sich hier diese Felder und Richtungen entweder ganz und alle plötzlich geschlossen, oder doch zumindest so, dass keins von ihnen sich ganz frei entwickeln konnte. So floss alles zusammen und sammelte sich in dem Lebenszweig, der seiner Natur entsprechend trotz Zensur und Polizei sich am freiesten entwickelt, am leichtesten der Kontrolle entgeht." 2 Der einzige Bereich also, in dem sich alles Empfinden verhältnismässig frei äussern konnte, war die Literatur. Da sie aber zum Sammelbecken so vieler verschiedenartiger Lebensgebiete geworden war, musste sich auch inre Struktur ändern, d.h. sie war nicht mehr nur reine Literatur, sondern $z u$ ihr gehörten nun auch wissenschaftliche Gebiete, Philosophie, Geschichte usw. Und dazu waren dieser Literatur noch ganz besondere Aufgaben erwachsen, sie sollte "dienen, retten, sollte sowohl die Seele des Volkes wie auch alle ihr noch verbliebenen Lebensmöglichkeiten vor dem Untergang bewahren." Dass sie dennoch oder vielleicht gerade deswegen im Vergleich mit der Literatur anderer Epochen, z.B. der der Romantik oder der des "Goldenen Zeitalters", künstlerisch nicht so hochstehend ist, liegt nicht nur an der Tendenz, die zu verfechten sie sich zur Aufgabe gesetzt hatte, sondern auch an dem Mangel an grossen Talenten, der aber wohl bis zu einem gewissen Grade auch wieder mit der Epoche selbst in engem Zusammenhang steht.

2 Stanisław Tarnowski, Historya Literatury Polskiej, IV, Krak. 1904 , S. 18. 
Die polnische Literatur der Zeit unmittelbar nach den Teilungen und ihre Vertreter sind von dem Towarzystwo Przyjacibł Nauk nicht zu trennen. Diese Gesellschaft der Freunde der Wissenschaften entwickelte sich aus anfänglichen privaten Aussprachen und Zusammenkünften in Warschau, in denen uber die verbliebenen Möglichkeiten zur Erhaltung und Förderung der alle verbindenden Muttersprache und Litertur beraten wurde. Diejenigen, die in ihr das Band der nationalen Einneit erkannten, waren zum grössten Teil Gelehrte und Schriftsteller aus der Zeit Stanisław Augusts, die sich schon von den Donnerstag-Zusammenkünften beim König kannten und schätzten. Aus diesen gelegentlichen Verabredungen wurden allmählich rezelmässige Versammlungen und Sitzungen, bis sich im November des Jaines 1800 die Gesellschaft konstituierte, der u.a. Schriftsteller wie Trembecki, Krasicki, Karpiński angehörten, der kluge und hoch gebildete First Adam Czartoryski, der auch gelegentlich zur Feder gegriffen hat, Staszic, der fruhere Redakteur der "Gazeta Narodowa i Obca", oder Gelehrte wie Linde, Kopczyhski, Bandtke und Czacisi.

Die meisten dieser Männer, die an dem kulturellen Kampf um die Erhaltung der Sprache und Nationalität teilnahmen, waren auch direkt oder indirekt an der Arbeit des grossen Sejm beteiligt gewesen, waren also durchdrungen von den Ideen ier Aufklärung.

In dieser Zeit zeichnete sich schon eine für die Getsteshaltung des damaligen Polen kennzeichnende Strömung ab: die Hinwendung zu der eigenen Vergangenheit, um in der $\mathrm{Be}-$ schiftifung mit ihr Trost in der augenblicklichen, hoffnungs los erscheinenden Lage, aber auch, um Antwort auf die bohrenden Fragen nach den Ursachen des Unterganges zu finden. Aus dieser Einstellung heraus entstanden z.B. die archäologisch-ethnoloEischen Arbeiten von Jan Potocki, Alexander Sapieha u.a.m., 
schreibt Manfred Kridl ${ }^{3}$ und fïhrt weiter aus, dass auf der Suche nach den Grundlagen des eigenen Volkstums, seinen Juellen und Horten manche dieser Forscher sich dem Volke, seinem Brauchtum und seinem geistigen Leben näherten. "In all diesem sehen sie den Ausdruck der ursprünglichen Volksseele, die sich hier behauptet, die alle Niederlagen überdauert hatte, die von aussen über sie gekommen waren, und die den Schatz der alten Traditionen erhalten hatte. Nan beginnt also, Denkmäler zu sammeln, Gräber auszugraben, Legenden, Volksmärchen und Volksdichtung niederzuschreiben. Im Zusammenhang damit zeichnet sich das streben ab, auf das Volk einzuwirken, es aufzuklären und zu nationalisieren." Kridl weist dann darauf hin, dass dieses studium der vergangenheit auf die gemeinsame Herkunft der Polen mit den anderen slavischen Völkern und damit also auch zu Untersuchungen über das ganze Slaventum führen musste, aus denen dann auf bestimmte gemeinsame Kennzeichen geschlossen werden konnte. Und vielleicht konnte es auf diese Weise sogar gelingen, daraus irgendwelche Hinwelse für die zukunft zu ziehen. Auf dieser Grundlage entwickelte sich das Slavophilentum, wie Kridl unterstreicht, nicht in politischem Sinn wie einige Jahrzehnte später in Russland, sondern als ein rein kulturelles Interesse, geboren aus einem gewissen Zusammengehörigkeitsgefül mit den anderen Slaven, das in manchen Fällen sogar zu einem Uberlegenheitsgefühl des Slaventums über die anderen völker führte.

Der Beschäftigung mit der Vergangenheit hat noch eine ardere geistige Richtung im Polen dieser Epoche ihr Aufblühen zu verdanken: der Messianismus, der zwar erst zwei Jahrzehnte später seine Blütezeit erlebte (Andrzej Towiahski, Mickiewicz), dessen viedererwachen aber schon in den Werken von Woronicz

3 lianfred Kridl, Iiteratura Polska Wieku KIX., Częst I, S.40' f. Warsz. 1930 
(+ 1829) deutlich zu erkennen ist. Auch hier wieder kam der neue Glaube an das "Unsterbliche" eines Volkes zum Ausdruck. Im Gegensatz zu dem weltabgewand ten Mystizismus von Towiański kommt Woronicz, der vom pastoralen Dichter des Puławer Kreises zum nationalen Psalmisten geworden war, durch seinen Glauben an die Gerechtigkeit und Barmherzigkeit Gottes zu seinem gewissermassen praktischen Messianismus, der in dem unerschütterlichen Glauben an die zukunft des Vaterlandes seinen Ausdruck fand. Und Woronicz hatte sich diese seine Zúversicht nicht nur für sich geschaffen, sondern er wollte auch seine Landsleute, die ja alle unter demselben Druck litten, aufrichten und an seiner Hoffnung teilhaben lassen. Vor allem aber wollte er si.e mit dieser Zuversicht für die Arbeit für das Vaterland gewinnen und sie aus inrer Resignation emporreissen. Die Quelle für seinen Glauben und die Zuversicht nahm Woronicz aus der Erkenntnis, dass nicht ein blind waltendes Schicksal die Schuld an dem Untergang Polens trug, sondern dass die Ursachen dazu bei den Polen selbst zu suchen seien, in ihren eigenen Fehlern nämlich: "Wie es kommt, fragt Ihr, dass die Last des Unglücks schon so lange Euer geplagtes Vaterland quält? Da diese Schuld nicht auf den Vater und Herrn fällt, muss die Quelle und der Ursprung bei Euch liegen." 4 Die Folge dieses sündigen Verhaltens war der Untergang, von der göttlichen Vorsehung als gerechte Strafe über die Polen gesandt. Diese Uberzeugung von der göttlichen Vorsehung hat Woronicz aus seinem eigenen inneren Verhältnis zu Gott gewonnen. In dem letzten Gesang der "Swiątynia Sybilli" weist der Dichter seinen Landsleuten den Weg: "Kann Er Euch, Ihr Kinder, die Ihr von der Ewigkeit inspiriert und bestimmt seid, an seinem Erbe teilzuhaben, auch nur für einen Augenblick vergessen? oder Euch dem Schicksal Uiberlassen, selbst dann, wenn Er

4 Jan Paweł Woronicz, Swiątynia Sybilli; zitiert bei Kridl, 1. C. S.62. 
Euch gerechtermassen betrüben müsste? lest in seinen Büchern die niedergeschriebene Wahrheit." 5 Die Idee der Vorsehung, die übrigens von Massilon, Rollin, Diderot, Rousseau, Voltaire u.a. aus der christlichen Ethik ubernommen worden ist Voltaire hat selbst in der Vorrede zum Dictionnaire philosophique festgestellt, dass "Le dogme de la providence est nécessaire au bonheur humain" - , erklärte also für Woronicz den Untergang Polens. ${ }^{6}$ Aber nicht nur das, sie gibt inm auch gewisse Hoffnungen auf ein Wiedererstehen, denn wenn die zeit der Sünden vorbei ist, hören auch die Strafen auf "Unsre Tränen sind die Zeugen von Fehlern und Besserung". 7 Es kann nichts anderes folgen, als die Wiedergeburt der früheren Grösse: "Morsche Knochen! Steht auf aus dem Grabe, nehmt Seele, Gestalt und Kraft an! $\$ 8$ Was Woronicz aber von den Aufklärern oder auch von Bossuet unterscheidet, ist sein Mystizismus, der auf der Uberzeugung des Dichters von dem besonderen Verhältnis Polens zu Gott basiert. Hier liegt die eigentliche Wurzel seines und des polnischen Messianismus überhaupt. Woronicz hat diesen Messianismus nicht geschaffen, vorher hatten schon andere, wie z.B. der "Bard Polski", ähnliche Ideen, aber noch sehr verschwommen geäussert. Woronicz hat aber als erster die grundlegenden Ideen des polnischen Messianismus klar formuliert. Begrindet war diese Uberzeugung von Polen als dem auserwählten Volke auf dem Gefühl der moralischen Uberlegenheit des Besiegten über die Sieger, wie es ja dem östlichen Nachbarn gegenüber in Polen allgemein der Fall war, und nicht zuletzt auf dem Uberlegenheitsgefuhl des katholischen Glaubens der Orthodoxie gegenüber. Hinzu kam die Berufung auf Tugenden und Verdienste, die wohl von manchen Geschlechtern durch Verfehlungen beeinträchtigt worden waren, aber immer von neuem

5 Ebd. S.61

6 Siehe dazu: Kazim.Jarecki, Die geschichtsphilosph. Ideen von Woronicz und der polnische Messianismus. Pamiętnix. Literacki, Rocznik 3, S. 414 .

7 Jan Pawel Woronicz, Hyin do Boga, Vers 193, zitiert bei Kridl, 1. c. S. 69

8 Ebd. 
hervortraten, da sie den Polen anjeboren sind. Am bemerkenswertesten an den Prophezeiungen von Woronicz ist die Tatsache, dass die Rolle des messianistischen Faktors bei inm dem revolutionären Frankreich zufällt, obwohl doch gerade Woronicz von echter Religiosität durchdrungen war und die Ideen der französischen Philosophie von der Leugnung des Zufalls im religiösen Sinne umgewandelt hatte, um die Notwendigkeit des Handelns mit der Freiheit des individuellen Willens in Einklang zu bringen. Ujejski kommt zu dem Schluss, dạss die heisse Vaterlandsliebe Woronicz's sich nicht mit dem einfachen und allzemeinen Trost des Glaubens an die Gerechtigkeit Gottes, die seinem Vaterland früher oder spiter die Existenz wiederbringen musste, begnügen konnte. Darum suchte er am politischen Horizont nach Zeichen, die inm die wiedergewonnene Gnade Gottes bald, vielleicht sogar schon jetzt verheissen konnten. So kam er auf das Beispiel Prankreichs, dem er zu entnehr.en glaubte, dass der Tag der Gerechtigkeit nahe ist. 9 Dieser französische, oder noch besser gesagt, napoleonische Messianismus wurde von einem grossen Teil der polnischen $0 f-$ fentlichkeit geteilt, zumal er auch noch von einem anderen, die polnische Offentlichkeit stark beeinflussenden Mann verkündet wurde: Hugo Kołıątaj. Der Grund ist bei Kołłątaj wohl in den poiitischen Ge ebenheiten zli suchen, die eine Verwirklichung jer polnischen Hoffnungen durch Napoleon als naheliezend erscheinen Itessen. Im grossen ganzen aber wandte sich Kołłątaj mehr dem panslavischen Messianismus zu. Auch im Tow. Prz. Nauk setzte sich diese Richtung durch. Unter dem Eindruck der politiscien Linie des Füsten Czartoryski, der während seines lanjen Aufenthaltes in Petersburg die Freundschaft des damalisen Thronfolgers Alexander erworben hatte und nun, nach der Krönung Alexanders zum Zaren, glaubte, Polen nur an der Seite Russlands aus seinem Unglück wieder zur Selbständigkeit führen zu können, begann nan im Kongress-Könizreicn die rioffnung auf kisiland und vor allew auf

9 Josef ijjejski, Jzieje Yoiskiejo liesjanizmu do Powstania Iistopajowego włącrnie. Lwow i931, S.69. 
seinen reformfreudigen Zaren Alexander zu setzen. Frankreich wurde dementsprechend in der halb mystischen Vorstellung des Retters Polens von den Slaven abjelöst. Am deutlichsten wird diese Hinwendung zum Slaventum in den etymologischen Untersuchungen. Kołłątaj hat z.B. in seinem Werk "Rozbior Krytycz= ny Zasad Historyi o Początkach Rodu Ludzkiego" die Slaven als die ältesten völker dargestellt. Das ist umso erstaunlicher, als Koiłątaj in seinen theoretischen Schriften eine Geschichtsauffassung vertrat, die in vielen Punkten der seiner Zeitgenossen vorauseilte. ${ }^{10}$ Jozef Ujejski glaubt, dass ein Mensch der Aufklärung par excellence, wie Hugo Kołłątaj es war, wahrscheinlich von demselben Motiv getrieben worden ist, das - ebenfalls nach Verlust der Unabhängigkeit par force - Fichte den Ursprung des deutschen Volkes nachweisen lässt. ${ }^{11}$

Der Messianismus ist aber nur der stärkste und überspitzte Ausdruck des eigentlichen Grundtones der polnischen Dichtung nach den Teilungen. Juliusz Kleiner nennt inn "das siegreiche schöpferische Sichaufbäumen des nationalen Geistes im Moment einer Todesgefahr". ${ }^{12}$ Kleiner stellt die Verbindung der polnischen Literatur mit der europäischen uberhaupt her, wenn er darauf hinweist, dass wie bei Jeanne d'Arc auch in Polen der Patriotismus zur Relizion und wie bei Fichte die Nationalität zum Mittelpunkt des iel tanschaungsproblems wurde. Die Literatur war im Polen dieser Epoche "die gottbegnadete Küstlerin, die ihre Nation $z$ e einer Idealgestalt formen, ihr eine unbeugsame Lebensstärke einflössen sollte, ähnlich den hebräischen Propheten, die ihr Volk in der babylonischen Sklaverei aufrechterhielten, oder dem Moses vergleichbar, der sein Volk in das gelobte Land hinüberführt". Kleiner führt dann weiter aus,

10 Siehe dazu auch Karol Chodynicki, Poglądy Zadania Historyi w Epoce Stanisława Augusta. Prace historyczno-literackie $\mathrm{Nr} .15$. Warsz. 1915.

11 Jozef Ujejski, 1.c. S. 88.

12 Juliusz Kleiner, Die polnische Literatur. 
dass diese Rolle bewusst zwar erst von den Dichtern nach dem Jahre 1831 ubernommen worden ist, dass aber auch die Vertreter der vorromantischen Periode bereits die neue Aufgabe der Nationalliteratur geahnt haben.

Diese vorromantische Periode der polnischen Literatur stand ganz im Zeichen der Rezeptivität, denn sie hatte alle ihre literarischen Keime aus dem Westen bezogen. Das geistije Polen dieser Zeit hat zwar nichts Eigenes geschaffen, aber die übernommenen Ideen den eigenen Bedürfnissen angepasst und sie damit gewissermassen nationalisiert. Ganz besonders trifft das auch für die geschichtsphilosophischen Anschauungen $z u$, wie u.a. auf die Verlagerung des Interesses an der gesamten Nenschheit (Voltaire) in Polen auf die polnischen Verhältnisse im besonderen. Woronicz's "Swiątyṇia Sybilli" bietet dafür ein gutes Beispiel. "Nadysław, Cwik" weist in seiner Untersuchung über den Ursprung der "Swiątynia Sybilli" auf die weitgehenden Analogien in der Einteilung und $2 . T$. auch im Ausdruck mit den "Rliines" von Volney hin. Der einzige Unterschied läge darin, schreibt $\dot{C}_{w i k}$, dass Volney das Schicksal der Menschheit überhaupt, Woronicz aber das Schicksal Polens beweint. Diese Ubertragung der geschichtsphilosophischen Ideen des Westens in den polnischen Bereich ist nicht nur für Woronicz, sondern auch für die tiefsten Denker dieser Zeit, Staszic und Kołłątaj, kennzeichnend. Auch sie verfechten in ihren geschichtlichen werken in erster Iinie nationale Tendenzen, wenn auch Kołłątaj die kosmopolitische Richtung in seinen theoretischen Schriften mit einbezieht.

Auch für die Geschichtsbetrachtung dieser Epoche gilt im grossen und ganzen noch das, was Chodynicki in seiner Arbeit über die Aufgaben der Geschichte in der Epoche Stanisław August's 14

13 :iładysław Cwik: Wpływ "Ruin" Volneya na "Sybillę" Woronicza. Famietnik Iiteracki, Rocznik XII, Lwdw 1913.

14 ïarol Chodynicki, l.c. 
ausführt, nicht zuletzt deswegen, weil die meisten Vertreter des geistigen Lebens in Polen nach den Teilungen, wie schon an anderer stelle ausgefürt, auch schon in der vorhergegangenen Epocne gewirkt hatten.

Als die besonderen in Polen hervortretenden Tendenzen nennt Chodynicki das Streben nach Reformen und die Verteidigung der nationalen Selbständigkeit, in diesem Zeitabschnitt natürlich die Bemühungen um die Wiedererlangung dieser Selbständigkeit. Das Hauptaugenmerk wurde daher in der Geschichtsschreibung hauptsächlich auf die $Z$ i e $l$ e der Geschichte gelegt, während das $w$ e $s$ e $n$ der Geschichte bis zu Kołłątaj ${ }^{15}$ von keinem Historiker wirklich tief erfasst worden ist.

Auch die Definition der Geschichte, also das, was man sich darunter vorstellte bzw. davon erwartete, hatte in den ersten beiden Jahrzehnten des 19. Jahrhunderts noch keine wirkliche Änderung erfahren. Neben dem vorherschenden narrativen Element traten auch typisch aufxlärerische $\mathrm{Zü} \breve{\text { ge }}$ auf: ein gewisser Kritizismus, der allerdings auf seinem Wege von Frankreich nach Polen an Wirksamkeit verloren hatte, da er hier ohne den notwendigen Skeptizismus bzw. ohne die notwendige Gründichkeit in Erscheinung trat, und vor allem der Utilitarismus, der in dem Bestreben deutlich wurde, nur tatsächliches Geschehen $z u$ berichten. In Polen wurde dieser Utilitarismus von rein moralischen Gesichtspunkten bestimmt, deren Schwergewicht auf der weltlichen Moral lag und zwar der individuellen sowohl als der öffentlichen. In bezug auf die Politik sollte die Geschichte das iissen um Gründe und Anlässe zum Zusammenbruch bzw. Aufstieg des Staates vermitteln und die

15 Die Tragik Kołłątaj's in bezug auf seine Geschichtsauffassung liegt darin, dass seine Ideen für Polen ganz neu, bei ihrer Veröffentlichung aber bereits Anachronismen waren. Daher hat er weder Einfluss auf Zeitgenossen noch auf Nachfolger haben können. 
Ursachen grosser Unglüke aufzeigen. Auf die sich daraus ergebende Frage, wie die Geschichte das alles lehren solle, fuhrt Chodynicki zwei Wege an, die die Historiographie jener Epoche beschritten habe. Der eine sollte mit Hilfe von Beispielen zu dem gewünshten Ziele führen. Diese Auffassung hatte schon Marcin Bielski in seiner Chronik vertreten; die Aufklärung steuerte dazu noch das Bestreben bei, beständige Normen aufustellen.

Der zweite Weg war mittelbar: die Geschichte sollte die Fakten geben, aus denen feste moralische und politische Normen gezogen werden konnten. In Polen versuchte die Historiographie am häufigsten, inrer Aufgabe mit Hilfe von Beispielen gerecnt zu werden. Zum Beweis zitiert Chodynicki den "Monitor" aus dem Jahre $1773^{16}$, wo es heisst, dass die Lebensläufe guter Monarchen und grosser Männer eine ausgezeichnete Schule seien, aus der die anderen lernen könnten, wie man sich verhalten solle.

Als weiteres Kennzeichen der $p$ o $n$ i $s$ h $e n$ Aufklärung nennt Chodynicki den Aufruf zur Achtung der Obrigkeit, eine der wesentlichsten Tendenzen der Publizisten und Propagatoren der Reformen des Grossen Sejms und auch des werkes von

Naruszewicz. Dessen "Dzieje Narodu Polskiego" (1780 ff) sind das bedeutendste Geschichtswerk nicht nur dieser Epoche, sondern seit dem Mittelalter uberhaupt. Mit diesem Werk vollzog sich eine Umwälzung auf dem Gebiete der polnischen Historiographie, weil es sich als erstes endlich den neuen Erfordernissen der aus der Aufklärung gewonnenen Erkenntnisse anpasste. Naruszewicz selbst hat seine Auffassung von der inm vom König gestellten Aufgabe folgendermassen formuliert: "Neine Pflicht wird es sein, sowohl die Geschichte des Volkes als die des Staates zu schreiben, ein Bild von dem Fortschritt der schönen und der nützlichen Künste zu entfalten, die Entstenung der

16 I:r. 71, S.560-61. 
religiösen Sekten und die Veränderungen in der Richtung der Wissenschaften zu verfolgen, ein Bild von den aufeinander folgenden Generationen zu geben, und schliesslich sogar die Veränderungen $z u$ berücksichtigen, die in Kleidung, Hauswesen, bei Festmahlen und Vergnügungen vor sich gegangen sind"177 Tarnowski kommentiert dieses 2 itat:mit dem Hinweis, dass so auch Macaulay die Aufgabe des Historikers auffasse. Damit berücksichtigt Tarnowski aber nur einen kleinen Teil der neuen Forderungen, nämlich den, dass ein Historiker nicht nur die Geschichte des Staates, sondern auch die der Zivilisation und der innenpolitischen Ereignisse untersuchen und berücksichtigen muisse. Diesen Vorsatz hat Naruszewicz durchgefuihrt. Er hat in Archiven und Bibliotheken nach Dokumenten geforscht, er hat auch Protokolle der Sejme, Privilegien von Schulen und Akademien und der Xirche verarbeitet. Aber in seiner Geschichte Polens sind nur die Grundsätze von Pragmati tismus und vor allem Utilitarismus verwirklicht, während der Grundsatz der Xausalität keine Vertiefung erfahren hat. Und auch der Pragmatismus wurde nur oberflächlich wirksam, da er bei Naruszewicz nicht philosophisch begründet, sondern rein didaktischer Natur war. Im Gegensatz zum Inhalt ist die Form, in der Naruszewicz sein Werk vorlegte, veraltet, denn er bex richtet, wie Długosz, in chronologischer Reihenfolge.

Obwohl Niemcewicz in diesem Werk von Naruszewicz für den Inhalt seiner Spiewy historyczne ein gutes Vorbild hatte, blieb er doch in den meisten Liedern weit von diesem Vorbild entfernt, und es hat den Anschein, als wirde er noch tief in der mittelalterlichen Geschichtsschreibung und -auffassung stecker. Eine genaue Untersuchung der Śpiewy aber wird erweisen, warum Niemcewiçz sich gerade in dieser "gereimten Geschichte Polens", wie die Spiewy von vielen Kritikern genannt wurden, so eng an die Chroniken und Legenden, anstatt an ein den zeitgenössischen Anforderungen entsprechendes Standardwerk der polnischer. Geschichte angelehnt hat.

17 Zitiert bei Tarnowski, Historya Literatury Polskiej, III, Krak8w 1904, S.328 
2) Niemcewicz - kurzer Uiberblick über Leben und Herk.

Niemcewicz's Leben erscheint wie eine Brücke von einer grossen literarischen Epoche zur anderen: vom Pseudoklassizismus zur Romantik. Aber auch rein geschichtlich gesehen reichte sein Dasein von den letzten Jahren der eigenstatlichen Existenz des Königreichs Polen über die Teilungen und die vergeblichen Reformversuche hinweg, in den Rumpfstaat des Herzogtụms Warschau und das Königreich von des Kongresses Gnaden bis in die Zeit der schwersten Unterdrückung und Unfreiheit nach dem Novemberaufstand.

Wie wir aus dem Tagebuch von Niemcewicz wissen, wurde er schon von seinen Eltern zur Liebe und dem Dienst am Vaterland erzogen. Der Aufenthalt in der Kajdettenschule, der ersten weltilchen Schule in Polen überhaupt, die von dem Pijsten Adam Czartoryski geleitet wurde, der "Szkoła rycerska" in Warschau, hat diese Einstellung des jungen Niemcewicz noch vertieft. Denn in dieser Schule wurde nicht nur militärisches Wissen gelehrt, sondern auch Vaterlandsliebe, so dass die Schüler nicht nur zu guten offizieren, sondern auch zu leidenschaftichen Patrioten herangebildet wurien. Ausser Niemcewicz hatten ihr so bekannte Männer wie Kofciuszko, Fiszer und Mokronowski anöehört. Aus dieser Zeit datierte die lebenslange Freundschaft Niemcewicz's mit der Familie Czartoryski, die auch das ihre dazu beigetragen hat, den Geist der Vaterlandsliebe in liemcewicz zu der alles beherrschenden Kraft seines Lebens und Wirkens werden zu lassen. Auch die Auslandsreisen, die er als Adjutant des Fursten unternahm, schwächten dieses Gefühl nicht etwa ab, im Gegenteil, a der Schmerz, den Niemcewicz bei dem Vergleich Polens mit Macht und Ansehen und der hohen Zivilisation der bereisten Länder (England!) über die Armut linj Schwäche des eigenen Volkes expfand, liessen in ihm den Wunsch erwachen, seine Arbeit in 
den Jienst des Vaterlandes zu stellen. Zum ersten Male trat Niemcewicz als Livländischer Abgeordneter auf jem Grossen Sejm hervor. Selbstverständlich gehörte er der Patriotenpartei an in dem festen Glauben, dass es noch eine Möglichkeit gäbe, Polen zu retten. Ganz besonders setzte sich Niemcewicz in seinen Reden, die, ohne Phrasen, für jeden verständlich waren, für die Rechte der Bürger ein, die, wie er in einer seiner Reden $2 . B$. ausführte, zwar die Pflicht hätten, Steuera zu zahlen, ohne dass ihnen das Recht eingeräumt würde, juber . die Verwendung dieser Gelder mit zu entscheiden, und er warnte vor dem Augenblick, wo den Städtern einmal die Diskrepanz in dem Verhältnis ihrer Pflichten und Rechte klar wïrde.

Aber Niemcewicz unterstütze die Arbeit des Sejms auch noch auf andere Weise, und zwar als Mitarbeiter an der ersten polnischen Zeitschrift, der "Gazeta Narodowa i Obca", die er zusammen mit Tadeusz Mostowski und Jozef Weyssenhoff, dem anderen livländischen Abgeordneten, herausgab. Nach der $\mathrm{Zu}-$ stimoung des Königs $z u$ den Abmachungen von Targowice ging Niemcewicz, wie viele andere, ins Ausland, um erst zu Beginn des Kościusko-Aufstandes (1794) wieder nach Polen zurickzukehren. Als Adjutant und Sekretär nahm er tätigen Anteil an dem Aufstand und wurde bei der unjlïcklichen Schlacht von Maciejowice verwundet und mit Kosciuszko zusaminen von den Russen gefangengenomen und nach Petersburg gebracht. Diesen Zeitabschnitt behandelt Niemcewicz in seinem Tagebuch sehr ausführlich, so dass wir über alle Einzelheiten genau informiert sind. Als inm bei der Freilassung durch den Ziren Paul Kosciuszko seinen Entschluss mitteilte, nach Amerika zu seinen dortigen Freunden zu gehen, brachte es Niemcewicz nicht über das Herz, den kranken Fihrer allein zu lassen, und willigte ein, ihn nach Amerika zu begleiten. Dort weilte er, mit einer anderthalbjährigen Unterbrechung, bis 1807. Dann $20 \mathrm{~g}$ es ihn mit unwiederstehlicher Kraft wieder in die Heimat, wo er sich seit 1809 ganz und gar der Arbeit fiur das Vaterland 
widmete. Wie aktiv Niemcewicz am politischen und literarischen Leben teilnahm, geht aus der Vielzahl der Ämter hervor, die er bekleidete. Er war u.a. Sekretär des Senates, Mitglied der Kulturkammer (Izba Edukacyjna), Theaterdirektor und Sekretär des Tow. Przyj. Nauk, dessen Vorsitzender er nach dem Tode des bisherigen Präses Staszic 1826 wurde. Während des Aufstandes vom Jahre 1830 wurde er mit einer wichtigen diplomatischen Aufgabe in England betraut. Von dieser Reise kehrte er nicht wieder nach Polen zuríck; er siedelte nach Paris über, wo er 1841 im Alter von 84 Jahren starb.

Seine fruchtbare literarische Periode fällt in die Jahre nach den Teilungen Polens. Unter seinen herken sind eigentlich alle Gattungen der Literatur vertreten: Märchen bzw. Pabeln, Oden, Elegien, Dumen, Lieder, Dramen und Erzählungen und die bereits erwähnten Tagebücher.

Der grösste Teil des literarischen Gesamtwerkes von Niemcewicz steht in direktem oder indirektem Zusammenhang mit der polnischen Geschichte. So hat z.B. das dramatische Schaffen fast ausschliesslich historische Themen zum Inhalt.

1819 wurde in Warschau das Jrama "Zbigniew" mit grossem Erfolg aufgefürt. Diese begeisterte Aufnahme durch das Publikum war zu einer zeit, als das Interesse für die Geschichte erwacht war, allein schon durch den historischen Inhalt gewährleistet. In ziemlich eintönigen Versen schildert der Autor die Auseinandersetzung des Königs Belesław Krzywousty mit seinem machthungrigen Bruder 2 bigniew, der sich nicht scheute, durch Uberfälle, Verschwörung und Verrat sein wahnsinniges Verlangen nach Herrschaft verwirklichen zu wollen. Dieser Machthunger, der zu dem für Niemcewicz wohl schändlichsten Verbrechen überhaupt, dem Verrat am eigenen Vaterland, fürte, hatte den Autor schon früher zu der Duma von Nichiel Gliński a:zerēt, die er dann später in die Śpiewy 
hystoryczne aufgenommen hat. Einer der Höhepunkte der Tragödie ist die erfolglose Belagerung Glogaus durch Heinrich V., deren Einzelheiten, wie es im Vorwort ausdrücklich heisst, wahrheitsgetreu den Berichten der Chronisten entnommen sind. Trotzdem ist es dem Autor nicht gelungen, den historischen Hintergrund dem Geist der Epoche entsprechend zu charakterisieren, er wirkt im Gegenteil konventionell, ebenso wie die Gestalten dieses Dramas. Von besonderer Bedeutung für. die Wirkung auf das zeitgenössische Publikum dürfte jedoch die Zeitbezogenheit gewesen sein - ein Faktor, der bei allen Werken von Niemcewicz zu berücksichtigen ist. Im Vorwort weist der Autor selbst darauf hin, dass es wohl wenig Theaterstücke gebe, deren Inhalt so zeitgemäss ist. Aber noch etwas anderes trug zu dem aussergewöhnlichen Erfolg bei: der Mangel an eigenen polnischen Theatersticken hatte zu einer Art Ubersättigung des Publikums mit Ubersetzungen geführt, so dass diese nationale Tragödie mit umso grösserem Enthusiasmus aufgenommen wurde.

Auch für die anderen Dramen - Wladysław pod Warną, Tragödie, Jadwiga, Krblowa polska, musikalisches Drama, und Kazimierz Wielki, Drama - gilt das von "Zbigniew" Gesagte, sowohl was die Werke selbst anbelangt, als auch was die Aufnahme beim Publikum betrifft. Vor allem bei "Kazimierz Wielki" steht die Bezogenheit auf die Gegenwart an erster Stelle. Das Drama entstand zur Feier des ersten Jahrestages der Konstitution vom 3. Mai und hinterliess trotz der offensichtlichen Schwächen einen starken Eindruck, eben weilies aktuell war. Die Änlichkeit zwischen Kazimierz und Stanisław August, zwischen dem Statut von Wislica und der Konstitution vom 3. Mai war augenscheinlich der Hauptzweck des Dramas. Es ginb dem Autor nicht darum, den Geist der Epoche Kazimierz's des Grossen oder des Statuts von Wislica lebendig werden zu lasser, sondern um die Anpassung der Fabel an den Augenblick, um, wie Chrzanowski es audruckt, "eine Apotheose der Konstitution rom 
3. Mai". 1 Und das zeitgenössische Publikum hat diesen Sinn gut verstanden.

Historischen Anstrich haben auch die sehr schwachen Vaudevilles "Giermkowie Krolla Jana" (Die Pagen des Königs Jan) und "Jan Kochanowski w Czarnym Lesie" (Jan Kochanowski in Czarny Ias).

Obwohl die Dramen bei weitem nicht die Qualität der Komödien erreichen, fandes sie doch - mit Ausnahme des Lustspiels "Powrbt Posła" (Die Rückkehr des Landboten) - beim zeitgenössischen Publikum und auch bei den Kritikern wesentlich mehr Anklang. Bystroń führt das darauf zurick, dass die Epoche selbst pathetisch und daher auch für grosse Worte besonders empfänglich war.

Zur Historiographie im eigentlichen Sinne gehört "Dzieje Panowania Zygmunta III." (Geschichte der Herrschaft Zygmunts III.), erschienen 1819. Ebenso wie die Śpiewy historyczne entstand das Werk im Auftrag des Towarzystwo Przyjaci61 Nauk. Da Naruszewicz seine "Geschichte Polens" mit der Heirat der Königin Jadwiga abgeschlossen hatte, vergab die Gesellschaft Aufträge, die polnische Geschichte in Einzeldarstellungen fortzuführen und zwar nach dem Vorbild von Naruszewicz. Viemcewicz entledigte sicht als einziger dieser Aufgabe mit grossem Eifer, Fleiss und Erfolg, jedenfalls bei seinen Zeitgenossen. (Ausser Niemcewicz haben noch Krajewski und Kwiatkowski einzelne Abschnitte aus der polnischen Geschichte dargestellt, aber nur in sehr schlechter Form. ${ }^{2}$ ) Niencewicz's Biozraph Adam Czartoryski ist der Ujberzeugung, dass diese Geschichte Zygmunts III. die meiste Aussicht auf

1 Chrzanowski, Ignacy, Historja Literatury Niepodległej Polski. warszawa s.a.

2 Tarnowski, Stanisław, Historja Literatury Polskiej, n̈rakau 1900 ff, IV, S.180. 
dauernde Wirkung habe, da sie der polnischen Öffentlichkeit - vielleicht zum ersten Male - den ganzen Genuss offenbar werden liesse, den man beim Lesen der Geschichte des eigenen Volkes empfindet, wenn diese, wie hier, interessante Einzelheiten in angenehmer Form darstellt und Lehre und Unterhaltung eng verbindet. Trotzdem ist die Geschichte Zygmunts III., eine ausführliche historische Kompilation in recht flüsigem Stil, heute völlig in Vergessenheit geraten.

Zu einer literarischen Sensation wurde das Erscheinen des Romans "Jan z Tęczyna" 1825, der ersten polnischen historischen Erzählung nach dem Muster Walter Scotts. Die Fabel selbst - die Liebe des jungen Magnaten Jan Tęczyhski zur Schwester des schwedischen Königs - ist wegen ihrer konventionellen Darstellung uninteressant; was bleibt, ist der breit ausgemalte historische Hintergrund, auf dem sich diese Fabel abspielt. Trotz einiger Anachronismen ist es Niemcewicz gelungen, eine lebendige Darstellung vom Polen des 16. Jahrhunderts zu geben. Von den Zeitgenossen wurde die Erzählung nicht nur wegen der neuen literarischen Gattung begeistert aufgenommen, sondern auch wieder wegen des geschichtlichen Inhalts, der besonders stark in einer Zeit auf die Leser wirkte, in der so viele Traditionen unterbrochen worden waren und die Erinnerung an die frühere Grösse und den Runm des polnischen Staates schon am Verblassen war. Zieht man dieses Phänomen in Betracht, bietet sich auch die originellste seite der Erzählung "Dwaj Panowie Sieciechowie" (Die zwei Herren Sieciech) dar: die literarische Fixierung der nächsten, aber doch schon in Vergessenheit. geratenen Vergangenheit. In der Einleitung dieses 1815 erschienenen Büchleins berichtet der Autor von Tagebüchern, die er anlässlich eines Besuches bei Freunden fand und die ihn wezen der starken Gegensätze, insbesondere zwischen der Sachsenzeit und der Gegenwart bzw. juingsten Vergangenheit, interessierten. Auf seine Bitten hin erlaubte ihm sein Gastgeber, zwei der Tagebücher abzuschreiben. 
Dieser Kunstgriff - mit Hilfe einer Erzählung von angeblich gefundenen authentischen Handschriften dem Werk mehr Glaubwürdigkeit zu verleihen - war zur Zeit Niemcewicz's ein gern geübter Brauch. Wie in allen Werken von Niemcewicz findet sich auch hier wieder die Tendenz, über die Vergangenheit zu schreiben, aber die Gegenwart zu meinen. Denn es geht dem Autorinicht so sehr darum, die historischen Epochen lebendig werden zu lassen, als um die aus dieser Gezenüberstellung zu ziehende Nutzanwendung. Am Schluss der Erzählung eröreift Niemcewicz nämlich selbst wieder das Wort, um zum Kampf gegen Unworal, mangelnde Achtung vor Gesetz und Eigentum und zur besonderen Pflege der nationalen Eigenheiten aufzurufen.

Gleichen didaktischen Charakter hat die Erzählung "Lejbe $i$ Sibra", 1821, ein Sittenroman in Briefform, der das Problem der stellung der Juden zum polnischen Staat behandelt und Weze für ihre Gleichstellung und Eingliederung aufzeigen will.

Historische Betrachtungen enthält auch das Reisetagebuch mit dem Titel "Podrbie historyczne po krajach polskich" (Historisehe Reisen durch die polnischen Lande). Für die damalige Zeit waren derartige Reisen durch Polen etwas durchaus Ungewöhnliches. Was Niemcewicz davon zu berichten weiss, ist lebendig und gut und vielseitig beobachtet. Die vielen aufgeführten Einzelheiten tragen dazu bei, die Berichte glaubhaft erscheinen zu lassen. Alle diese Informationen über geographische und wirtschaftliche Gegebenheiten der bereisten Gebiete, deren soziale Struktur, ihre Menschen und deren Kultur und Geschichte sind in leichtem und gefälligem Erzählton darge $\rightarrow$ stellt. Ausser den historischen vermitteln diese Berichte auch dem heutigen Leser noch interessante und wissenswerte Eindrilcke, so dass dieses Tagebuch eigentlich zu Unrecht in Vergessenheit geraten ist. Fir die Beurteilung von Niemcewicz als Persönlichkeit ist hieran noch wichtig, dass aus diesem Buch seine Haitung zu Polen als Ganzem und dem Kongresskönig- 
reich als Besonderem klar und eindeutig zu ersehen ist. Für Niemcewicz umfasst Polen das Gebiet, das es vor den Teilungen innehatte. Mit seinen Reisen in die Ukraine, nach Iitauen, Yomorze und Rotrussland wollte er auch in den Bewohnern dieser Gebiete, die von den Teilungsmächten gewal tsam abgetrennt worden waren, das Bewusstsein wachhalten, dass Polen nicht an den Landesgrenzen aufhört. Um diese Uberzeugung in seinen Lesern zu festigen, verband er in seinem Tagebuch Gegenwart. mit historischer Tradition.

Von diesem Gesichtspunkt aus müssen auch seine Śpiewy historyczne betrachtet und beurteilt werden. 


\section{Die "Śpiewy historyczne"}

\section{1) Gattung}

Die "Śpiewy historyczne" liessen sich mit einem Satz etwa folgendermassen charakterisieren: sie sind eine Sammlung von Liedern, die an Hand der Lebensbilderrpolnischer Könige und Heerführer die Geschichte des polnischen Volkes darstellen sollen.

Niemcewicz, der Autor dieser Lieder, war kein Historiker, ihn interessierte die Geschichte nicht als wissenschaftliche Disziplin, sondern nur in dem bereits erwähnten Zusammenhang von historischer Tradition und Gegenwart und als Mittel zur Erlangung eines bestimmten zieles. Für inn war alles nur als Mittel zu dem einen grossen $2 i e l$ bedeutungsvoll, aur Errettung des Vaterlandes, um durch die Hinwendung seines Volkes zu der ruhmreichen Vergangenheit in inm den Wunsch, die Hoffnung und die Kraft $z u$ wecken, eine ebenso ruhmreiche $\mathrm{Zu}-$ kunft aufzubauen.

Trotz aller Versicherungen im Vorwort zu den Śpiewy, dass es der Leser hier nur mit der reinen geschichtlichen Wahrheit zu tun hätte, trotz des Verzichtes auf künstlerischen Ruhm zugunsten eben dieser historischen Korrektheit ist es Niemcewicz doch nicht gelungen, beim Leser den Eindruck einer historischen Darstellung $z u$ erwecken. Auch die Tatsache, dass der Autor die Lieder nur bis zum Jahre 1696 - dem Tode Jan III. Sobieskis - gefuhrt, er also die gerade vergangenen sächsischen Zeiten unberücksichtigt gelassen hat, kann nicht in diesem Sinne gewertet werden. Denn zur Beurteilung dieser Erscheinung muss man wohl in Betracht ziehen, dass Niemcewicz einer Generation angehörte, die in unsicheren Situationen lebte und vor einer unsicheren zukunft stand, und dass solche 
Zeiten und Generationen ungern in die jüngste Vergangenheit schauen, die auch gerade vor den Problemen der Gegenwart etwas verblasst.

Ebenso wie die Geschichte war für Niemcewicz aber auch die Kunst, die Dichtung nur ein Mittel zum 2weck. Er schrieb nicht, um künstlerischen Ruhm zu ernten, sondern um seinen Lesern die eigene Geschichte nahezubringen, sie über die Vorzüge und Fehler der Vergangenheit zu belehren und sie damit die Probleme der Gegenwart besser erkennen zu lassen, und schliesslich, um bestimmte ideologische Parolen zu verkünden. Die Literatur war für ihn eines der Mittel, seine nationalen und sozialen Ideen zu popularisieren, während er die künstlerische Seite nur indirekt als zweitrangig anerkannte. Am deutlichsten wird dieses Verhältnis von künstlerischem Interesse und historischen Ambitionen wie auch die Stellung des Autors zu beiden in den drei Dumen "O Michale Glifskim", "Zठłkiewski" und "Stefan Potocki". Diese Dumen entstanden bereits in den Jahren zwischen 1786 - 1804, also lange bevor die Spiewy überhaupt geplant wurden. Niemcewicz machte sie dann später zum Kern dieser Liedersammlung. In den genannten Dumen nimmt das literarische Problem die erste Stelle ein. Wilhelm Bruchnalski hat sich in seiner Arbeit "Mickiewicz-Niemcewicz" ${ }^{1}$ mit der Einführung der Ballade und der von inr abgeleiteten Formen in die polnische Literatur durch Niemcewicz eingehend auseinandergesetzt. Leon Ploszewski berichtet in seinem Aufsatz "Pierwsza Redakcja Spiewరw historycznych" 2 , dass man im Nachlass des Dichters u.a. auch Diarien aus seiner Schulzeit in der Kadettenschule des Firsten Czartoryski gefunden habe, in denen Ubersetzungen deutscher und französischer Dichtung enthalten sind, ein Zeugnis für die

1 Bruchnalski, Wilhelm, Mickiewicz-Niemcewicz. Pamiętnik Literacki, Rocznik II ff.

2 Ploszewski, Leon, Pierwsza Redakcja "Siewów historycznych". Pamiętnik Literacki, Rocznik XIV, Lwow 1916. 
schon fruhzeitig einsetzenden literarischen Interessen von Niemcewicz. Den Impuls zu den Dumen - und zwar in zweifacher Hinsicht - empfing Niemcewicz auf seinen Auslandsreisen, in deren Verlauf er auch nach England gekommen war. Die politische Maoht und hohe Zivilisation dieses Landes liessen ihn die Schwäche des eigenen Vaterlandes besonders stark empfinden. Dieses schmerzliche Bewusstsein konnte fur einen Menschen wie Niemcewicz Veranlassung genug gewesen sein, seine ganze Kraft und Arbeit dem Vaterland zu widmen. Hier in England zeigte sich inm auch gleich einer der vielen Wege, auf dem er seine Arbeit, seinen Talenten entsprechend, für Polen nutzbar machen konnte. Niemcewicz hatte seine erste Bekanntschaft mit der modernen englischen Poesie und den alten schottischen Balladen im Ursprungsland selbst gemacht. Diese Unmittelbarkeit des Eindrucks hat offensichtlich ihre wirkang nicht verfehlt. Er empfand den Mangel an derartigen volkstümlichen Heldenliedern um so schmerzlicher, als er gerade in ihnen ein wirkungsvolles Mittel sah, die Tradition im Volke wachzuhalten und damit die patriotischen Empfindungen $2 u$ wecken. Die wichtigste Voraussetzung für die Uberlieferung solcher lieder aber, dass sie nämlich vom ganzen Volk gesungen werden, fehlte in Polen, im Gegensatz zur Ukraine, wo Volk und Adel gemeinsam um die Freiheit gekämpft hattén. Hier war denn auch die besondere Art des Liedes entstanden, die zwar nicht in der Form und den künstlerischen Elementen, aber dem Wesen und ihrer Bedeutung in der Volksdichtung nach den englischen Balladen und spanischen Romanzen entsprachen: die Dumen. Niemcewicz stammte selbst aus den ehemals litauiscinen Gebieten und hat als Kind oft genug bei der Landbevölkerung die ikrainischen Dumen gehört. Nur von dieser sicht aus ist die selbstverständiche Gleichsetzung der Bezeichnung Duma-Ballade zu verstehen. Ausserdem war Niemcewicz wie kaum ein anderer bemüht, alles Fremde aus dem polniscnen Dasein zu entfernen und dafür Eigenes, Polnisches zu setzen. Darum begnügte er sich auch nicht mit einfachen 
Ubersetzungen, wie "Alondzo i Helena, Duma nasladowana $z$ angielskiego" eine ist, sondern übertrug die fremden Vorbilder in den polnischen Bereich, wie z.B. "Sen Marysi". Im Gegensatz zu Alondzo und Helena, die beide der mittelalterlichen Ritterschaft angehören ("Nach Palästina eilt der tapfere Ritter ..."n ) sind Marysia und Stas Gestalten aus dem polnischen Volk, wofür vor allem der Refrain "Marysiu, nie płacz juz po mnie" (Mariechen, weine nicht um mich) spricht. Sehr bald folgen dann originalle Balladen wie "Zamek Jazlowiecki". So erschienen in Polen ziemlich gleichzeitig die ersten aus dem Englischen ubertragenen Balladen und die ersten Dumen (1786 "Duma O Michale Glifrskim", 1794 "Duma o Zbłkiewskim" und "Duma o Stefanie Potockim"). Was Niemcewicz aus diesen beiden Elementen, der Erinnerung an die ukrainische Duma und dem Eindruck von der englischen Volksballade geschaffen hat, ist zwar für Polen etwas völlig Neues, aber nicht die polnische Ballade, wie allzu vereinfachend angenommen wird, Niemcewicz hat unbewusst $z u$ dieser Irrefuhrung selbst beigetragen, wenn er die Ubertragung aus dem Englischen im Untertitel mit "Duma" bezeichnet. Da er sich selbst aber zu theoretischen Fragen im allgemeinen und $z u$ dieser Frage im besonderen nie geäussert hat, müssen wir auf indirekte Stellungnahmen zurïckgreifen, aus denen zu ersehen ist, dass die Gleichsetzung Duma Ballade keine begriffliche; sondern nur eine wert- bezw. bedeutungsmässige ist. Als erstes Argument für die Richtigkeit dieser Auffassung kann eine Stelle aus der Vorrede zu den Spiewy dienen, in der zwar von volkstümlichen Heldenliedern, aber nicht von der Ballade die Rede ist: "Tief wirkt der Klang der Musik auf das menschliche Herz und Gedächtnis: Bevor zuerst Herodot begann, mit gewichtiger Feder die Ursprünge der Völker zu schildern, reichten schon die Generationen den Generationen die Abenteuer ihrer Vorväter in einfachen Liedern weiter, nichts vermochte sie zu vernichten; die Zerstörer der

3 Zitiert bei Manfred Kridl, 1.c. S.80- 
Welt können die Völker ins Verderben stürzen, diese Bücher einsammeln und vernichten, in denen Glück und Unglück des Menschengeschlechtes aufgezeichnet sind, aber niemals werder. sie auf den Lippen der Mïtter die Lieder unterdruicken, mit denen diese die Kinder daran erinnern, dass sie ein Vaterland hatten. Das aus dem heiligen Land umgesiedelte Volk Israel gedachte an den Ufern der babylonischen Gewässer des Jordans, in seinen traurigen Liedern summte es vom Vaterland, von den Taten der Vorfahren: es erlangte dieses Land darum wleder, weil es nicht aufhörte, daran zu denken und sich nach inm zu sehnen." Niemcewicz weist hier also auf die grosse Aufgabe der Volksdichtung hin, deren besondere Wirkung auf ihrer engen Verbindung.mit der Musik beruhe. Der Autor fährt dann fort: "Eigentlich hatten alle Völker in ihren Anfängen ermächtigte öffentliche Sänger, stark wirkten ihre Lieder auf den Geist der ritterlichen Jugend. Die griechische Geschichte lehrt uns, mit welchem Geist des Mutes die kriegerischen Reime des Tyrtaios die Spartaner erfülten." Nach einem ausfürlichen Zitat Gibbons über die Barden führt Niemcewicz weiter aus: "Zu unsrer Zeit, wieviele Siege schulden die französischen Revolutionsheere den Hymnen der Marseiller und ähnlichen. In Polen musste es ausser dem frommen Liede "Boga Rodzica", das bis zu Jan Kazimierz von unsrer Ritterschaft vor Beginn der Schlacht gesungen worden ist, auch andere Lieder gegeben haben, die durch die Zeit und durch Fahrlässigkeit verloren gegangen sind. Bis heute singt unser ukrainisches Volk Dumen von Niczaj, Doroszehko und anderen. Wir lesen bei DIugosz, dass noch er sich erinnern kann, wie man in Grosspolen die Duma von der unjlicklichen Luitjard gesummt hat, die im Jahre 1295 von König Przemysław, ihrem Manne, umgebracht worden ist, dass man sogar den grausamen Tod dieser Königin im Theater dargestellt hat." 4

Die englischen Balladen werden hier also mit keinem Wort erwähnt.

4 Niemcewicz, J.U.,Spiewy historyczne, Paryż 1868, S. III. 
Denn es ging unserem Dichter auch gar nicht um sie, sondern darum, den so schmerzlich spürbaren Mangel an eigener Volksepik bzw. volkstümlichen Heldenliedern zu beseitigen. Die gute Kenntnis der englischen Volks- und Kunstballade zeigte Niemcewicz den Weg, auf dem auch die Polen zu solchen Liederm kommen konnten. Die Erinnerung an die ukrainische Duma aber wies inn auf die Möglichkeit hin, auf traditionellem polnischem Boden die der englischen Literatur entnommenen Anregungen zu verwirklichen. Die Ballade in der westeuropäischen Iiteratur, vor allem in der deutschen, stellt eine Synthese der drei Urformen der Dichtung Epos, Lyrik, und Drama dar. Die drei Formen bilden in der Ballade eine Einheit. "Der reinste Balladentypus stellt eine Handlung konzentriert und einheitlich, unmittelbar und gegenwärtig dar. Ein Vorgang ohne Vorher und Nachher taucht, oft durch die Frage eines noch unbekannten Sprechers heraufgefüht, blitzartig auf, wird mit wenigen Strichen in seinen Umrissen gezeichnet und in ungebrochener Bewegung zum Ausgang gefihrt. -- Sie (die Ballade) behandelt das Ungewöhnliche, einen handlungsreichen Einzelfall meist tragischer Natur." 5 Die Dumen und historischen Lieder verstossen jedoch gegen die meisten dieser Forderungen. Vor allem entsprechen sie nicht dem Verlangen nach gedrängter Kürze und Totalität, weil sie sich aus mehreren selbständigen, zeitlich sogar getrennten Episoden zusammensetzen. Sehr of auch treffen wir in den Spiewy auf reine Situationsschilderung, ohne dass diese sich zur Handlung verdichten würde. Was aber dem Wesen der Ballade als einer Synthese aus Epos, Lyrik und Drama am meisten widersprichs, ist die Auffassung Niemcewicz's von der Ballade als epischem Gedicht. Seine Dumen und Lieder sind dementsprechend mit epischen Details überlastet, sie versanden in "einseitig-gegenständlichem Aneinanderreihen". 6 Hinzu kommt die reflektierende und didaktische Haltung des Autors in den Spiewy, die

5 Heallexikon d. dtsch. Literaturgeschichte, Berlin 1931, IV, S. $51 \mathrm{f}$.

6 Ebd. S. 55 
der echten Volksballade völlig fremd ist.

Neben den eigentlichen Balladenstoffen setzten sich bei Niemcewicz bald das didaktische Bestreben und sein geschichtliches Interesse durch. Mit diesen Dumen und historischen Liedern glaubte Niemcewicz nämbich eine Form gefunden zu haben, in der er dem Volke seine patriotischen Empfindungen einfach, klar und eindringlich darstellen konnte. Auf der Suche nach entsprechenden Themen aus dem polnischen Bereich vertiefte sich Niemcewicz in die Chroniken des Gallus, Kadłubek, Dlugosz und Bielski. In ihren Beschreibungen der Kriege polnischer Könige mit dem Kaiser oder dem deutschen Orden, mit Türken und Tataren - eine beliebte Stoffquelle des 19. Jahrhunderts ubberhaupt glaubte er, echte volikstüliche Balladenstoffe gefunden zu haben.

\section{2) Entstehung}

Die Entstehungsgeschichte dieser Liedersammiung ist uns weitgehend bekannt. Die Śpiewy verdankten inr Dasein dem Towarzystwo Przyjacib 1 Nauk in Warschau, das 1800 mit Genehmigung des Königs von Preussen entstanden war. Es hatte sich zur Aufgabe gestellt, neben Wissenschaft und Sprache auch die nationalen Jen'rmäler zu erhalten und zu fördern. In diesem Sinne hatte sich 1803 der Bischof Woronicz mit der Zusammenstellung eines Liederbuches befasst, das nach seiner Vorstellung aus drei Teilen, aus religiösen, ethischen (moralischen) und historischen Liedern bestehen und den Titel "Piebnioksiąg Polski" (Polnisches Liederbuch) tragen sollte. Hierin sollten neben neuen Gedichten, von denen Voronicz einen Teil selbst schreiben wollte, Werke von Kochanowski, Sarbiewski, Szymonowicz, Zimorowicz, Karpihski, Naruszewicz u.a. aufgenommen werden. Dieser Plan gelangte nie zur Durchfïhrung. Aber einige der Dichtungen des Bischofs Woronicz, die für dieses Buch bestimmt waren, 
sind uns erhalten. $\mathrm{Zu}$ ihnen gehört die "Hymn do Boga", für den ersten Teil vorgesehen, dann "Assarmot" und "Lech". Die Idee dieses Werkes und die von Woronicz dafür geschriebenen Teile sind insofern wichtig, als sie neben der für diese Epoche kennzeichnenden Hinwendung zur Vergangenheit, in der man Trost und Hinweise für die Zukunft suchte, noch eine andere zeitgenössische Strömung enthalten: die Slavophilie. Woronicz versucht den Ursprung der slavischen völker zu finden - typisch für den Traditionalismus, der schon den Ubergang von der Historiographie der Aufklärung zum Historismus ankündigt - und gelangt dabei in dem Gedicht von "Assarmot" zu der Uberzeugung, dass dieser der Urahn des Noe und der Patriarch der slavischen Völker gewesen wäre, der seine Söhne nach Norden ausschickte, um dort "sarmatische Staaten" zu gründen, und ihnen eine glänzende Zukunft und eine Ausnahmestellung unter den anderen völkern prophezeite, denn "die Tugend ist Euer Element, der Ruhm Euer Handwerk." 7 Anklänge daran werden wir in dem programmatischen ersten Lied der Spiewy wiederfinden, in dem ein Engel dem Piast erscheint und inm die ruhmreiche Zukunft seines Volkes vorhersagt:

"Aber der gute Gott schaute auf die Polen, denn er bereitete sie für grosse Bestimnungen vor." Piast 4 . "Eine grosse Laufbahn zeichnet er den Polen vor, Er öffnet Euch das Feld zu ruhmreichen Taten, Gibt Euch Siege, Ruhm und Preiheiten." Piast 16.

"Polen wird sich in der Reihe der ersten Mächte sehen, Und ehrwürdige Fürsten werden inm huldigen." Piast 18. Dieser von Woronicz vor allem ideologisch breit angelegte Plan für ein polnisches Liederbuch, das alles, was nur immer "Einen Christen, einen Menschen und einen Polen" interessieren könnte, enthalten sollte, fand dann durch Niemcewicz auf einer

7 Zitiert bei Manfred Kridl, 1.c. S. $71 f$. 
wesentlich schmaleren Basis und in viel nüchternerer Form seine Verwirklichung. Nach der Berufung des Bischofs Woronicz nach Krakau übernahm der Präses der Gesellschaft, Stanisław Staszic, 1806 die Initiative. Nach seiner Konzeption sollte die Sammlung die vichtigsten Taten der Polen, heldenhafte oder aussergewöhnliche Tugenden allgemeiner oder auch besonderer Art zur Darstellung bringen, geschrieben von polnischen Dichtern nach dem Vorbild der Hymne des Woronicz oder der damals schon bekannten Duma von Z6łkiewsil. Ausserdem sah Staszic eine musikalische Bearbeitung der Lieder und inre Ausstattung mit Kupferstichen vor. Niemcewicz selbst schreibt dazu in der Vorrede: "Die königliche Gesellschaft wollte kein Mittel zur Erlangung eines so winschenswerten Zieles ausserachtlassen und empfahl mir, in historischen Liedern die berühmtesten Abenteuer, die glänzendsten Taten und Siege der polnischen Könige und Heerfürer darzustellen. Die Gesellschaft wünschte, dass das Wissen von der vaterländischen Geschichte, durch die Bündigkeit des Reims und besonders durch den Reiz der Musik für die Jugend anziehend, aller Gemeingut wird".

Płoszowski nennt als Entstehungszeit der meisten Lieder die Jahre 1809-1812. Aus dem hinterlassenen Album mit den grösstenteils eigenhändigen Eintragungen des Dichters geht auch die Reihenfolge hervor. Und zwar entstanden zuerst die Gesänge von den polnischen Königen, um den äusseren Rahmen zu schaffen. Erst dann schrieb Niemcewicz die Lieder, die dem Leben und Wirken grosser Männer gewidmet sind und in denen das Schwergewicht nicht auf grossen geschichtlichen Ereignissen liegt, sondern die Taten der Helden zum Anlass dienen, das geschichtliche Bild kulturgeschichtlich abzurunden. Niemcewicz selbst sagt dazu, dass z.B. das Lied von Zavisza Czarny Lasarh die Sitten der damaligen Ritterschaft mit ihrem uneinsghsänkt ritterlichen Geist aufzeigen könne, das Lied von Tarnowski dagegen solle eine Vorstellung von den Bräuchen 
vermitteln, mit denen die Vorfahren ihre Führer und Helden bestatteten. Auch wollte Niemcewicz der ganzen Sammlung mit diesen Liedern ein gewisses Moment der Abwechslung geben.

Die Beendigung der Śpiewy war jedoch noch nicht gleichbedeutend mit ihrem Erscheinen. Während sich Niemcewicz um die Kupferstiche, die in Dresden hergestellt wurden, bemühte, und die Damen der polnischen Gesellschaft mit der Vertonung der Lieder beschäftigt waren, befasste sich das Towarzysto in Warschau mit der Beurteilung der Lieder selbst. Man hatte dafür eine besondere Kommission ins Leben gerufen, zu der auch Kajetan Kozmian gehörte. Im Namen der ersten Deputation vertrat er die Meinung, dass es besser wäre, das Werk verspätet erscheinen zu lassen, wenn es dafür den Wïnschen und edlen Absichten des Autors mehr entspräche. Kozmian verfasste auch die erste Kritik, die in der Sitzung der Gesellschaft am 1. März 1813 als "Report o Epiewach" verlesen wurde. Gestützt auf den ausführlichen pseudoklassizistischen Apparat von Regeln geht Kozmian scharf und kleinlich mit Niemcewicz ins Gericht, denn nach seiner Meinung bedurfte der Autor keiner Nezchsicht. Das Wesentlichste aus Kozmians Kritik ist seine Frage nach dem Sinn der Lieder und was dementsprechend für Regeln anzuwenden sind. Das Ziel der Lieder könne ein zweifaches sein:

1. dem Volk durch die Darstellung berünmter Männer und grosser Taten Stolz auf die Vergangenheit und eine grössere Achtung vor dieser einzuflössen und es zur Nachahmung anzufeuern. Oder

2. das Wissen von der Vergangenheit allgemein bekannt zu machen und zum Studium der Geschichte anzuregen. Nur diejenigen Werke, die die zuerst genannten Ziele verfolgen, können sich an poetische Regeln halten, denn sie gehören der Gattung der Dramen an. Diesen Regeln entsprechend muss der Dichter seine Auswahl treffen und die Komposition vornehmen; 
die Einheit von Raum, Zeit und Handlung muss gewahrt und den Personen ein entsprechender Charakter gegeben werden. Dieser Vorstellung eines "Dramas" - Kokmian fuhrt die "Ilias" und die schottischen Bardengesänge an - nähert sich am meisten die Duma von Z61kiewski. Der strenge Kritiker unterzieht diese Duma einer eingehenden Untersuchung und spendet Niemcewicz hierfuir das höchste Lob, das ein pseudoklassizistischer Dichter und Kritiker zu vergeben hat, wenn er sagt: "Nichts ist hier zufällig, alles ist wohlüberlegt angeordnet, um das gesteckte $\mathrm{Ziel}$ besser zu erreichen." 9 Auch die anderen beiden Dumen von Michael Glihski und Stefan Potocki wie auch die Iieder von Tarnowski und Ostrogski und der Trauergesang für dẹ Fürsten Poniatowski können noch zur ersten Gruppe gerechnet werden.

Für die im zweiten Punkt genannten Ziele gibt es keine Muster, also auch keine Regeln. Kozmian fürt weiter aus, dass man nach dem Lesen der Spiewy zu dem Schluss käme, dass der Autor sich die ziele der zweiten Gruppe zu eigen gemacht und es vorgezogen habe, nutzlich zu sein, und um dieses Zweckes willen den fur inn glanzvollen Weg verworfen und sich erniedrigt habe, um dafür den grössten Teil seiner Landsleute zu erheben. 10 So hätte der Autor "Śpiewy" von niederer Art geschaffen, obwohl sich in vielen von ihnen Wendungen und sogar ganze Strophen fänden, die eigentlich zu der erstgenannten höheren Art gehörten und es daher bedauerlich erscheinen lassen, dass der Autor sich nicht ganz für diese "Dramen" entschieden habe.

Die Durchsicht des musikalischen Teils hatte der Komponist Elsner ubernommen. Bei der Vertonung lässt sich eine gewisse Pietät beobachten: Zofja Zamoyska hatte die Musik zum Liede von Jan Zamoyski verfasst, die Gräfin Chodkiewicz das Lied

9 Zitiert bei Zdzisław Iibera in Wstęp do Śpiewow historyEznych. Warszawa 1947 , S. X.

10 Eltiert bei WRad. Jankowski, Geneza i dzieje "Spiewow historycznych" Niemcewicza. Pamiętnik Literacki,Rocznik IX,S.66. 
von Rarol Chodkiewicz vertont. ther das Verhältnis von Melodie und Vers wird später noch zu reden sein.

Trotz aller persönlichen Bemühungen des Dichters um die Ausfuhrung der Stiche dauerte es doch noch sechs Jahre, bis die Spiewy endilich am 7. Dezember 1816 erscheinen konnten. Zu den Grínden, die diese grosse Verzögerung verursacht hatten, gehörte zweifellos die schlechte finanzielle Lage der Gesellschaft. Trotz eifrigster Bemühungen Binzelner waren bis zum Oktober 1815 von 1000 Karten für eine Vorbestellung nur 190 verkauft worden. Umso erstaunlicher war der Br6blg des Buchleins nach seinem Erscheinen: im $\mathrm{Nu}$ war die erste Auflage von 1500 Exemplaren vergriffen, für die polnischen Verhältnisse der damaligen Zeit eine ungewöhnliche Erscheinung. Auch die zweite Ausgabe vom Jahre 1818 mit 1000 Exemplaren war sehr schnell verkauft, so dass schon im nächsten Jahr eine dritte Auflage erscheinen musste. Charakteristisch für Niemcewicz ist seine Haltung in der Behandlung der materiellen Seite seines Werkes: er stellte den Reinertrag dem Towarzystwo Przyjacibl Nauk zur Verfugung. Zum Dank dafur bestimmte die Gesellschaft in der Sitzung vom 6. Februar 1820, dass ein Porträt von Hiemcewicz im Sitzungssaal angebracht werden solle.

Den Śpiewy war zweifellos die grösste und längste Wirkung von allen Werken Hiemcewicz's vergönnt. Der Biograph des Autors, Adam Czartoryski, schreibt, dass dem Dichter keines seiner Werke so viel Belfebtheit, Lob und Binfluss gebracht hat wie seine historischen lieder. Sie waren so populär, dass sogar die sonst literarisch Oninteressierten sie kannten. Czartoryski stellt fest, dass sie auf die oberen und mittleren Schichten den heilsamsten Binfluss ausgeúbt hätten. Sie wurden gelesen, gesungen und auswendig gelernt. "In kurzer Zeit... kamen sie aus den vornehmen Salons in die Häuser der Schlachta, aús Warschau und Krakau gingen sie nicht nur in 
die Provinzstädte, sondern auch auf die Dörfer zu den Gutsherren und vom Gutshof zum Vorwerk. Es schien, dass die Spiewy sogar aus den Salons in die Vorzimmer eindrangen... und in allen Stockwerken lehrten, was Polen ist, was es war und wie man es lieben muss"... "Eltern überlieferten sie ihren Kindern, die sie ihrerseits ihren Nachkommen weitergaben, und auf diese Weise ging der Ruhm von Niemcewicz als dem Autor des "Piast" oder der Duma von Z6łkiewski von einer Generation auf die andere über."ll Und Jan Bystroh weiss ays eigener Erfahrung $z u$ berichten, dass die Spiewy bis $z u$ den Jahren vor dem ersten Weltkrieg einer der ersten Lesestoffe der polnischen Jugend waren und dass in den populären Vorstellungen dieser Generation, von dem früheren polnischen Staat ein starker Einfluss der Spiewy spürbar war, obwohl inzwischen Kraszewski und später Sienkiewicz die von Niemcewicz geschaffenen Bilder bedeutend geändert und erweitert hatten. Auch die historische Malerei hat sich vorzugsweise an die von Niemcewicz geschaffenen Szenen angelehnt. Es sei hier nur an Matejko erinnert.

Jedenfalls ist die vom Autor in der Vorrede ausgedrückte Hoffnung auf Erfolg bei weitem übertroffen worden. Dort sagt er: "Ich bin nicht so verblendet und eitel, für meine lieder dieselbe Verbreitung und Dauer (wie für die Lieder der Nachfolger des Ossian) zu erwarten; ich bin glücklich, wenn sie von der Jugend gesummt, den Kindern von guten Müttern und Polinnen vorgesagt werden und so imstande sind, den späteren Generationaridiese Vaterlandsliebe, diese Tapferkeit zu úberliefern, wegen der der Pole einst berüht war und durch die er heute das verlorene Vaterland und den verlorenen Ruhm wieder $2 u$ erlangen suchte."12

11 Niemcewicz, J.U., Spiewy historyczne. istęp. Warszawa 1947, S. V.

12 Niemcewicz, J.U., Śpiewy historyczne. Paryz 1868, S. IV. 
Der Schlissel zu dieser, alle Brwartungen des Autors ubertreffenden Wirkung und Popularität ist nicht zuletzt in der Geschichtsauffassung von Niemcewicz zu suchen, in der Art, wie er versucht, dem Volk und besonders der Jugend, die Geschichte der eigenen Vergangenheit näher zu bringen. 


\section{Die Geschichte und inre Darstellung}

\section{1) Der historische Gehalt}

In den nun folgenden Kapiteln wird zu behandeln sein, wie und mit welchen Mitteln Niemcewicz die polnische Geschichte in seinen historischen Liedern und Dumen darstellt. Bevor von seiner Geschichtsauffassung die Rede sein kann muissen wir zuerst einmal die Geschichte uberhaupt, wie sie in der Sammlung erscheint, einer genauen Untersuchung unterziehen. Für Niemcewicz als Kind der Aufklärung ist die nur aus Legenden bekannte Vorzeit in einem auf "geschichtlicher Wanrheit" beruhenden Werk nicht darstellbar. Er konnte aber doch der Versuchung, der er als Zeuge grosser Umwälzungen im Geistesleben zu Beginn des 19. Jahrhunderts ausgesetzt war, nicht ganz widerstehen, und so greift er mit dem Liede uber Piast, den Stammater des ersten polnischen Herrschergeschlechtes, über die eigentliche geschichtliche Epoche hinaus. In diesem Gedicht von dem legendären Piast lässt der Autor von Gott gesandte Engel gleichsam ein Zukunftsbild der polnischen Geschicke enthillen, das dann in den folgenden Liedern seine Realisierung erfährt. D.h. also, dass Niemcewicz mit diesem Iiede sein ganzes Programm darlegt. Es wird daher auch zu untersuchen sein, wie weit dieser Plan verwirklicht wurde.

Zunächst einmal erfährt das Wesen des polnischen Volkes seine grundlegende Charakterisierung: seine kraft beruht auf Pflug und Schwert. Ein Merkmal, das in den Liedern immer Wiederkehrt:

"Die Pflugschar fröhlich führend, fand er in der Arbeit seinen Lebensunterhalt." Piast 6.

"Lasst Piast in der glücklichen Kässigkeit bei seinem Pflü, bei den Bienen und dem Acker." Piast 12. 
"Schon legte er den Purpur an, nahm das kriegerische Schwert, bekränzte seine Schläfen mit der glänzenden Krone, und den Bauernstand dankbar ehrend befahl er, seinen Pflug neben den Thron zu stellen." "Landsleute, sagt er, wenn ich nun regieren soll, Wenn Ihr und der Himmel selbst es so gefügt haben, beschwöre ich Euch, achtet den Ackerbau:

In Schwert und Pflug liegt die Kraft der Polen." Piast 23, 24

Auch in den Liedern über die Nachfolger des Piast finden sich diese Hinweise:

"Unter inm pflügte auch der arme Bauer sein Feld in Sicherheit." Bolesław Chrobry 14.

"Gut ist es Polen unter Chrobry ergangen!

Er erfuillte die Hoffnungen des Landes: Der Nachbar zitterte, und der Bauer pflügte frei das Feld." Kazimierz Mnich 1.

"Möge der Pflug wiedergutmachen, was die Waffen umgestüzt haben." Wladysław Eokietek 12.

"Den Wert des Lobes kannte man nicht, wenn man ihn König der Bauern nannte." Kazimierz Wielki 8.

Die Gestalt des Piast, wie sie von Niemcewicz gezeichnet wird, ist die Verkörperung des Polen schlechthin: gottesfürchtig, menschenfreundich, fleissig, gastfreundlich und freigebig. Die Vorstellung von den Polen als fleissigen und gastfreundlichen Ackerbürgern kehrt dann später bei Chomiakov und den polnischen Messianisten wieder. Auch die negativen Seiten des polnischen Nationalcharakters zeichnen sich schon in diesem ersten Lied ab. Der Dichter lässt seine warnende Stimme vernehmen und weist auf das Grundübel, auf die Quelle allen Unheils, das ein Volk treffen kann, hin: die Uneinigkeit. 
"Wo eine grosse Vielzahl, ist Eintracht schwer zu suchen; die kostbare Zeit verfloss in lautem Streit." Piast 3

Dieselbe Warnung verkïndeten die Engel in ihrer Prophezeiung, als sie die Zukunft des polnischen Volkes beschrieben:

"Aber der Wohlstand führt zur Verderbtheit:

Mutwillen und schwere Zwietracht schleichen sich ein." Piast 19

Im Lied von 2ygmunt I. wird der beginnende Zerfall schon offenbar, die Prophezeiung findet ihre Erfüllung:

"Das Volk, das Eindringlinge leicht vernichten konnte, fuhrte mit dem eignen.König Streit, es wollte nicht kämpfen, sondern in Scharen beraten, so verpasste es die Gunst des Augenblickes." Zygmunt I. 12

Mit dem Wahlkönigtum geht der Zerfall seinem bitteren Ende entgegen:

"Die Zwietracht entfacht ihre Fackeln und bereitet Blutbad und schreckliche Verbrechen vor." Henryk Waleziusz 3

"Und im Interregnum liess der unterdrückte Geist der Zwietracht seine Wut aus." Zygmunt III. I

"Schon hat der Geist der Zwietracht das teuflische Gift in die wahnsinnigen Horden des Heerführers gehaucht." Zygmunt III. 9

Neben der Darstellung der Charaktereigenschaften des polnischen Volkes enthält das programmatische erste lied auch eize Vorschau auf die Geschicke Polens, und zwar in der Prophezeiung der Engel, die dem bescheidenen Piast den Befehl Gottes uberbringen, die polniscne Krone anzunehmen. Mit Ausnahme des letzten Punktes der Prophezeiung - "dies Land wird von fremden Völkern zerrissen werden" -, der schon eine Anspielung 
auf die jügste Vergangenheit und auf die Gegenwart ist, hat Niemcewicz den hier dargelegten Plan auch durchgeführt, d.h. er hat in den folgenden Liedern das im einzelnen geschildert, was er im Liede von Piast in grossen Zügen angedeutet hatte. Vor der Darstellung der Teilungen aber ist der Autor zuricks geschreckt. Die Beweggründe mögen verschieden gewesen sein. Niemcewicz hätte die Zerstückelung seiner Heimat, die er ja selbst miterlebt hatte, nicht ohne Ressentiments darstellen. können, wodarch aber das ganze Werk gefährdet worden wäre. Ausserdem - und das gilt besonders für die in der Unzulänglichkeit des eigenen Volkes liegenden Ursachen zu dem Untergang Polens - stimmten derartige negative Bilder - man denke an die Sachsenzeit - nicht mit dem Ziel der Sammlung überein, wie Niemcewicz es in der Vorrede selbst erläutert: die Jugend mit den glänzendsten Epochen der Vergangenheit bekannt zu machen. Diesem Zweck hatte sich alles andere unterzuordnen. Nicht umsonst steht dieser Satz zu Beginn der Vorrede. Und auch nur hierauf kann sich demnach die im weiteren Verlauf der Einleitung erwähnte "geschichtliche Wahrheit" beziehen, nämlich nur auf die wahrheitsgetreue Darstellung uben dieser "glänzendsten Epochen". Denn nur die Erinnerung an Glück und Ruhm und Macht kann den gebrochenen Mut eines Volkes wieder aufrichten. So müssen auch die folgenden Verse interpretiert werden:

"Am jüngsten Tag beginnt für Euch der schreckliche Ton der Posaunen inmitten der Donnerschläge zu dröhnen, da der allmächtige, immer barmherzige Gott in den erkalteten Gliedern den Lebensfunken neu entfacht." Piast 20

Beim Lesen dieser Zeilen drängt sich ein Vergleich mit der Hymne an Gott oder dem "Heiligtum der Sibylle" des Woronicz auf. ${ }^{1}$ Auch die folgenden Zeilen lassen Parallelen zwischen

1 Vergl. Woronicz, J.P., "Hymn do Boga" 196-198, "Świątynia Sibylii" 87-92. Bei Manfred Kridl, 1.c. S.69fr. 
diesen beiden Zeitgenossen als durchaus möglich erscheinen:

"Nach schweren Stürmen gab uns der barmherzige Himmel einen grossen Mann, um Polen damit giuckliche Tase wiederzubringen..."

Zygmunt I. I

"Anders wollte es ein dem Volke neidischer Genius, anders wollte es die Vorsehung!" Stefan Batory 17.

" $\mathrm{Zu}$ jener Zeit entzündete sich Gottes Zorn an uns."

Jan Kazimierz 4

Angesichts dieser Verse ${ }^{2}$ könnte man in Versuchung geraten, in innen einen, wenn auch schwächeren Ausfluss des von Woronicz neu belebten Messianismus zu sehen, zumal sie sich auch in demselben Rahmen bewegen: böse Tat - gerechte Strafe, Gnade und Barmherzigkeit Gottes. Gewisse Anklänge an "die irrationalen Elemente in der Atmosphäre dieser Zeit sind nicht zu bestreiten, ein Beweis dafür, wie stark sie waren, stärker als Niemcewicz's Kritizismus, aber sie drangen eher in seine Seele ein, als dass sie in inr ihren Ursprung hatten." 3 Von . Messianismus im eigentlichen Sinne, wie er bei Woronicz auftritt, kann man, vor allem auch unter Berücksichtigung des Gesamtwerkes von Niemcewicz, nicht sprechen. Denn Niemcewicz war nichts weniger als religiös. Woronicz's Messianismus aber beruhte auf seiner tiefen Religiosität, seinem Glauben an die Vorsehung und seinem persönlichen, gefühlsbetonten Verhältnis zu Gott, alles Paktoren, die bei Niemcewicz nicht gegeben waren. Ein Vergleich mit "Hymn do Boga" lässt den Unterschied in beider Konzeptionen klar erkennen. Die Hyme enthält in Andeutungen an gescnichtlichen Ereignissen fast dasselbe, was die Spiewy in Einzelheiten ausfuhren. Bei Woronicz haben wir es mit der polnischen Geschichte als Ganzem, dargestellt in grossen Linien, zu tun, während Niemcewicz uns

Siehe auch Zitat S. 42.

3 Ujejski, Josef, Dzieje polskiego meşjanizmu. S. 139. 
eine Sammlung von Bildern vorlegt. In beiden Dichtungen - bei Niemcewicz kommt für einen Vergleich eigentlich nur das lied von Piast, Strophe 15-20 in Frage - sind unbedingt ähnliche, wenn nicht gleiche Vorstellungsbereiche enthalten. Bei Niemcewicz heisst es:

"Der Herr, der im Himmel wohnt, der Deinen Enkeln den Schleier des Irrtums von den Augen reissen wird, sendet seine Engel zu Dir mit dem Befehl, die polnische Krone anzunehmen. Achte in Demut Seinen heiligen Willen; Eine grosse Laufbahn wird er den Polen vorzeichnen." Piast 15

Diese Zeilen enthalten einen Hinweis auf die kommende Christicnisierung und ruhmreiche Zukunft Polens. Von einem Abhängigkeitsverhältnis dieser beiden Faktoren, d.h. dass die ruhmreiche Zukunft in ursächlichem Zusammenhang mit der Christianisierung stände, kann hier nicht die Rede sein. Anders bei Woronicz, Zeile 15-19:

"Wie sie, nachdem sie Dich als wahren Gott anerkannt hatten, Dir treu dienen sollten in beständigem Glauben;

Und Du hast ihnen dafür gnädig versprochen, Sie zu Grösse und Ruhm zu führen.

Noch waren die Zeichen dieses heiligen Abkommens nicht getrocknet, Als unsre Vorväter, zum Zeichen dieses Abkommens..."

Wo Niemcewicz nur die Legende für die poetische Einkleidung seines Programms verwendet - die Erscheinung der Engel ist, wie Niemcewicz es selbst in den Prosaergänzungen zum liede von Piast erwähnt, der Chronik des Diugosz entnommen -, da schafft sich Woronicz durch die Formulierung eines in seinen Augen zu einer unumstösslichen Tatsache gewordenen Ereignisses eine Grundlage für seinen Glauben an Polen als das auserwählte Volk. 
In Strophe 18 weist Niemcewicz lediglich auf die in den folgenden Iledern zu berichtende Machtstellung Polens hin, die in der Huldigung "achtbarer Fursten" ihren Ausdruck findet. Woronicz aber funrt das alles auf die eine Tatsache zurück, dass nämlich Gott damals der "Gott der Polen" war:

"Welch Wunder, dass vor ihnen die völker niederknieten, die benachbarten Selbstherrscher, Fürsten und Könige Ihren Rat, ihre Verwandtschaft, Freundschaft suchten; Die Armen kamen wegen Unterstutzung, um weisen Rat die

Klugen:

Damals warst Du, o Gott! Gott der Polen, Auch nicht der Nachbar wagte ihnen zum listigen Feind zu werden."

Die anderen, vorher zitierten Formulierungen in den Sipiewy, wie "barmherziger Himmel", "Gottes Zorn" u.ä. dúrfen bei Niemcewicz nur als Redewendung angesehen werden, die zu jeder zeit auch in der Umgangssprache gebraucht wird. Auch Jozef Ujejski betont, dass Niemcewicz von Natur aus kein Träumer war. Er hatte wohl eine lebhafte Phantasie, die aber von einem recht gesunden Verstand beherrscht wurde. Von den vorhandenen Anzeichen irrationaler Elemente bei Niemcewicz sagt Ujejski: "Und es wird immer eine offensichtliche Bemuhung vorhanden sein, diese Elemente zu rationalisieren, sie fur den Verstand annehmbar zu machen, wobei sie sich bei ihm dadurch nie festigen, sondern im Gegenteil geschwächt hervorgehen. Keine Spur von Prpphezeiung ist darin enthalten. 4

Nach eigener Aussage sieht es Niemcewicz als den Hauptzweck seiner Iieder an, geschichtliche Wahrheit zu berichten. Dabel hält er sich 80 genau an die $T$ a $t$ sachen, dass der gei-

4 Ujejski, Josef, Dzieje polskiego mesjanizmu. Iwow 1931, S. 139. 
stesgeschichtliche Zusamnenhang nicht einmal in der von den Denkern der späten Aufklärung schon geforderten Form (Montesquieu, Kołłątaj) deutlich wurde, erst recht nicht die Strömungen und politischen Ideen, aus denen diese Tatsachen geboren wurden. Andrerseits ist es kaum möglich, geschichtliche Realitäten und politische Ideengeschichte in einer Liedersammlung darzustellen, die für die Jugend und die Masse des Volkes bestimmt ist. Und diese von Anfang an feststehende Zielsetzung der Spiewy ist es, die einen wesentlichen Einfluss sowohl auf die Gestaltung der Geschichte selbst als auch auf die Geschichtsauffassung des Autors ausgeübt hat.

Die Gesellschaft der Freunde der Wissenschaften in Warschau hatte durch Hinweise und schon seit längerer zeit entwickelte Vorstellungen von einer derartigen Sammlung diese bereits in bestimmte Bahnen gelenkt. So hatte Stanisław Staszik z.B. an funfzig bis hundert Lieder gedacht. Niemcewicz aber hatte sich in der berechtigten Befürchtung, damit die "schon so viele Male geschilderten Bilder von Kriegen, Gefahren und Siegen wieder und wieder zu wiederholen" 5 , auf 32 lieder beschränkt, dafür aber zusätzliche Prosaberichte zwischen die einzelnen Lieder eingefügt. Der Wunsch der Gesellschaft, diese Lieder für die Jugend und das Volk zu schaffen, kam den eigenen didaktischen Bestrebungen des Autors durchaus entgegen. Für den Demokraten Niemcewicz - Ujejski und auch die modernen polnischen Literaturwissenschaftler wie Krzyzanowski rechnen ihn sogar zu den "Jakobinern" -, der sein Leben hauptsächlich in der Hauptstadt Warschau verbracht hat, bestand das polnische Volk bei weitem nicht nux aus den grossen Magnatenfamilien; obwohl er mit einer von ihnen, den Czartoryskis, von Jugend an in enger Freundschaft verbunden war, setzte er dennoch das Volk als Träger des Staatsgedankens an die erste Stelle. Ein beredtes Zeugnis dafur haben wir in seinen

5 Niemcewicz, J.U., Śpiewy historyczne. Paryż 1868, S. IV. 
Reden als Abgeordneter Iivlands auf dem Grossem Sejm, wo er für die Rechte der Bürger und des Volkes eingetreten ist.

Von dieser Volksnähe muss man ausgehen, wenn man die Darstellung der Geschichte in den historischen Liedern verstehen will.

Für das Volk besteht die Geschichte seines Landes nicht aus der Summe allen Geschehens, also politischen, geistigen, kulturelien oder religiösen Geschehens, sondern aus der Geschichte und dem Lebenslauf seiner Könige und Helden. Diese Identifizierung der Lebenszeschichte des Herrschers mit der Geschichte des Staates war nicht nur für das Volk vergangener Jahrhun. derte kennzeichnend, sondern sie gilt mutatis mutandis vielfach auch heute noch. Darum ist es auch gar nicht erstaunlich, wenn sich Niemcewicz in den Śpiewy in erster Linie nicht auf die zeitgenössischen Historiker Naruszewicz und Badtke stützt, von denen er selbst sagte, dass er sich ihrer mehrmals mit grossem Nutzen bedient habe, 6 sondern sehr gern und oft auf die alten Chroniken von Dlugosz, Bielski, Kadłubek, Gallus u.a. zurückgegriffen hat, in denen Iegenden in grosser Zahl verarbeitet waren. In diesem Zusammenhang wäre ein Vergleich mit dem Werkchen des Waga, eines Zeitgenossen Niemcewicz's, interessant, das den Titel "Historya Xį̨z̨̧t i Krolow Polskich krotko zebrana" (1770) führt, un festzustellen, wie weit die Spiewy damit übereinstimmen. Aus dem Titel geht schon das Ziel des Büchleins hervor; auch weist Niemcewicz in der Vorrede darauf hin, dass es dem Geschmack der Jugend und den finanziellen Gegebenheiten des Volkes durch seine Kürze mehr entsprechen wirde als mehrbändige Werke. Leider jedoch war mir dieses Büchlein nicht zugänglich.

Schon der Aufbau der Śpiewy trägt dieser Geschichtsvorstellung des Volkes Rechnung. Zunächst hat Niemcewicz, wie aus seinem

6 Niemcewicz, J.U., Spiewy Historyczne.Paryz 1868,S.8 Fussnote. 
Nachlass hervorgeht, das Leben der polnischen Könige dargestellt und dann den geschichtlichen Verlauf durch Hinzufügung von Taten berühmter, im Volke lebendiger Helden und Heerführer abgerundet.

Der ungeheure Erfolg der Sammlung bei den Zeitgenossen bestätigt die Richtigkeit der Auffassung des Autors.

So enthalten die Spiewy also in erster Linie Schilderungen kriegerischer Unternehmungen, denen das polnische Volk, "vọn Natur aus tapfer, zum grössten Teil von barbarischen völkern umgeben, mehr als andere ausgesetzt war" 7 . Eine hervorragende Stellung nimmt dabei die ständige Auseinandersetzung mit dem Ritterorden ein. Das mag z.T. schon durch die Herkunft Niemcewicz's - er stammte aus den litauischen Gebieten - bedingt sein. Im Liede von Władysław Eokietek wird zum ersten Male eine Schlacht mit dem Orden, die von Płowce, erwähnt. Hauptthema des Liedes von Władysław Jagiełło ist die Schlacht von Grunwald (Tannenberg). Die Hand des Publizisten ist hier besonders in der zweiten Strophe zu spüren, wo die Gegentiberstellung des räuberischen Ordens und des friedliebenden polnisch-litauischen Volkes sehr geschickt mit der Taufe der Litauer verbunden ist. Auch in der Schilderung der Regierungszeit Kazimierz Jagiellohczyks nimmt der Kampf gegen den Orden einen wichtigen Platz ein. An Hand dieses Krieges gibt Niemcewicz eine ziemlicn negative Charakterisierung des Königs, wenn er von ihm berichtet: "Schon fühlt der König, der tapferen Heere beraubt, seine Kräfte schwinden... Als er in dieser schrecklichen Lage verzweifelt.." Jan Kazimierz, 5,6. In der Cambridge History of Poland dagegen heisst es, dass der König gewaltsam vom Schlachtfeld getragen werden musste, um seine Gefangennahme zu verhüten. ${ }^{8}$

7 Ebd. S. IV.

8 The Cambridge History of Poland I, Cambridge University Press 1951, S. 244. 
Auch nach der Verweltlichung des Ordens findet das nunmehrige Herzogtum Preussen immer wieder Erwähnung, so bei Zygmunt I. und Zygmunt August, wo die Belehnung Albrechts durch den polnischen König in drei Strophen geschildert wird und Höhepunkt und Abschluss des Liedes bildet. Gleichzeitig soll mit dieser "Huldigung Preussens", die von Matejko nach der Schilderung Niemcewicz's gemalt worden ist, der vorerst endgultige Sieg Polens über den Orden und damit die Macht des polnischen Staates ausgedrückt werden. Die letzte Strophe weist aber schon auf die späteren Ereignisse hin, die Niemcewicz dann doch nicht mehr in die Sammlung aufgenommen hat:

"Sei, Fürst, treu dem ehrbaren Königreich, den Königen, die über Euch so viel Gnade ergossen haben, diene dem allgemeinen Wohl, habe mit uns die Feinde gemeinsam; bedenke, dass Gott in verdientem Masse früher oder später die Undankbaren bestraft."

Auch die Tüken- und Tatarenkriege spielen in den Liedern eine grosse Rolle, die ihrem Anteil an der fruhen polnischen Geschichte durchaus entspricht. Ausserdem bietet ihre Darstellung Niemcewicz eine gute Gelegenheit, nicht nur Polens Zugehörigkeit zum Abendland, sondern auch seine Leistung und Bedeutung für dessen Bestand aufzuzeigen. Als erster erkämpft Zawisza Czarny, der Ritter ohne Furcht und Tadel, für Kaiser Sigismund einen Sieg gegen die Türen, und Niemcewicz misst diesem Ereignis so grosse Bedeutung bei, dass er ihm acht der sechzehn dem Leben des Ritters gewidmeten Strophen einräumt. Das gleiche Thema wihlt Niemcewicz mit Recht als das Wesentlichste aus dem Leben des jungen Königs Wadysłzaw, der nach seinem Heldentod in der Schlacht bei Warna Warnehczyk genannt wird. Hier spricht nicht nur der Moralist Niemcewicz, der auf die verderblichen Folgen eines Treuebruchs - den Bruch des angeblich mit den Türken geschlossenen Friedens (bbj wiarołomny) - hinweist, sondern ganz besonders der Realist, fur den an 
erster Stelle und über allem Polen steht. Bei dieser zweiten Schlacht ging es nicht mehr um den Bestand des heiligen Glaubens oder um die polnische Kirche, sondern um Roms Machtansprüche und die eigensüchtigen Bestrebungen "christlicher Herren", die den jungen, vom Ruhme geblendeten König für ihre eigenen, den polnischen konträren Interessen benützten und ihn sein Vaterland vergessen liessen. Auch die Bilder von Jan Albrycht und den Heerführern 61 kiewski und Chodkiewicz. werden von den Türkenkriegen ausschlaggebend beeinflusst. Bei den beiden Feldherrn sollen diese kriegerischen Ereignisse nicht so sehr die politischen Geschicke beleuchten als in erster Linie die bespielhafte Erfullung eines ritterlichen Lebensideals par excellence vor Augen führen. Krönung und siegreichen Abschluss der Türkenkriege bildet das lied von Jan III. Sobieski. Hier spürt man, wie die Begeisterung über den erfochtenen Sieg den Autor mitreisst und inn gewissermassen zu Dramatisierungen zwingt, die das Gesamtbild der Situation etwas verschieben:

"Hier ruft des Kaisers Gesandter, als er König Jan erblickte, Rette Wien und das Reich!

Mit diesen Worten fiel er weinend auf die Knie, Und der Legat fügte hinzu: Rette das Christentum!"

"Verschieden waren die Gestalten der Monarchen. Der Kaiser wollte sprechen, aber als er keine Worte fand, Sagte der polnische König zu ihm:"Ich bin froh,mein Bruder, Dir diesen kleinen Dienst erwiesen zu haben!" Jan III 7, 13 Niemcewicz stellte also das als Idealismus dar, wozu Jan Sobieski durch die am 31. März 1683 vertraglich festgelegte Hilfe verpflichtet war. Dass der Anteil Sobieskis und mit inm der des polnischen Heeres von ausschlaggebender Bedeutung war, kann nicht bezweifelt werden. In Polen selbst ist Jan Sobieski $z$ allen Zeiten als Nationalheld und Retter des christlichen Abendlandes gefeiert worden, so dass Niemcewicz in einem derartigen Liederbuch dieser Auffassung unbedingt Rechnung tragen 
musste. Uberdies bot sich hier, wie schon vorher gesagt, eine Gelegenheit, Polens Leistung für Europa, die von diesem nur zu gern bagatellisiert bzw. überhaupt verneint wurde, hervorzuheben und zu unterstreichen, was in einer Weise geschieht, die für einen Patrioten von Niemcewicz's Graden wirklich erstaunlich ist. Dieser grossartige Sieg war das letzte Aufflackern eines einst mächtigen Feuers vor seinem Erlöschen, die letzte grosse Tat eines zum Untergang bestimmten Volkes. Was schon in den ersten Strophen angedeutet worden war, wird in den letzten Zeilen dieses Liedes noch einmal resumiert:

"Hier starb er: und wie die Sonne im Westen

die Erde mit nellerem Strahl bescheint, so hat auch er tapfer·den Ruhm des Volkes erhoben bevor Polen sich mit den Schatten des Todes bedeckte."

Für die hinreichend bekannte unversöhnliche Haltung des Autors dem grossen östlichen Nachbarn gegenüber, die in anderen Werken, ganz besonders in den Tagebiichern zum Ausdruck kommt, sind in den Spiewy wenig Anzeichen zu finden. Mehrere Erklärungen bieten sich dafür an: das Streben nach historischer Wahrheit und damit nach Objektivität; das Fehlen grosser, ausschlaggebender Schlachten, die eine Dramatisierung wie im Falle Grunwalds oder Sobieskis vor Wien möglich machen wirde; oder - und das dürfte wohl am nächsten liegen - die Rücksichtnahme auf die Zensurbehörden und den, zumindest zur Zeit der Entstehung der Lieder noch polenfreundlichen Zaren Alexander I. 9 Für diese Annahme spricht die Tatsache, dass Niemcewicz in der Duma von Michael Glihski die vierte Zeile der vorletzten Strophe geändert hat. "Gebe Gott, dass sich niemand im Grimm seiner Rache mit dem trügerischen Nachbarn verbändet" hiess es in der ersten Fassung, 10 der endgültige Text dagegen lautet: "Gebe Gott, dass niemand im Grimm seiner Rache den Spuren meiner Taten folgt." Jedenfalls nehmen die Auseinandersetzungen

Siene dazu auch J6zef Ujejski, I.c..S. 132.

10 Płoszewki, Leon, Fierwsza kedakcja Spiewbw. I.c. S. 84 . 
mit Moskau nur einen zweitrangigen Platz in den Śpiewy ein, denn kein lied ist nur ihnen gewidmet, wie wir das sowohl bei den Kriegen mit dem Orden als auch bei den Türkenkämpfen haben feststellen können. In den Liedern von Bolesław Chrobry, Kazimierz Mnich, Bolesław Śmiały oder Wladysław Łokietek ist wohl von Kriegen mit der "verräterischen Rus'" die Rede, aber nur als von elnigen unter den vielen kriegerischen Taten dieser Könige. Das entspricht auch dem historischen Sachverhalt. Aber auch nach Beginn des Moskauer Reiches, das doch seine Ausdehnung nach Westen auf Kosten Polens vorantrieb, wird der Moskauer Staat in den Liedern von König Alexander, Michael Glifski, Ostrogsk1 und Zygmunt August nur beiläufig erwähnt. Erst das Lied von Stefan Batory enthält eine ausführliche Schilderung des dreijährigen Krieges mit Moskau, aber in einer so konventionellen Form, dass man den Eindruck gewinnen könnte, Niemcewicz hätte diesem für Polen doch tödlich gewordenen Antagonismus innerlich völlig unbeteiligt gegenübergestanden.

Eine kontinuierliche Darstellung erfährt auch das Verhältnis Polens zum Reich nicht, Abgesehen von einzelnen Bemerkungen, wie z.B. im Liede von Kazimierz Mnich, wo es von der deutschen Gemahlin Mieczysławs heisst, sie käme aus einem den Polen abgeneigten Lande ( $z$ niechętnej do nas przywiedziona ziemi), oder im Lied von Jan III.Sobieski, der für seine Hilfe bei der Errettung Wiens vom Kaiser nur Undank erntete: "In jedem Bundnis und in jedem Feldzug fand er nichts als Enttäuschung und Verluste", wird nur das Lied von Bolesław Krzywousty von einer Auseinandersetzung mit dem Kaiser geprägt. In diesem Falle geht es aber um die Unabhängigkeit Polens, um eine Entscheidung also, die durchaus würdig und geeignet ist, den Stoff für ein historisches lied abzugeben. Aber der Bericht von der Schlacht auf dem Hundsfeld, wie sie in der polnischen Ubersetzung genannt wird, entspricht nicht den Tatsachen. Nach 2ivier ${ }^{1 l}$ ist es 1109 gar nicht zu einer rich-

11 Zivier, E., Polen. Gotha 1916, S.19. Dieselbe Darstellung in der Gambridge History of Poland. I, S.45f. 
tigen Feldschlacht gekommen. Heinrich V. zog sich zurïck, da die polnischen Streifscharen inm die Versorgung seines Heeres mit Nahrungsmitteln fast unmöglich machten und ausserdem sein Verbündeter, Sẅatopluk von Böhmen, ermordet worden war. Eine derartig nüchterne Erklärung eines für Polen so wichtigen Erfolges aber hätte dem Verlangen des Volkes nach Berichten von Heldentaten nicht genügt, so dass Niemcewicz sich auch hier wieder lieber an die volkstümliche Uberlieferung hielt, die von einer grossen Schlacht auf einem freien Felde spricht, auf dem nach der Schlacht die vielen Leichen der Deutschen von Hunden gefressen worden wären. Auf dieser Uberlieferung beruht auch das Drama "Zbigniew", dessen historische Ereignisse Niemcewicz wahrheitszetreu aus den Chroniken übernommen haben will. Ebenso heisst es in einer Ode von Kajetan Kozmian am Schluss: "Die Welt wird ein neues Hundsfeld erblicken". 12

Auch die für Polen so wichtige, aber verkannte Potenz des Kosakentums ist in die lieder einbezogen worden. Nach einer kurzen Erwähnung des ersten Kosakenhetmans Ostafi im Liede von Zygmunt I.,5: "Und Du, der Du mit kleiner Heeresmacht die Tataren durch wilde, unwegsame Lande verfolgtest, tapferer Ostafi, Führer der Zaporożer!" drückt der Dichter in knappen, klaren, dafür aber umso eindrucksvolleren Worten das ganze Problem dieses zum Staat im Staate gewordene Phänomens aus: "Unsre Habgier und unmenschlichen Strafen empörten das tapfere Volk der Kosaken und der listige Chmielnicki rächte sich gesichert durch das Bündnis mit den Tataren". "Obwohl denkwitrdig gewonnen, löschte die Schlacht bei Beresteczko den Schandfleck der Pilawcer nicht aus, noch rächte sich die kampfbereite Jugend für den Tod des Hetman," Jan Kazimierz 2-3. Gemeint ist die grosse Schlacht bei Beresteczko vom Jahre 1651, in der es Jan Kazimierz endlich gelang, den mit den Tataren verbündeten Kosakenhetman Chmielnicki zu schlagen. Jie Pol'en konnten aber diesen Sieg nicht ausnutzen, da

12 Zitiert bei Tarnowski, 2.c. IV, S.94. 
das uneinig gewordene allgemeine Aufgebot sich auflöste. Somit konnte auch der Tod des in der Schlacht bei den Gelben Wassern 1648 gefallenen Hetman Potocki nicht gerächt werden. An keiner anderen Stelle hat Niemcewicz so offene und harte Kritik an seinem eigenen Volk geübt. Daher sind diese beiden Stellen in einem Werk, das doch ausschliesslich der Verherrlichung der Vergangenheit Polens dienen sollte, sehr bemerkenswert. In diesen Zusammenhang (dritte Strophe) gehört auch die a.0. erwähnte Zeile "Da entzündete sich Gottes Zorn an uns", hier eingefügt, um den Fluch der bösen Tat besonders stark hervortreten zu lassen. An das lied von Jan Kazimierz schliesst sich dann die Duma von Stefan Potocki, dem Hetmanssohn, an, in deren Mittelpunkt der Kosakenaufstand und die verlorene Schlacht bei den Gelben Wassern steht. Aber hier geht es nicht in erster Linie um den politischen oder historischen Wert der militätischen Unternehmungen, sondern Niemcewicz will an Hand dieses im Volke uberlieferten Kampfes die ritterliche Tugend polnischer Männer hervorheben. Das gilt ganz besonders für das Lied von Stefan Czarniecki. Auch hier wählt Niemcewicz die Kriege mit Chmel'nyc'kyj und den Kosaken als Hintergrund, auf dem sich das Schicksal des tapferen Szlachcicen abspielt, der beweist, dass man auch ohne Feldherrnwïrde zu Ruhm und Ehren gelangen kann: "Aber der Pole sah, dass man auch ohne Peldherrnstab siegen und Ruhm erwerben kann". Ausserdem aber bringt der Autor noch zum Ausdruck, wie Erfolg oder Misserfolg bei den Polen, sowohl bei den Soldaten - und das ist hier der Fall - als auch bei dem ganzen Volk, von guten Führern abhängig ist: "Der Sieg, den Unsern so sicher, geht durch den Tod des jungen Puhrers verloren, Mut wandelt sich in tiefe Trauer.." Stefan Potocki 13. Die erste Strophe des Liedes von Stefan Batory lautet:

"Die Geschichte und das eindeutige Bild der ständigen Siege unter Stefan lehren uns, was Polen vermag, wenn ein tapferer König Fürer und Herr zu sein versteht." 
Und das Lied von Zygmunt $I$. hat in der ersten Strophe folgende Verse: "Der Himmel ... wollte ... beweisen, dass der Pole auf dem Weg des Ruhmes ist, wenn er von einem tapferen und rechtschaffenen Manne regiert wird." Das sind wiederum Beweise eines für Niemcewicz kennzeichnenden Zuges: er spricht und schreibt von der Vergangenheit, meint aber damit die Gegenwart. Der Autor nützt hier die günstige Gelegenheit, seife ne politischen Ideen zu popularisieren und gleichzeitig historisch zu untermauern: nämlich die Forderung nach einem starken Königtum und der Nachweis für dessen tatsächliche Notwendigkeit in Polen.

Wenn, auch in ungleich geringerem Masse, trägt der Autor in den Spiewy den innenpolitischen Ereignissen Rechnung. Eines der wichtigsten Kapitel daraus ist die Union mit Litauen. Inrer Bedeutung entspricht eine verhältnismässig kontinuierliche Darstellung der polnisch-litauischen Beziehungen, die schon unter Wladysław Łokietek ihren Anfang nahmen. Dieser König vermählte seinen Sohn Kazimierz mit der Tochter Gedymins von Litauen, Die Enkelin Kazimierz's des Grossen verwandelte dann diese lockere dynastische Verbindung in eine politische Personalunion. Wenn Niemcewicz in dem Lied von der Königin Hedwig dieser die Entscheidung zu dem für Polens Geschichte so bedeutungsschweren Schritt uberlässt; so wird er damit nur den Auffassungen des Volkes gerecht, in dessen Uberlieferung die Königin Jadwiga als leuchtendes Beispiel für frauliche Schönheit, politische Klugheit und persönlichen Mut lebendig ist. Darüber vergisst der Autor aber nicht die eigentlichen Ideologen dieser Verbindung, als deren Verkörperung wohl Ziemovit, der Fürst von Masowien, anzusehen ist, der nach dem Auftreten von Jagiełıo von seinen eigenen Ansprïchen auf die Hand der Könisin Hedwig zugunsten Jagiełłos mit folgenden verantwortungsbewussten Worten zurücktritt:

"Ich fürchte keine Drohungen, ich warte nicht bis zur Absage; 
Genug für einen Piasten, wenn Polen glücklich ist, Heirate Jagiełło, ich verzichte auf meine Rechte." Hedwig 9.

Von der Belohnung, die der polnische Adel für seine Unterstützung Jagiełłos bei der Werbung um Hedwig von diesem als "Herrn und Pfleger des Königreiches Polen" in einem Privileg erhalten hat, das Jagiełło dann nach seiner Krönung in Korczyn bestätigte, berichtet Niemcewicz allerdings nichts. Dafür aber werden in den Prosaerläuterungen diese Privilegien erwähnt, die Jagiełło gezwungen war, dem Adel zu gewähren, insbesondere auch das letzte auf dem Sejm von Jedlna 1430, mit dessen Hilfe Jagiełło die Nachfolge seines Sohnes aus dritter Ehe sicherstellen musste und das dem Adel die Unverletzlichkeit der Person garantierte. Im Anschluss an diesen Bericht äussert sich Niemcewicz: "Die Pflicht des Historikers erlaubte es nicht, die Fehler Jagiełłos zu verschweigen, die Dankbarkeit des Polen spornt dazu an, sie suweit wie möglich zu entschuldigen und $z u$ bagatellisieren". ${ }^{13}$ Nur in dem Liede von Heinrich Valo1s, wo in den ersten Strophen ein kurzer Rückblick auf die Jagiellonenzeit geworfen wird, erwähnt der Autor die gerade unter diesen Herrschern, besonders aber von Władysław Jagiełło gewährten Privilegien: "Jeder erinnerte sich der verliehenen Freiheiten". Henryk Waleziusz 2.

Auch die Spannungen zwischen Wladysław und Witold verschweigt der Autor, wahrscheinlich, um die Einheit Polen-Litauen im Bewusstsein des Volkes auf keinen Fall in Frage zu stellen. In diesem Sinne müssen auch, die Strophen 2-5 des liedes von Władysław Warnehczyk gewertet werden, in denen von der Zuneigung Witolds zu dem Sohne Jagiełłos die Rede ist. Damit soll die Verbundenheit der beiden Völker unterstrichen werden, und zwar in einer für die Zeit kennzeichnenden sentimentalen Weise. Der dem Dichter dabei unterlaufene Fehler in der Angabe des

13 Niemcewicz, J.U., Śpiewy historyczne. Paryż 1868.II, S.18. 
Alters von Wladysław Warnehczyk beim Tode Witolds - Witold si starb schon 1429 - ist, da von keiner politischen Bedeutung, wohl nur eine Vereinfachung, denn der Dichter berichtet vom Tode des Oheims und des Vaters in einem Satz:

"Aber der Prinz zählte kaum zwölf Jahre

Als er Witold verlor und nach des Vaters Tode

den Thron erbte."

In dem folgenden lied von Kazimierz Jagiellohczyk wird das Verhältnis Polen-Litauen nur oberflächlich angedeutet. Niemcewicz wird der Bedeutung dieses Königs durchaus nicht gerecht, wenn er sagt: "Er stellte Litauen über alles". Zivier dagegen kommt $z u$ dem Schluss: "Bei aller Vorliebe, welche der in Litauen aufgewachsene Kazimierz für die unermesslichen, wildreichen Wälder dieses Landes hatte und Zeit seines Lebens behielt, war seine Politik mehr von den polnischen als von den litauischen Interessen bestinat". ${ }^{14}$ Und in der Cambridge History of Poland wird darauf hingewiesen, dass die Litauer aus Furcht vor Benachteiligung (Wolhynien, Podolien) gegen eine Wahl Jan Kazimierz's zum König von Polen waren, Jan Kazimierz selbst aber sowohl seine Stellung in Litauen behalten als auch König von Polen werden wollte: "He therefore pursued a policy of deliberate procrastination". 15 weder in dem Liede von Jan Albrycht noch in den Erläuterungen dazu wird die 1499 zwischen Bolen und Litauen getroffene Vereinbarung erwähnt, in Zukunft nur mit gegenseitigem Wissen und Ubereinstimmung den Herrscher zu wählen, was dann auch nach dem Tode Jan Albrychts bei der Wahl seines Bruders Alexander verwirklicht wurde. Von nun an blieben beide Länder vereint, wie es der Wahlreichstag bestiramt hatte. Niemcewicz berichtet darüber nur in einem Satz: "König Alexander übernahm im gegenseitigen Einverständnis nach dem Bruder die Lasten der Regierung." Das polnisch-litauische Verhältnis wurde Gekrönt durch die Union von Lublin im Jahre 1569, die das Werk Sigismund

14 Zivier, E., I.c. S. 87

15 Cambridge History of Poland, I, S.240. 
Augusts war. Auch Niemcewicz sieht hierin die bedeutendste Leistung des letzten Jagiellonen und widmettem denkwürdigen Reichstag, dem ersten wirklich gemeinsamen polnisch-litauischen, das ganze lied.

Wie weit Litauer und Polen sich schon als ein Volk fühlten bzw. Wie weit die Litauer schon zu Polen geworden waren, möchte Niemcewicz in zwei Liedern zeigen. In der Duma von Michael Glihski lässt er diesen von sich selbst als Polen sprechen, nachdem vorher in derselben Strophe von den "brüderlichen" Wappen die Rede gewesen war:

"On ewige Schade! Oh traurige Erinnerung!

Der Anblick der brüderlichen Adler und Reiter konnte mein grausames Herz nicht erweichen; zwischen den rasenden Reihen der fremden Heere, leider! ich, ein Pole, bekämpfte die Polen!"

Um diese blutsmässige Verschmelzung zu versinnbildlichen, hat Niemcewicz das Schicksal des Füsten Ostrogski herausgegriffen und gestaltet. Er spricht es zwar nicht aus, aber schon aus den Anwerkungen im Anschluss an das Lied ist die Absicht zu erkennen. Dort wird von der Herkunft der Fursten Ostrogski berichtet, deren mit Litauen und der Rus' gemeinsames Wappen der Fürst Konstanty Ostrogski als erster ablegte, weil er nach der schrecklichen Gefangenschaft in Moskau nichts mehr mit den Feinden des Vaterlandes gemein haben wollte. Die Vorfahren des Konstanty Ostrogski hatten erst nach langem Widerstand die polnischen Könige als ihre Herren anerkannt. $\mathrm{Zu}$ der politischen Einheit gehörte nach Niemcewicz's Auffassung auch die religiöse, d.h. der gemeinsame Glaube. Zur Bestätigung dessen fügt der Autor in den Anmerkungen auch einen kurzen Hinweis uber das weitere Schicksal der Familie Ostrogski hinzu, um in diesen Zusammenhang berichten zu können, dass einer der letzten Sprossen, Anna Ostrogska, die Gemahlin des Hetman Chodkiewicz, ebenso sehr der römischen Kirche verbunden war, wie inre Ahnen inr hartnäckig Widerstand geleistet hatten. Um die Vorstellung von 
Polen als einer geistigen Einheit nicht zu zerstören, hat Niemcewicz offenbar auch die Erwähnung der Reformation, die ja aus Polen, ohne politische Spuren zu hinterlassen, sehr schnell wieder verschwunden war, in den Liedern völlig vermieden, von ihren Auswirkungen aber in den Anmerkungen berichtet. Die Haltung, des Autors zu Kirche und Religion iberhaupt ist in den Spiewy, im Gegensatz zu seinen Tagebüchern, eine durchaus positive. Hier wird die Einheit von Staat und Kirche unterstrichen und die ethische Bedeutung der Kirche fuir Volk und Staat anerkannt. Der beste Ausdruck für diese Einstellung ist das Lied von Bolesław Smiały, dessen Mord an dem Bischof Stanisław Niemcewicz rein vom kirchlichen standpunkt, d.h. vom religiös-moralischen aus beurteilt:

"Die Rückkehr nach Polen setzt der entfesselten Begierde, die alles beleidigt, keine Grenzen.

Bischof Stanisław, inmitten der Geistlichkeit, wirft die Fehler vor und droht mit dem Bann; Bolesław Śmiaxy unterdrückt seinen Ärger kaum, er verbirgt seinen Groll, aber bereitet die Rache vor.

Als bald darauf in Skałka der heilige Kaplan Gott vor dem Altar sein Opfer darbringt, Fällt eine wïtende Schar Höflinge im Auftrag des Königs Mit gezogener Waffe in die Kirche ein:

Dreimal schlagen sie $z$, aber eine geheimnisvolle Macht streckt dreimal die Verwegenen zur Erde.

Bolesław, im Zorn kein Mass kennend, vollbringt unerschrocken die Rache."

Diese Deutung der Handlungsweise des Königs ist durchaus umstritten, zumal Gallus, der berufenste chronist, sich über die Vorgeschichte Schweigen auferlegt. Ausserdem berichtet er nur von einer Verstimmelung des Bischofs, nicht von einer Ermordung, und tadelt Bolesław, dass er den Verrat, 
den der Bischof an ihm geübt habe, auf solche Weise gerächt hätte. Die Darstellung in der Cambridge History of Poland spricht von einem königlichen Gerichtshof, dem auch das Haupt der Kirche angehörte, der 1079 den Bischof Stanisław wegen Verrat an König zum Verlust seiner Glieder verurteilte. Das Urteil wurde dann am 11. April vollstreckt. "Die zeitgenössische öffentliche Meinung hat das als niedrige Rache des gesalbten Königs gegen den gesalbten Bischof angesehen, der dennoch des Verrats schuldig war. Wahrscheinlich war auch eine deutsch-böhmische Intrige im Spiel, um den gefährlichen König loszuwerden. Spätere Legenden berichten, dass der König gleich darauf das Land habe verlassen müssen. Es scheint jedoch, dass trotz eines gewissen Zusammenhangs zwischen dem Tod des Bischofs und der Revolte gegen Bolesław, die zu seiner Flucht fühte, diese Revolte dennoch nicht sofort ausbrach und der König seine Position noch für eine gewisse zeit halten konnte, bevor er kurz vor seinem Tode, 1081 oder 1082, ausser Landes gehen musste. Die genannten Umstände der tragischen Ereignisse des Jahres 1079, die Revolte und die Rolle, die Bolesław, Hermann und Stanisław dabei gespielt haben, bleiben ein ungelöstes Geheimnis."16 Nicht einmal Th. Glemma ${ }^{17}$ nimmt eindeutig für den Bischof Stellung: "Der seeleneifrige Oberhirte zog sich den Unwillen des jähzornigen Bolesław II. zu und wurde (wie überliefert wird, in der St.Michaelskirche vor den Toren Krakaus beim heiligen ilessopfer) getötet. Ursache und Umstände sind seit Wojciechowski (Szkice historyczne XI wieku, Warszawa ${ }^{2} 1925$ und $W$ sprawie $s w$. Stanisława biskupa, Krak8w2 1926) umstritten. Erst zur Zeit der von den Krakauer Bischöfen Ivo und Prandota betriebenen Kanonisation 1253 schrieb ein Dominika-

16 Cambridge History of Poland, I, S. 4lf.

17 In Buchberger's Lexikon für Theologie und Kirche. Freiburg, 193off. IX, S. 774 . 
nermönch die sog. Vita maior, die viel Legendarisches enthält. Eine andere Vita verfasste Dlugosz." In seinem lied hat sich also Niemcewicz bei der Charakterisierung dieses Königs wiederum an die volkstümliche Uberlieferung gehalten, die ihren Ursprung zweifellos in den Legenden hat und den Bischof Stanisław als Nationalheiligen verehrt. Trotzdem aber hat sich auch hier eine, wenn auch nur leise Kritik an der Einmischung Roms und dem bedingungslosen, der Kirche von den Polen entgegengebrachten Gehorsam eingeschlichen:

"Vor dem Vatikan das Knie beugend,

Verleugnete der Pole den eigenen Herrn." Bolesław Śmiały 10. Eine ähnliche Stellungnahme enthalten die Anmerkungen, wo es von dem Bischof heisst, dass er sich mehr vom priesterlichen Eifer leiten liess, als dass er auf die dem Monarchen angeborene Lebhaftigkeit geachtet hätte.

Eine positive Haltung zur Religion zeigt auch das lied von dem Fürsten Ostrogski, den der Gang ins Gotteshaus und sein Gebet vor den Häschern des Zaren rettet. Auch diese Episode muss auf volkstümlicher Uberlieferung beruhen, denn viemcewicz, der sonst in den Anmerkungen sehr of die Chronisten zitiert, weist in diesem Falle nur darauf hin, dass sich der im lied geschilderte Vorgang tatsächlich zugetragen habe, ohne aber die Quelle zu nennen.

Dieselbe Haltung kommt in dem Liede von Władysław Jagiełło zum Ausdruck:

"Die in gotteslästerlichen Irrtümern befangenen Li tauer brachten ihre Opfer den falschen Göttern dar, als Jagiello kam, um sein geliebtes Volk den wahren Glauben Christi zu lehren: er zerstörte die Götzenbilder; wo heidnische Bauten waren, errichtete er Tempel und Altäre des Herrn." 
Die Reihe der wichtigen innenpolitischen Ereignisse (von der Union mit Litauen abgesehen) wird mit dem Bericht aus der Regierungszeit Kazimierz des Grossen eröffnet. Im Mittelpunkt dieses Liedes steht das Statut von Wislica, das auch schon in dem Drama "Kazimierz Wielki" behandelt worden war. Als nächstes wird dann der Sejm von Petrikau erwähnt, von dem schon in anderem Zusammenhang die Rede war. Als einziges Resultat weiss der Autor nur zu berichten, dass auf diesem Sejm zum ersten Male die Abgesandten aller Provinzen versammelt waren. Im Zusammenhang mit König Alexander wird auf den Beschluss des Sejms von Radom hingewiesen, die Legislative allein in die Hände dieser Institution zu legen. Die Königswahl - in den Śpiewy sind die Lebensbilder von sieben Wahlkönigen enthalten - wird in fün Liedern beschrieben, am ausführlichsten in dem von Michael Korybut, weil von diesem König nicht viel mehr zu berichten war, aber hauptsächlich wohl - wie es der Autor selbst ausdrückt - weil: "Durch die Liebe des Volkes oder ein glückliches Los allein die Wahl Michaels eine wirkliche Wahl war".

Auch Ansätze zur Berücksichtigung der Kulturgeschichte sind schon in den Spiewy $z u$ beobachten; wenn auch nur sehr bescheidenen Ausmasses, sind sie doch erwähnenswert. In erster Linie beziehen sie sich auf kleidung und Sitten. So soll 2.B. das lied von Zawisza Czarny Kenntnis von den Bräuchen der damaligen Ritterschaft geben und das lied von Jan Tarnowski ein Bild von den Zeremonien vermitteln, mit denen das polnische Volk seine Heerfuhrer beisetzte. Aber auch den heidnischen Bräuchen widmet der Autor im Liede von Piast drei Strophen, in denen er von der feierlichen Aufnahme des ältesten Sohnes in die Gemeinschaft der Erwachsenen, versinnbildlicht durch den ersten Haarschnitt (postrzyzyny), erzählt. Die Grossen aus Kunst und Wissenschaft dagegen werden nur mit kurzen Bemerkungen erwähnt:

"Als alles blühte, alles vom Ruhm gekrönt ist, gab Kopernikus der Welt neue Gesetze." Kazimierz Jagiełło 13 
Mit der Erwähnung Kopernikus' in dem Liede von Kazimierz Jagiełłohczyk, der von 1447-1492 regierte, ist dem Autor ein kleiner Fehler unterlaufen, denn Kopernikus begann sein Werk erst $1515 \mathrm{zu}$ schreiben.

Bei der Schilderung der Epoche Zygmunts I. werden nach den siegreichen Feldherren auch die am Hofe des Königs lebenden Dichter erwähnt:

"Ein Schwarm grosser Männer umgibt den Herrscher, Tomicki steht am Staatsruder, mit dem Kennzeichen der Klugheit bestimmt er die Gesetze; auf der lieblichen Leier des Ovid rührt Janicki mit wehmiutigem Reim; Jan Kochanowski lässt sich mit fröhlichem Gesang vernehmen." Zygmunt I. 7 .

Diese Zeilen sind in zweifacher Beziehung bemerkenswert. Einmal wegen der Vorverlegung von Kochanowskis Wirken bei Hofe in die Regierungszeit Zygmunts I., als Kochanowski, 1530 geboren, noch die Schule besuchte (er trat erst 1564 in den Hofdienst). Zweckhafte Uberlegungen dürften Niemcewicz dazu veranlasst haben. Da er gerade beim Aufzählen berühmter Männer und ihrer Taten war, hat er Kochanowski auch in diesen Zusammenhang hineingenommen. Ausserdem aber hätte der Dichter in das folgende Lied von Zygmunt August, wie Niemcewicz es mit dem Reichstag von Lublin als dem alleinigen Ort der Handlung aufgebaut hatte, gar nicht hineingepasst. So mechanisch diese Erklärung erscheint,..sie entspricht doch dem ganzen Aufbau der Lieder, wie später noch festzustellen sein wird. Für die Beurteilung des Künstlers Niemcewicz aber kann man aus den oben zitierten Zeilen schliessen, wie wenig Niemcewicz Dichter war und dass er sich vor allem selbst nicht als solcher fülte. Wie wäre es sonst zu erklären, dass er für Janicki, den ersten poeta laureatus, und Kochanowski, die doch nicht nur seine grossen Vorgänger waren, 
sondern ihm vor allem hätten Vorbilder sein müssen, nur einen dürftigen Satz übrig hat, der im Falle Kochanowskis als "fröhlicher Sänger" auch noch ein völlig falsches Bild vermittelt. Schliesslich ist der Dichter aus Czarny Las nicht wegen seiner Praszki, sondern vor allem wegen der Treny und des Psalters berühmt.

In zwei Strophen trägt Niemcewicz den kulturelien Bemühungen Stefan Batorys Rechnung und hebt die aktive Rolle des Königs hervor:
"Gleich nach Beendigung der verbissenen Kämpfe befasst er sich mit anderen Aufgaben:
er belebt die Wissenschaften, erlässt heilige Gesetze und untermauert das Glück des Reiches.
In der Hauptstadt Litauens.... erklang der Gesang der neun Musen zu Ehren des den Wissenschaften geneigten Mannes."

\begin{abstract}
Ähnliches berichtet der Autor von dem Ratgeber und Freund des Königs, von dem Kanzler Jan Zamoyski. Auch dieses Lied klingt aus mit einer Aufzählung seiner kulturellen Leistungen und der Beteuerung, dass die dankbaren Musen seine lobenswerten Tugenden und Taten nicht in Vergessenheit geraten lassen werden.
\end{abstract}

Die Erwähnung von Skargas Beredsamkeit schliesslich soll dazu beitragen, die Zeiten Zygmunts III. in der Erinnerung des Volkes etwas rühmlicher erscheinen zu lassen.

Der geschichtliche Zusammenhang ist in der ersten Hälfte der Sammlung, wie der Historiker Lelewel bemängelte, nicht gewahrt worden. Das mag einmal daran liegen, dass für die frühen Zeiten die Nachrichten zum Teil recht dürftig sind, zum anderen aber Niemcewicz gerade die Zeiträume auslässt, die von staatlicher Zerrissenheit und Uneinigkeit gekennzeichnet sind. Ziel dieser Iieder aber sollte sein, die "ruhmreichen Epochen" 
zu besingen. Aus der frühen Zeit sind keine Heldengestalten vorhanden, die entweder geschichtlich oder auf Grund volkstümlicher Uberlieferung geeignet wären, in einem Heldenlied dargestèllt zu werden. Um die Lücke nicht allzu gross werden zu lassen, musste der Autor z.B. die sentimentale und recht naive Geschichte von Leszek, seiner Mutter Helena und dem getreuen Goworek einfügen. Und Leszek war weder ein Held noch ein König, sondern nur einer der vielen Teilfürsten. An seiner Lebensgeschichte jedoch konnte Niemcewicz seine moralischen Belehrungen illustrieren. Auch die Bezeichnung Piast's als König ist geschichtlich unhaltbar, man kann sie aber insofern gelten lassen, als sie Ausdruck eines nicht unberechtigten Stolzes auf die Bodenständigkeit des ersten polnischen Herrschergeschlechts sein soll.

Zusammenfassend kann gesagt werden, dass den äusseren Erscheinungen der polnischen Geschichte in Einzelschilderungen oder in chronikartigen Aufzählungen, besonders was die kriegerischen Ereignisse anbelangt, durchaus Rechnung getragen wird, während die innenpolitischen, die Union mit Litauen ausgenommen, und kulturellen Geschehnisse nur gestreift werden. Umwälzende Erscheinungen auf diesem Gebiet, wie die erstmalige Verwendung der polnischen Sprache in der literatur, finden keinerlei Erwähnung, und das Goldene Zeitalter der polnischen Literatur tut Niemcewicz mit der Nennung zweier Namen ab. Von einem Versuch, grosse geschichtliche Zusammenhänge darzustellen oder gar zu deuten, kann keine Rede sein. Die in den Spiewy enthaltene Darstellung entspricht aber ganz und gar den im Volke überlieferten Vorstellungen von der eigenen Vergangenheit $u n d$ den von Niemcewicz vorzugsweise benutzten Quellen. 
2) Die Quellen zur Geschichte Polens in den Spiewy historyczne

In der Vorrede führt Niemcewicz selbst an, woher er sein Wissen entnommen hat: aus Chroniken, Wappenbilchern, Lebensläufen berühmter Männer, also nur aus sekundären Quellen. An Hand von Fussnoten und $\mathrm{Zitaten}$ in den Anmerkungen ist auch feststellbar, auf welche Chronisten bzw. Historiker der Autor zuriuckgegriffen hat. Wir finden die Namen von Gallus, dem Polen seine erste Chronik verdankt und der besonders für die Zeit des Königs Bolesław Krzywousty eine wichtige und wegen seiner Aufrichtigkeit und Zivilcourage auch glaubwïrdige Quelle ist; Wincenty Kadłubek, der erste, polnische Autor aus der zweiten Hälfte des 12. Jahrhunderts, der Bischof von Krakau und ein sehr gebildeter Mann war. Seine Chronik entstand auf Wunsch Kazimierz des Gerechten und sollte die "Vortrefflichkeit der Vorfahren" hervorheben. Dieser Wunsch seines Auftraggebers wurde dann auf Kosten der Glaubwirdigkeit erfullt. Hinzu kam das Bestreben des Bischofs, die Jugend Vaterlandsliebe, Klugheit und Tugend zu lehren. Sechshundert Jahre vor Niemcewicz ein anderer polnischer Schriftsteller mit genau demselben Ziel! Charakteristisch für den Kirchenfürsten Kadłubek ist seine Uberzeugung von der Vormachtstellung der Kirche gegenüber dem Staat, die sich in der Art auswirkt, wie er die Gestalt Bolesław Śmiałys zeichnet, den er gewissermassen als eine Ausgeburt der Hölle ansieht im Gegensatz zu dem Bischof Stanisław, dem heiligen Märtyrer. Es ist anzunehmen, dass Niemcewicz sich bei dem Iiede von Bolesław Smialy nicht nur an die Iegenden, sondern auch an die Chronik des Kadłubek gehalten hat, die nicht nur im Mittelalter, sondern bis zum Erscheinen der Geschichte Polens von Naruszewicz sehr bekannt und geschätzt war.

Ganz besonderes Ansehen nicht nur in Polen uberhaupt, sondern bei Niemcewicz genoss offensichtlich die Chronik des Jan 
Długosz, des ersten polnischen Historiographen. Długosz ist bemerkenswert wegen seiner Quellenforschung, seiner schon an den Humanismus erinnernden Heimatliebe und wegen seiner Bemühungen, die Quellen auch kritisch zu bewerten. Da es für ihn als leichtgläubigen mittelalterlichen Menschen noch schwer war, Wahrheit von Unwahrheit, Geriuchte von Fakten zu unterscheiden, enthält seine Chronik auch Heiligenlegenden und Erzählungen, die mit der historischen Wahrheit unvereinbar sind. U.a. stammt auch die in dem liede vom Piast angeführte Sage von Popiel von Długosz, ebenso die Erscheinung der Engel aus dem gleichen Lied. Daneben zeigt Dlugosz bereits ein gewisses Bemihen, Anlässe und Folgen der Erscheinungen herauszufinden und sie vor allem auch moralisch auszuwerten, wie es später z.B. Woronicz tat: Strafen für begangene Sünden, Belohnung für erworbene Verdienste. Im liede von Leszek Biały bewertet Niemcewicz auch die Handlung seines Helden in diesem Sinne: "Reichlich belohnte der Himmel diesen Edelmut, soviel Tapferkeit." Mit diesem Masstab gemessen,wird auch Władysław Warnehczyk, dessen Tod gewissermassen als die Folge des "treuebrüchigen Kampfes" anzusehen ist. Niemcewicz fusst mit diesem Bericht von dem Vertragsbruch offensichtlich auf Długosz, der auch, im Gegensatz zur modernen Forschung, von einem den Türken gegebenen Eid berichtet, den Władysław durch die Wiederaufnahme des Kampfes bei Warna gebrochen hätte. In der Cambridge History heisst es aber: "Through the enthusiasm of Cesarini a bold invasion of the Balkans in 1443, under Hunyadi and the King, was partially successful, and could be concluded in the next year by a ten year's peace on favourable terms for Hungary. Unhappilly, Cesarini persuaded the king to rejekt the offer und repeat the invasion." Aus grosser Liebe zu Polen und der katholischen Kirche hat Dlugosz sogar manchmal absichtlich die Dinge verdreht oder auch verschwiegen, wie im Falle der Christianisierung Litauens. In seiner Chronik erwähnt er mit keinem Wort, dass

1 The Cambridge History of Poland, I., S. 239. 
Litauen z.T. schon vor 1386 nach östlichem Ritus christianisiert worden war, wohl um das ganze Verdienst daran der katholischen Kirche und Polen zukommen zu lassen. Dieselbe Darstellung gibt auch Niemcewicz in der ersten Strophe des Liedes von Władysław Jagiełło:

"Die in gotteslästerlichen Irrtümern verblendeten litauer brachten die Opfer falschen Göttern dar, als Jagiełło kam, um sein geliebtes Volk den wahren Glauben Christi zu lehren.."

Eindeutig auf Długosz beruht die Schilderung der jchlacht bei Grunwald, die der Chronist nach dem Bericht eines Augenzeugen, nämlich seines Vaters, der an diesem Kampfe teilgenommen hatte, beschreiben konnt. Auch den 2 weikampf zwischen dem ersten Jagiellonen und einem Ordensritter hat Niemcewicz von Długosz übernomisen. ${ }^{2}$

Weiterhin hat sich Niemcewicz aus Długosz auch die durch dessen enges Verhältnis zu Zbigniew Olesnicki, dem offenen Gegner Kazimierz Jagiellohczyks, beeinflusste negative Charakterisierung dieses Königs angeeignet und ist so dem Verdienst dieses Herrschers nicht gerecht geworden. Für die Zeit bis zur Regierung Kazimierz's IV. greift Niemcewicz vorzugsweise auf $D\lfloor u g \circ s z$ und Marcin Kromer zurück. Kromers "O Pochodzeniu i Czynach Polakbw" ist aber eigentlich nichts weiter als ein ungearbeiteter Długosz. Nur selten zitiert wird die Chronik des jüngeren Zeitgenossen von Długosz, das Maciej z Miechowa - Miechowita, dafür aber umso mehr des Marcin Bielski "Dzieje w Koronie Polskiej", die jedoch in ihrem Polen betreffénden Teil nicht auf Eigenleistungen des Verfassers, sondern hauptsächlich auf dem Werk des Miechowita beruht und nur in den Berichten über einige Erlebnisse aus den letzten Regierungsjahren zygmunts $I$. selbständig ist. Kennzeichnend für Bielski ist, dass er nicht kritisch

2 Siehe auch Cambridge History of Poland, I, S. 214. 
war, dass inm alles Gedruckte wahr erschien. Für die Zeit der Regierung Zygmunts I. und seines Sohnes Zygmunt August bediente sich Niemcewicz hauptsächlich der Schrift von Eukasz G6rnicki "Dzieje w Koronie Polskiej",als historische Quelle nicht so wertvoll wie als literarisches Werk, da der Autor lediglich das erzählt, was er selbst sah oder hörte. Weit besser sind die "Rocznike" von Orzechowski, dessen "Zycie Hetmana Jana Tarnowskiego" Niemcewicz zu dem Liede über diesen Heerfuhrer herangezogen hat. Für das Leben des Kanzlers Zamoyski gab es bereits zu Niemcewicz's Zeiten zwei Darstellungen, und zwar eine aus dem Jahre 1775 von Franciszek Bohomolec, von der Niemcewicz sagt, sie wäre eigentlich nur eine tbersetzung der von Hajdenstajn, Zamoyskis Sekretär, und die andere aus dem Jahre 1785 von Stanisław Staszic. Offenbar aber hat sich Niemcewicz in erster Linie an die erste Darstellung gehalten.

Fuir die weiteren Lieder gibt Niemcewicz dann so gut wie gar keine Quellen mehr an, er spricht immer nur von "zeitgenössischen Geschichtsschreibern" (bwczesne dziejopisarze). Seine eigenen Zeitgenossen hat der Autor der Spiewy offensichtlich nur selten zu Rate gezogen. Für die ersten Lieder zitiert Niemcewicz einige Male die Stellungname von Lelewel bzw. Naruszewicz, wenn es sich um historisch nicht einwandfrei nachgewiesene Dinge handelt, wie z.B. in einer Fussnote zu dem Liede von Bolesław Smiały, in dem vom Grabe des Königs im Kloster Ossa die Rede ist: "Das Grabmal Bolesław Smiałys ist erdichtet, da, wie Martin Gallus schreibt, dieser König in Ungarn gestorben ist. Siehe J. Lelewel". 3

Dieser letzte Hinweis auf Lelewel bei einem Zitat von Gallus lässt die Vermutung zu, dass Niemcewicz einen grossen Teil seines Wissens von den Chronisten aus den Zitaten bei Naruszewicz, Lelewel und Bandtke geschöpft hat. Das scheint auch insofern naheliegend, als die dem Autor zur Verfügung

3 Niemcewicz, J.U., Śpiewy historyczne. Paryż 1868. S. 8. 
stehende Zeit viel zu kurz war, un all diese Chroniken und Berichte durchzuarbeiten, wenn man bedenkt, dass die meisten Lieder in den Jahren I809/1810 entstanden sind, unmittelbar nach der Rückkehr des Autors aus Amerika, er also keine grossen Vorarbeiten hat machen können. In diese Richtung könnte auch die zweite Fussnote zu den Anmerkungen des Iiedes von Piast weisen, wo es heisst: "Bischof Naruszewicz und Bandtke haben in ihrer Sammlung von der polnischen Ge-. schichte mit grosser Arbeit, Ausführlichkeit und Vernunft uns das alles auseinandergesetzt, was unsere und fremde frühe Chronisten von den Slaven und den Anfängen unseres Volkes gesagt haben. Ich habe oft mit grossem Nutzen die Sammlungen beider zu Rate gezogen. " 4

Auch Niemcewicz's Biograph, Furst Czartoryski, äusserte sich zu dieser Frage und stellte fest, dass der Autor "nicht immer aus zeitgenössischen Quellen" geschöpft habe. 5

Dafur hat sich Niemcewicz aber bemüht, in den Prosaanmerkungen soweit als möglich eine objektive Haltung einzunehmen und der geschichtlichen Wahrheit den ihr gebuhrenden ersten Platz einzuräumen. Für eine für das Volk bestimmte Liedersammlung aber.mussten ihm die alten Chroniken weit brauchbarer erscheinen, schon weil sie zum grossen Teil noch mit der im Volke lebendigen Uberlieferung ubereinstimmten. Um nur ein Beispiel herauszugreifen, sei auf das Lied von Kazimierz I. hingewiesen. In der offiziellen polnischen Geschichtsschreibung wird er der Erneuerer genannt (Odnowiciel). Niemcewicz aber zieht es vor, inn der Sage entsprechend als Kazimierz den Mönch mit der dazugehörigen Legende darzustellen. Dass er sich dieser Diskrepanz bewusst war, geht aus der Fussnote zur letzten Strophe hervor, in der es heisst: "Die Angaben und Beweise, die im Kloster Tyniecki aufbewahrt werden: dass Kazimierz Mönch war, werden von B. Naruszewicz und $J$. Lelewel ausführlich widerlegt." 6

4 Niemcewicz,J.U., Spiewy historyczne. Paryz 1868. S. 8.

5 Czartoryski, Adam, Zywot Jul.U.Niemcewicza.Paris 1860, S.168.

6 Niemcewicz,J.U., Spiewy historyczne. Paryz 1868, S. 21 . 
Das sichere Gefühl des geborenen Publizisten, der Niemcewicz im eigentlichen Sinne war, liess ihn erkennen, dass, sollten seine Lieder tatsächlich zum Volksgut werden, mit dessen Hilfe die eigene Geschichte auch der grossen Masse vertraut wird, sie der traditionellen Uberlieferung nicht widersprechen dürfen. 
III. Die sprachlichen und künstlerischen Mittel der Darstellung

\section{1) Die Spiewy und inr Verhältnis zur Ballade}

Wiewohl die Uberzeugung von dem geringen künstlerischen Wert der Spiewy unbestritten ist, erscheint es in diesem Zusammenhang, der Feststellung der in diesen Liedern ausgedrückten Geschichtsauffassung des Autors, doch notwendig, eine Untersuchung uber die künstlerischen Mittel anzustellen, mit deren Hilfe Niemcewicz die wichtigsten Ereignisse der Vergangenheit einprägsam gestal tet hat, so dass sie fast hundert Jahre lang ihren Einfluss auf das Volk nicht verloren haben.

Niemcewicz wählte hierfür die von ihm von der Ballade abgeleitete Form des historischen Liedes.

Niemcewicz hat einen grossen Teil seiner Arbeit (u.a. Dumen, Reisetagebücher, der historische Roman "Jan z Tęczyna") der Erneuerung der polnischen Literatur gewidmet. Den "old ballads" der englischen Literatur hätte man nur Märchen und Lieder des Volkes gegenüberstellen können. Dazu war aber am Anfang des 19. Jahrhunderts in Polen die Zeit noch nicht reif. Einen Ersatz dafür schuf Niemcewicz mit den Dumen. Bruchnalski gibt die für die polnischen Verhältnisse kennzeichnenden Unterschiede in den Bezeichnungen für derartige Dichtungen folgendermassen an:

Duma: Thema aus dem täglichen Leben mit traurigem Ende. Powiesc: Dasselbe, aber heiter, scherzhaft. Duma historyczna oder spiew historyczny: Grosses Geschehen oder grosse Tat aus der Geschichte des Volkes.

In der Einleitung zu den Śpiewy nimmt Niemcewicz selbst ausführlich zu dem Problem der Benennung Stellung: "Allein der Titel der historischen Lieder bezeichnet eine Art der Dichtung, 
die höher steht als die gewöhnlichen Lieder und dem Schreibenden die Verpflichtung auferlegt, sich an die Wahrheit zu halten und inm damit die vorzüglichste Triebfeder in der Poesie uberhaupt, die Phantasie, nimmt." Aus dem folgenden Satz ist zu entrehmen, was Niemcewicz zu den wichtigsten Zügen der Duma zählt: "In zwei Liedern, die ich in meiner Jugend geschrieben habe, von $26 \geqq k i e w s k i$ und Stefan Potocki, habe ich neben den Mut die Liebe eingefügt; sie ist gewiss von der Tapferkeit nicht zu trennen; aber es schien mir nicht dienlich zu sein, sie des öfteren in liedern zu wiederholen, die der Wahrheit, der Vaterlandsliebe und dem wirklichen, nicht erdichteten Ruhme unserer Vorfahren gewidmets tsind. " 1

Da Niemcewicz aber kein Theoretiker der Kunst war, hat er sich nur ganz selten diesbezüglich geäussert und aus nisthetischen Prinzipien nie ein Lebensproblem gemacht". 2 Trotzdem ist er zum Initiator einer neuen polnischen Poesie geworden, was aus der Zahl seiner Nachahmer zu ersehen ist, die sich hauptsächlich der Bezeichnung "Duma" für die Balladendichtung bedienen. Ignacy Gorski hat festgestellt, dass vpn achtundfüfzig Balladen aus der Zeit vor Mickiewicz (ohne die von Niemcewicz) 24 den Titel "Duma" führen." Aber die Leser und auch die Kritiker sind sich dieser Neuerung kaum bewusst geworden, da sich bei Niemcewick neue und traditionelle Züge leicht und ungezwungen ineinander fügten. Wie zwanglos diese Vermischung der alten und neuen Elemente vor sich gegangen und auch vom Publikum und von den Kritikern aufgenommen worden ist, dafür sind die Dumen von Michal Glihski, 26łkiewski, Potocki und die Lieder von Tarnowski und Ostrogski die besten Beweise. Kajetan Kozmian hob in seinem Bericht an das Towarzystwo PrzyjacibI Nauk gerade

1 J.U. Niemcewicz, Spiewy historyczne. Paryz 1868.S.V. 2 feiftef, Juliusz, Przyczynki do dziej6w romantizmu w Pólsce.' Pamiętnik Ii teracki, Rocznik 19, S. 21.

3 Gorski, Ignacy, Ballada polska przed Mickiewiczem. Prace historyczno-lit terackie, Nr.15, S.51. 
diese Lieder als vorbildlich hervor, da sie den Prinzipien der klassischen Poetik in jeder Weise entsprächen. Die Einheit des Ortes ist in allen diesen Gedichten gewahrt: Glihski - Kerker, Z6łkiewski - Schlachtfeld von Cecora, Tarnowski - Beisetzung, Ostrogski - Krankenbett von Rewera. Nur die Duma von Stefan Potocki spielt sich erst nach einigen einleitenden Strophen, die aber schon Hinweise auf den Ort der Handlung geben, auf dem Schlachtfeld bei den Gelben Wassern ab. Auch die zeitliche Einheit ist allen Liedern eigen, ebenso die Einheit der Handlung. In seiner eingehenden Untersuchung weist Kozmian auf den vortrefflichen Aufbau dieser Gedichte hin und nennt sie als Beispiel dafür, wie die Sammlung insgesamt hätte sein sollen. ${ }^{4}$ In seiner Begeisterung ist ihm aber gar nicht klar geworden, welch revolutionäre - jedenfalls für einen Pseudoklassizisten - Elemente in innen enthalten sind. Jankowski zieht daraus den berechtigten Schluss, dass der Kampf der Klassiker und Romantiker mehr ein Kampf um Worte, um Kodzes, Definitionen und Regeln als um die Wirklichkeit der Kunst gewesen sei. 5 Eine Bestätigung dieser Ansicht ist die Äusserung Paul van Tieghem's: "Ainsi presquetoutes les formes de la litterature dimagination. que cultivait $l$ 'age classique pouvaient etre modifiés dans un sens conforme des besoins nouveaux, animés d'un esprit nouveau, pour répondre de nouvelles aspirations." 6 Das eigentliche Strukturelement der Ballade, die Darstellung nur einer selbständigen Episode, ist nur in sechzehn der dreiunddreissig Lieder zu erkennen. Eine Erklärung dafür liegt in dem besonderen 2 weck der Lieder, der es nicht erlaubte, in diesem engen Rahmen einer Liedersammlung fur das Volk in jedem lied nur ein Geschehen festzuhalten. Wo dies aber doch der Fall ist, handelt es sich immer um eine, wie

4 Siehe auch Seite nych" Niemcewicza. Pamiętnik Li teracki, Rocznik IX, S.52.

6 van Tieghem, Paul, Le romantisme dans la litterature europeenne. Paris 1948, S.21. 
Wolfgang Kayser es nennt, "schicksalhafte Begegnung", das Kennzeichen der Ballade. ${ }^{7}$ Als Beispiele wären die Begegnung Piast's mit den Engeln zu nennen oder aber die BolesŁaw Krzywoustys mit Heinrich V., Hedwig-Jagiełło, Leszek Biały-Goworek u.a.m. (Diese angeführten "schicksalhaften Begegnungen" beziehen sich naturgemäss nicht ausschliesslich auf den "Helden", sondern auch auf das Schicksal Polens). Bemerkenswert ist, dass in den ersten Liedern, die Ereignisse aus der frühen Vergangenheit zum Inhalt haben, dieses Merkmal wesentlich stärker hervortritt als in den späteren Liedern, wo es z.T. sogar ganz verschwunden ist. Das dürfte damit zusammenhängen, dass aus den frühen $\mathrm{Zei-}$ ten nur einzelne Ereignisse bekannt und uberliefert sind, während die Nachrichten mit der Annäherung an die Gegenwart verständlicherweise immer vielfältiger und vollständiger werden. Das Nebeneinander mehrerer Ereignisse in einem Lied - nur in den wenigsten Fällen könnte man von einer mehrsträngigen Fabel sprechen - beeinträchtigt den Wert der Lieder ungemein. Denn nur selten kann der Inhalt derartig zusammengesetzter Lieder einem Hauptgedanken untergeordnet sein. In der Duma von Stefan Potocki dagegen kann man von einer Aufteilung der Fabel in mehrere Stränge sprechen (weil eine Fabel klar zu erkennen ist): Kosakenkriege im allgemeinen, Vater-Sohn Verhältnis, Stefan-Elzbieta und Kosakenkriege im besonderen, die'letzten beiden konsequent $z u$ Ende geführt; sie sind aber einem Hauptgedanken unterstellt: dem des ritterlichen Heldentums. Und wenn Niemcewicz auch hier nicht ganz auf die Belehrung verzichten kann: "Möge die Erinnerung an frühere Heldentaten in Euch das Verlangen nach Ruhm erwecken", so überwiegt doch die Absicht, im Leser Mitgefül mit dem jungen Ritter und Begeisterung für sein Heldentum wachzurufen. Aber seine wohl lebhafte, jedoch stets vom Verstand beherrschte Phantasie und

7 Kayser, Wolfgang, Das literarische Kunstwerk. Bern 1948, S. 356 . 
die nüchterne Sprache des Rationalisten haben die lyrischen Elemente nicht zur Geltung kommen lassen, im Gegensatz zu den von Niencewicz aus dem Englischen übertragenen (Alondzo i Helena, Cief Éweliny) bzw. originellen Balladen. Niemcewicz hat diesen Mangel auch selbst empfunden und sich gewissermassen dafür entschuldigt: "Der Dichter-Historiker berichtet nur das, was war: die Geschichte der Menschheit ist selten poetisch." 8 Niemcewicz verisennt aber, dass das Poetische nicht vom Stoff, vom Inhalt abhängt, sondern von der Art und Weise, wie dieser Stoff gestaltet und in eine künstlerische Form gefasst wird, wie die Dumen von Michał Glihski und Stefan Potocki zeigen. Beide sind aber vor den Spiewy entstanden. Von den Liedern der Sammlung weisen das von Piast und der Trauergesang für den Fürsten Poniatowski den grössten Stimmungsgehalt auf, der dem ganzen Liede nicht zuletzt mit Hilfe der eindrucksvollen Sprache eine lyrische Note verleiht. In den ubrigen Liedern sind Versuche zu erkennen, Stimmung mit Hilfe dichterischer Bilder hervorzurufen. Das Wesen dieser Bilder in den Siewy ist aber in den meisten Fällen der epische Vergleich, so dass sie keinen Stimmungsgehalt schaffen konnten. Von einiger Ausdruckskraft ist die Schilderung Bolesław Chrobrys: "Wie ein verwundeter Löwe, die blutunterlaufenen Pupillen rollend, sich auf das dreiste Tier stürzt, so kämpft Chrobry". Die Kraft dieses Bildes aber reicht nicht aus, um bis an das Ende des Liedes wirksam zu bleiben. Das gleiche gilt für die Schilderung des Schlachtfeldes: "Schon breitet die Nacht ihre traurigen Schatten aus, nur der Lärm der Krieger ist zu hören, hier und da auflodernde Flammen der Lagerfeuer, dabei standen die Krieger, um von den Miihen der langen Kämpfe auszuruhen, gestiutzt auf die Schilde und sprachen von den Ereignissen der Schlacht. Der Mond, $a b$ und zu aus den Wolken hervorkommend, zeigte die Opfer der entsetzlichen Schlacht". Diese

8 Niemcewicz,J.U., Spiewy Historyczne. Paryż 1868. S.V. 
Schilderung kann wohl im Leser einen fluchtigen Eindruck von Trauer und Schmerz erwecken, aber eben nur einen flüchtigen Eindruck, kein anhaltendes Gestimmtsein. Das ist das Schicksal allẹ lyrischen Züge dieser Liedersammlung überhaupt. In den Spiewy steht die epische Breite im Vordergrund und das Gefülsmoment im Hintergrund, im Gegensatz zum Wesen der Ballade. Aber in den historischen Liedern und Dumen hatte sich Niemcewicz ja eine ganz andere Aufgabe gestellt als in den Balladen: er wollte "alles, was der Erinnerung wert ist", ith Rahmen des Liedes vorbringen.

Neben dem epischen und lyrischen Element hat die Ballade auch dramatischen Charakter, der z.B. durch starke Gegensätze he:vorgehoben werden kann. Dieses Mittel wird von Niemcewicz häufig angewandt, $z . B$. in der Gegenüberstellung von Władys\aw Jagiełıo und dem Ritterorden. Die zweite Strophe umreisst diesen Gegensatz auf sehr geschickte Weise:

"Und wo die Fluten der Wilija fliessen,

Empfing das Volk, in weissen Gewändern in Reihen versammelt

Mit der Taufe Erleuchtung und Erlösung;

Als während des heiligen Zeremoniells der Priester

Boten berichten, dass der verräterische Orden

Mit Feuer und Schwert die polnischen Lande verwuistet."

In der Gegenüberstellung des anmassenden Ordensmeisters mit dem tapferen und edlen Władysław, der auch in dem toten Herausforderer den tapferen Gegner $z u$ ehren weiss, ist eine ganz besonders wirkungsvolle dramatische Gestaltung erzielt worden. Mit derselben Wirkung hat Niemcewicz den Gegensatz zwischen Heinrich von Valois und dem polnischen Edelmann Jan von Tęczyhski gestaltet. Diese Art der Dramatisierung findet sich in kleinerem Ausmass in sehr vielen Liedern, z.B. Zawisza Czarny-Kaiser Sigismund, Kazimierz Jagiellończyk - der verwundete Ritter. Ein weiteres wirksames Mittel zur Dramatisierung ist die direkte Rede. Auch von ihr macht der Autor sehr viel Gebrauch, dern nur vier Lieder weisen überhaupt keine unmittelbare Rede auf. 
Trotz dieser zweifellos häufig vorkommenden dramatisierenden Elemente sind die Dumen und Śpiewy doch keine kleinen Dramen, wie es Kajetan Kokmian gern gesehen hätte, sondern sie gehören in erster Linie der Epik an, denn in ihnen sind nicht "die Personen und ihre Handlungen das Massgebende der Gestaltung" (Kayser), sondern das Geschehen steht eindeutig im Vordergrund.

\section{2) Strophe, Reim, Metrum und Rhythmus}

Im äusseren Bau der Śpiewy historyczne hat sich Niemcewicz offensichtlich am Volkslied bzw. der Ballade orientiert, denn sowohl die Dumen wie die Lieder sind ausnahmslos strophisch ("Der Bau der guten Ballade ist immer strophisch"l), und zwar bewegt sich die zahl der Strophen zwischen zwölf und dreiundzwanzig, der Durchschnitt liegt bei fünzehn. Die meisten Strophen haben entweder sechs oder vier Zeilen, nur zwei Lieder sind achtzeilig. Lieder mit gleicher strophenzahl haben in den meisten Fällen auch gleichen Strophenbau: Alle lieder mit zwölf Strophen z.B. haben sechszeiligen Strophenbau, diejenigen mit dreiundzwanzig Strophen vierzeiligen u.s.f. Auch die vierzeilige Volksliedstrophe, deren Kennzeichen der Wechsel zwischen drei- und vierhebigen Versen ist, hat Niemcewicz in einigen Liedern verwandt (Stefan Batory, Kazimierz Mnich, Karol Chodkiewicz, z.T. auch in den Liedern von Władysław IV. und Jan Kazimierz). Ziemlich mechanisch kann auch die Gliederung der Strophen durch den Reim genannt werden. Alle Vierzeiler haben das Reimschema abab, die Achtzeiler ababcdcd, während bei den sechszeiligen Strophen das Schema ababcc für einen kräftigeren Abschluss sorgt. Eine Ausnahme macht die Duma von

1 Wilhelm Scholz, Ballade und Drama. In: Gedanken zum Drama. Müchen 1905. Zitiert bei Ignacy Gorski, 1.c. S. 59. 
261kiewski, denn das Reimschema wechselt hier einige Male: die erste Strophe hat umschliessenden Reim, die zweite Kreuzreim, die dritte Strophe Paarreim, die vierte und funfte wieder Kreuzreim, die sechste umschliessenden Reim und die letzten sieben Strophen sind dann einheitlich im Kreuzreim. Dieser Wechsel kann nur in Vers drei und vier der zwölften Strophe mit einer Ausdruckssteigerung in Zusammenhang gebracht werden:

"Krolu! narodzie wolny i potęzny! Wiodęt rbd carów nieszczęsny lecz mężny, Przyjm go nie jako chluby widowisko, Lecz jak odmiennej fortuny igrzysko."

(O König! Du freies und mächtiges Volk!

Ich fuhre Euch das unglückliche aber tapfere Geschlecht der Zaren zu

Empfangt es nicht wie ein Schauspiel des Ruhmes Sondern wie das Schauspiel des wandelbaren Glückes.) Damit soll der Gegensatz bzw. die leicht verwischbare Grenze zwischen beiden Phänomenen hervorgehoben werden.

Um die Gliederung der Strophen aufzulockern, bedient sich auch Niemcewicz des einfachsten Mittels, nämlich des Zeilensprunges: "Dzielnoscią swoją on m6gł by poprawit/narbd, pogrązon w swych wadach" (Stefan Batory 16); "Rzadko los szczerych przyjaciol udziela/ temu, co ludom panujen (Jan Zamoysiki 3).

Im Gegensatz zu den englischen und deutschen Balladen fehlt in dẹ polnischen Versionen vor Mickiewicz, also auch in den Spiewy, der Refrain.

Nicht nur inhaltich, auch formeil fällt der Ruckgriff des Autors auf die literarische Tradition des 16.Jahrhunderts ins Auge. Das lässt sich schon beim Reim feststellen, der als solcher entweder grammatischer bzw. morphologischer 
Glelchklang ist oder aber von der Bedeutung ausgeht, d.h. er soll mnemotechnische Wirkung ausuben und dariuber hinaus die Assoziation verschledenartiger Vorstellungen hervorrufen und verwirklichen. Wir finden in den Spiewy also nicht nur Reim im Hinblick auf die Gleichheit des Klanges, sondern sehr oft auch im Hinblick auf die Gleichnelt des Ausdruckswertes. Ist letzteres der Pall, dann entstammen die Worte des Reims zum grössten Tell der Sphäre moralischer oder mit dieser in Zusammenhang stehender Begriffe, eine Reimtechnik, die auch schon die polnischen Dichter des 16. Jahrhunderts angewand hatten und deren $81 \mathrm{ch}$ dann die Dichter der Vorromantik vorzugsweise bedienten. ${ }^{2}$ BeI Niemcewicz sind sehr oft belde Arten des Gleichklanges miteinander verbunden: panowat - powodowat (Wladysław Warneticzyk 6); panowat - szanowat (Piast 24); potęznym - męznym (Leszek Biały 9); męzne - potęźne (Hedwig 10); hordy - mordy (Zawisza Czarny 7); smiały - wspaniały (Władysław Warnetczyk 8); wspomnienie - sumienie (Michał Glihski 18); więzienie cienie (Michal Glihski 5); boju - znoju (Ostrogsk1 15); bitwami - laurami (Ostrogski 5) und viele andere mehr. Mit diesem Gleichklang wurde eine weitgehende Steigerung des Ausdruckes erzielt. Das gleiche gilt fur die besonders gern. im Reim angewandte Antithese: zwycięski - klęski (Jan Albrycht 13, 26łkiewski 15); więzienia - promienia (Ostrogski 5); uczony - znuzony (Ostrogski 23); cienie - promienie (Jan III. 17, Potock1 15); panowat - hamowat (Wladystaw Warnehczyk 12); boju - pokoju (Potock1 4, Wlady8ław Warnehczyk 13); rzǫdzic - big̨dzit (Zygmunt III. 3); braterski - morderski (Zygmunt III. 7). Diese Beispiele können beliebig vermehrt werden. Sie zeigen, dass Hiemcewicz den Reim vorwiegend auf die bedeutungsstarken Worte gelegt hat. Im Gegensatz dazu treten diese Worte vor der Zäsur nur selten auf. Fälle wie: juz czarne smierci/okryły ją clenie (Glitiki 18) oder: gdzie Z6łkiewskiego/spotkał los okrutny, / jechaz

2 Bruchnalski, Wilhelm, l.c. Rocznik IV, S. ig. 
Sieniawski/odważny i smutny (Z6łkiewski l) sind nur vereinzelt.

Während zu fast allen Zeiten der Dreizehnsilber der traditionelle Vers der polnischen epischen Dichtung war, hat Niemcewicz in seinen historischen Dumen und Liedern fast äusschliesslich den Elfsilber verwandt. Unter den dreiunddreissig Liedern sind nur drei Achtsilber, von den restlichen dreissig sind zehn reine Elfsilber, funf sapphische strophen, während in dreizehn Liedern elf- und achtsilbige Verse abwechseln. Bruchnalski spricht vom Elfsilber als der epischen Form der polnischen Yornomantik. Auch Mickiewicz hat sich seiner in seiner vorromantischen Zeit vorzugsweise bedient. Der Achtsilber dagegen ist in allen neuzeitlichen Poesien die gebräuchlichste Form, der Gedankenlyrik. Diese Art der Anwendung trifft aber bei den drei liedern nur bedingt $z u$, weil in ihnen (Leszek Biały, Kazimierz Wielki, Stefan Potocki) erzählende und reflektierende Elemende vermischt sind. In den Śpiewy handelt es sich also um isometrische, metabolische Strophen, deren stlbenzählendes Prinzip von Niemcewicz konsequent durchgeführt worden ist. Nur in einem einzigen Falle stehen statt acht Silben neun (Stefan Czarniecki 4), und das ohne ersichtlichen Zwang. Die Zeilen enden ausnahmslos weiblich. Wie Gorski feststellt, gilt das für die polnische Ballade bis zu Mickiewicz überhaupt. 3 Dadurch wird die Liedhaftigkeit der Gedichte besonders betont. Auch der Anvers hat vor der Zäsur weiblichen Schluss. Es finden sich wohl einsilbige Worte vor der Zäsur, sie stehen aber nie unter dem Akzent. Die Zisur liegt beim Elfsilber traditionsgemäss nach der füften Silbe. Eine Ausnahme macht nur Vers drei der ersten Strophe des Liedes von Kazimierz Mnich: "Drżaz sąsiad a kmiet oraz pole smiało." Bei der Teilung des Elfsilbers in einen fünsilbigen Anvers und einen sechssilbigen Abvers

3 G6rski, Ignacz, 1.c. S. 62 . 
handelt es sich in den Śpiewy oft nur um eine rein visuelle Zufriedenstellung der Forderung nach einer Zäsur, die den Pseudoklassizisten jedoch vollkommen genugte. 4 Aber diese mechanische Einhaltung der Zäsur trug nicht wenig dazu bei, die Lieder monoton erscheinen zu lassen. Diese Technik wirkte sich auch noch insofern nachteilig aus, als die Lieder ja vertont wurden. Maria Dłuska ${ }^{5}$ zitiert den Komponisten Elsner mit seinem Hinweis auf die Duma von z6łkiewski, in der z.B. die erste Zeile der ersten Strophe die gedankliche Trennung, wie gefordert, nach der funften Silbe hatte: "Za szumnym Dniestrem, na cesorskim błonia.." . Dementsprechend wurde die Musik gesetzt. In der ersten Zeile der vierten Strophe aber befindet sich die Zäsur sinngemäss bereits nach der dritten Silbe: "Tak dumaz, alic po bladym promieniu..", so dass also Musik- und Versrhythmus nicht mehr übereinstimmen und die sinngemäss zusammengehörenden Teile durch die Pause in der Melodie auseinandergerissen werden. In den anderen Strophen finden sich noch mehrere derartige Beispiele $(10,12,18)$. Zur Erklärung ist aber in diesem Falle darauf hinzuweisen, dass die Duma lange vor dem Plan der Spiewy entstanden ist, elne Vertonung vom Dichter also nicht berücksichtigt $z u$ werden brauchte. Anders liegt der Fall in den Liedern. Aber man stösst nur selten auf so krasse Fälle, in denen eine wirkliche Diskrepanz spürbar wïrde. Dazu gehörten die erste Zeile der sechzehnten Strophe des Liedes von Wladysław Warnefczyk: "Na koniec tylu straty rozjątrzone", wo also die gedankliche Pause nach der dritten Silbe, in der ersten Strophe dagegen nach der funften silbe steht. Im Liede von Jan III.Sobieski gibt es neben den oben angefibrten Beispielen auch noch zwei strophen, in denen die erste Zeile die Zäsur nach der sechsten Silbe hat. Alle anderen Verstösse fallen nicht ins Gewicht, da die Melodie so

\footnotetext{
4 Diuska, Maria, Studia z historii $i$ teorii wersyfikacji polskiej. Krak6w 1950, I.

5 Dłuska, Maria, Prozodia języka polskiego. Krakbw 1947.
} 
verläuft, dass elne gedankliche Trennung, glelch an welcher Stelle, uberhaupt nicht spurbar wird.

Die Zäsur wird also in allen Versen syllabisch gesetzt. -Trotzdem 1st die Silbenzählung nicht das einzige metrische Prinzip der Lieder und Dumen. Daneben sind schon Ansätze des episodischen Syllabotonismus vorhanden. Die Vertretungen der Versfusse befinden sich in diesem Falle in zwe1 Positionen, entweder am Ende als katalekt1scher Fuss oder im Anvers. In den Elfsilbern wird der sechssilbige Abvers im allgemeinen selten rhythmisiert. Die Spiewy weisen jedoch auch schon einige Zeilen auf, die über die Zäsur hinweg einen einheitlichen Verlauf nehmen:

August mu dając chorągtew rozwitg̨: Jasnosc1 Waszej-rzekl-dotąd powierzam To księstwo Pruskie, tę ziemię obfitą, I na zngk hozdu tym mieczem uderzam. W nagrodę wiasnej 1 przodkbw twych cnoty $L_{-} L_{-}-L_{-}-L_{-}$ Od krola twego przyjm ten lahcuch złoty. $L_{-} L_{-} L_{-} L_{-} L_{-}$

Der dreihebige Amphibrachys bestimmt die Strophe. Darauf weisen nicht nur die Akzentgefuge, sondern vor allem auch der Schluss der Zeilen hin. Da dem prosodischen Verlauf des Polnischen entsprechend (Betonung der vorletzten silbe) der letzte Amphibrachys nie katalektisch sein kann - wenn man wie Budzyk es verlangt, die Metren nur ubereinstimmend mit Akzent--oder Intonationsgefüge setzt ${ }^{6}$ - muss also in einem gleichzeitig nach dem silbenzählenden Prinzip aufgebauten Vers an irgendeiner Stelle entweder ein katalekt1scher Amph1brachys oder ein Trochäus bzw. Jambus stehen. Fúr den katalekt1schen Fuss käme dann, da der Schluss dafür nicht in Betracht kommt, nur noch der Anfang in Prage. In Versen aber, die auch die Zäsur einhalten, ergibt sich noch die Möglichke1t, einen Trochäus oder Jambus vor der Zäsur einzubauen.

6 Budzyk, Kaz., Co to jest polski sylabotonizm? Pamiętnik Li teracki, Rocanik XIVI, S. $123 \mathrm{ff}$. 
Davon hat Niemcewicz in dem angefuhrten Beispiel in den Zeilen zwel bis sechs Gebrauch gemacht, während er die erste Zeile mit einem katalektischen Amphibrachys beginnen lässt. Die letzte Strophe dagegen hat im Abvers an Stelle des zweihebigen Amphibrachys einen dreihebigen Trochäus, der hier offensichtlich dem besonderen Bedeutungsgehalt dieser Zeilen Ausdruck verleihen soll.

Ein derart einheitlicher Verlauf einer ganzen Zeile und Strophe ist aber sehr selten. In den meisten Fällen ist nur der Anvers rhythmisiert, wie das folgende Beispiel zeigt:

Niebieskie oczy przyjęły go mile, Bo z dawna cnotę tylko zwykzy cenic: Po bojach słodkie przyszedł pędzit chwile I laur za mirtu gałqzzkę zamienit.

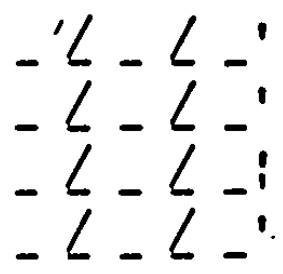

Es sind also je ein Amphibrachys und ein Trochäus verbunden. Geht man aber davon aus, dass Amphibrachys und Daktylus beide das Kennzeichen der zweisilbigen Senkung tragen und also zusammengehören und diese ganze Familie unter die metrische Bezeichnung des Daktylus gebracht werden kann, dann steht vor der Zäsur jeweils ein katalektischer Daktylus.

Es gehört zu den Besonderheiten des polnischen Syllabotonismus, dass die erste Hebung an verschiedenen Stellen stehen kann, während die weiteren Hebungen immer auf derselben Silbe im Vers liegen müssen. Eine weitere logische Folge aus der Vermischung zweier Prinzipien ist die Notwendigkeit, in einem Vers unter Umständen mehrere Versfüsse nebeneinanderzustellen. Die am häufigsten auftretenden Verbindungen in den'Śpiewy sind Daktylus-Trochäus oder Amphibrachys-Trochäus, weil diese drei Metren dem prosodischen Verlauf der polnischen Sprache am meisten entsprechen. Diese Feststellung berechtigt dann auch zu der vor allem von Budzyk vertretenen Meinung, 
dass das Metrum mit dem Akzent- bzw. Intonationsgefüge übereinstimmen muss. Und wenn schon Wolfgang Kayser für das Deutsche sagt: "Belauschen wir deutsche Verse mit zweisilbiger Senkung, so hören wir in den meisten Fällen weder daktylische noch anapästische Worte und Wortgruppen, sondern "amphibrachysche" 7 , um wieviel mehr gilt das dann erst für eine Sprache, deren Prosodie durch den festen Akzent bestimnt wird.

Aafschlussreich für die Beurteilung der nach dem Prinzip des Syllabotonismus rhythmisierten Lieder des Niemcewicz aber ist die Ausfuhrung Maria Diuskas uber die nistorische Entwicklung des Syllabotonismus in Polen. Nach einer kurzen Blute im 16. Jahrhundert (Kochanowski) geriet der Syllabotonismus bei den Dichtern des Parnass in Vergessenheit. Dafür nahmen sich die Tanzlieder - wir würden sagen Schnadahüpferl -, die Spott- und frivolen Lieder seiner an. Dieses Absinken in die niederen Gattungen der Literatur führte zu einer Art Disqualifikation für die höhere Dichtkunst. Aber aus vielen Beispielen geht hervor, dass der Syllabotonismus den Dichtern des Parnass nicht unbekannt war: sie verwendeten ihn nämlich immer an den Stellen, wo die Sprache des gewöhnlichen Volkes nachgeahmt werden sollte. Mit anderen Worten also, der Syllabotonismus war zu einem Element der Volksdichtung geworden. Und das dürfte wohl für Niemcewicz Anlass genug gewesen sein, sich seiner in den Spiewy besonders zu bedienen. 8 Leider hat sich Niemcewicz selbst mit all diesen theoretischen Pragen wenig oder gar nicht auseinandergesetzt. So ist es auch zu erklären, dass darüber von ihm selbst keinerlei Aufzeichnungen vorhanden sind. Weder in seinen Briefen noch in den Tagebüchern befasst sich Niemcewicz mit künstlerischen Problemen. Darum sind wir ge-

7 Kayser, Nolfgang, Kleine deutsche Versschule. Bern 1949. S. $33 f^{\circ}$.

8 Die ersten deutlichen Spuren d.Syllabotonismus bei Krasicki; Hauptvertreter d.klass.S. Mickiewicz. Vgl.DIuska, Maria, Studia $z$ historii $i$ teorii wersyfikacji polskiej.II. 
zwungen, unsere Schlüsse nur auf Grund seiner Werke als des Ausdrucks seiner Gedanken und Empfindungen zu ziehen. Ein kleiner Teil Ungewissheit wird uns dabei allerdings nie erspart bleiben.

Ein weiterer Hinweis auf die Ursache der Vorliebe Niemcewicz's für den Syllabotonismus düfte in den Ausführungen Maria DIuskas zur expressiven Ausbeute des episodischen Syllabotonismus zu finden sein. Dieser episodische Syllabotonismus brachte in die syllabischen lyrischen Verse ein musikalisches Element hinein, das den lyrischen Ausdruck wesentlich zu steigern vermochte. Hinzu kommt noch ein anderer Kunstgriff, nämlich der des Kontrastes zwischen den in bezug auf den Akzent regelmässigen und unregelmässigen Versen. Der expressive Wert des Syllabotonismus bewegt sich also in zwei Richtungen: auf der Linie der Musikalität und auf der Linie des Kontrastes. Hier dürfte es vor allem der musikalische Ausdruckswert gewesen sein, der Niemcewicz den Syllabotonismus gerade für die Spiewy so geeignet erscheinen liess.

Der rhythmische Ausdruckswert, der in diesem Prinzip mit seinen vermischten Metren liegt, ist von Niemcewicz in der Duma von Stefan Potocki am wirkungsvollsten herausgearbeitet worden.

Słuchajcie, rycerze młodzi, Źałosnej lutni jęczenie; $x \& x / x+x \times x /$ Niech w was chęe do sławy rodzi $x \& x / 4 \quad x \quad x \quad x \quad x /$ Dawnego męstwa wspomnienie. $x \times x^{\prime} x \& x * x /$ Słuchajcie, jak sławy wieniéc, $x \dot{x} \times \dot{x} \times \quad x \quad \dot{x} x /$ Walcząc w ojczy $x \& x / x \quad \& \quad x \quad \dot{x} x^{\prime}$ Zyskax́lodważny młodzieniec $\dot{t} \times \times \& \times x \quad x \quad x /$ I w szlachetnym poległ zgonie. $\dot{x} \times \mathbf{x} \times \times \& \times /$ $x \times * x+x \leqslant x /$

Juź Podola żyzne niwy \& $\times \& \times \times \times * x /$ Chmielnicki hordy zalegał, $x \& \times * \times \times * x /$ Juź głos matek przerazliwy $x \& \& \times \times \times \& x /$ W smutnych się skałach rozlegał; 
Rzuca rolnik pług i rolę,

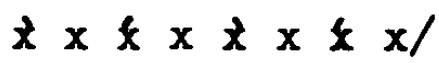
Wszędzie hoze wiodą branki, $\forall x \neq x \neq y \& x \mid$ Pasterz woli ist w niewolę, $\dot{x} \times \dot{x} \times \dot{x} \times \dot{x} \times \mid$ Niz odstąpit swej kochanki. $z \times \& \times \geq \times \& x /$ Syt wieku, szczęscia i sławy, $x<x \cdot x \times x<x /$ Mikołaj wojsku przywodził: Gdy jęk ludu i mord krwawy Do uszu jego dochodzix, Westchnąl i twarz mu sędziwą Eez potok skropil obfity, Wspomniał na miodost szczęsliwą I na wiek swoj nieużyty. A gdy siła cheęi zdradza, Gdy grot 2 słabej pada dłoni, Syn cięzką starost nagradza, Zdolny do konia i broni. Niechętnie Potocki młody

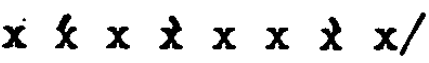
$x \times \& \& x \times x \& x$ $x \notin \times \neq \times \times \neq x \times$ $\forall x \times x \times x \neq x$.

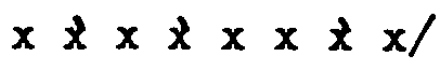
$\dot{x} \times x \notin x \times x \times x$ $\begin{array}{llllllll}x & x & x & x & x & x & \dot{x} & x /\end{array}$ $\begin{array}{llllllll}x & x & \dot{x} & x & \boldsymbol{t} & x & \dot{x} & x /\end{array}$ $x \notin x \times x \times \& x /$ $\forall \dot{z} \times \& \times x \not x \times /$ $x \times x \& \times x \& x /$ $x \& \times x \neq x \neq x$ Dni swoje trawiz w pokoju, $\forall \times x \neq x \times|x|$ Męstwo łączył do urody $\& \times x \times x \times \& \times$

I drżał na wspomnienie boju. $x \& \times \times \times \times<\times 1$ "Synu! - rzekł hetman ze \zami $* x / x \neq x \times x \times x /$ "Kraj twoj w cięzkiej jest potrzebie: $k x+\& \times x \times x \times /$ "Idz, broh go twymi piersiami,

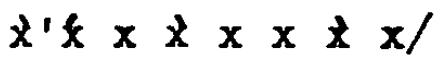
"Bądz godnym przodkbw i siebie. $x \times x+4 \times x \& x /$ "Wiedz, ze $w$ kazdej zycia dobie $\&^{\prime} x \& x \& x \& x^{\prime}$ "Dla ojczyzny tylko zyjesz; $x \times \& \times \times x \times x /$ "Ja szczęsliwy legnę $w$ grobie, "Gdy się ty chwalą okryjesz." $\begin{array}{llllllll} & x & * & x & * & \times & * & x /\end{array}$ $x \times x \& 4 \times x \times x /$

Zwei Kola bestimmen das Lied: $x \notin x$ und das dynamische $\dot{x} \times * \times \neq \times \& \times$, das immer dann erscheint, wenn die Handlung vorangetrieben und verdichtet werden soll, während das erste Kolon Ausdruck für die Stimmung des Dichters bzw. für seine Äusserungen überhaupt ist. Diese rhythmischen Leitmotive unterstreichen zugleich wirkungsvoll die Bedeutung der auf sie entfallenden Stellen innerhalb der Duma. 
Das erste Kolon, das in vielen Zeilen auf den ganzen Vers ausgedehnt, $x \dot{x} \times \mathbf{x} \times \mathbf{x} \times$ ergibt, mit der ersten ausgeprägten Hebung und den zwei schwächeren Hebungen leitet ein und schliesst auch mit der letzten strophe ab. In den anderen Strophen tritt es immer dann auf, wenn ein ruhiger, gleichsam beschaulicher Erzählton vom Dichter selbst angeschlagen wird, wie z.B. zu Beginn der dritten Strophe, wo von dem alten Potocki die Rede ist, der "mit Jahren, Glück und Ruhm gesättigt ist", oder in der vierten bzw. füften Strophe, wo es vom jungen Potocki heisst, dass er seine Tage nur ungern in Frieden verbracht habe, bzw. in der Aufforderung des Vaters an ihn, sich "seiner selbst und der vorfahren würdig zu erweisen". Am Schluss des Liedes wird dieser Rhythmus noch ausgeprägter verwirklicht als in der ersten Strophe:

Spoczywaj, rycerzu, mile $x+x^{\prime} x+x^{\prime} \dot{x} x^{\prime}$ Między cichym drzew tych cieniem; $x \times \leq \times \leq \times \leq x /$ Niech księzyc głuchej mogile $x \dot{x} \times \dot{x} \times \dot{x} x^{\prime}$ Przyjaznym $t w\{e c i$ promieniem. $x \boldsymbol{x} \times \dot{x} \times \mathbf{x} x /$ Jeßli kiedy rycerz męzny

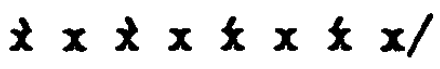
$W$ tej sie tu znajdzie krainie. $t \times x * x \times k x /$ Spojrzawszy na grob potęzny, $x \dot{x} \times x \& \times \dot{x} \times /$ Niech, jak ty, walczy 1 ginie.

$\dot{t} \times x^{\prime} \dot{x} \times x|x|$

Auch das zweite Leitmotiv erscheint in der letzten Strophe noch einmal, aber in abgeschwächter Form, die Hebungen sind nicht mehr so schwer wie in den anderen Strophen.

An diesem Beispiel wird deutlich, wie eng im polnischen Syllabotonismus Rhythmus und Metrum miteinander verbunden sind. Das Phänomen des polnischen Syllabotonismus, dass verschiedene Versfusse innerhalb einer Zeile nebeneinander stehen können, führt zu einer eigenen rhythmischen Ausdruckskraft, besonders spurbar an der hier aufgefunrten Duma von Stefan Potock1. Beide hier herausgestellten Kola sind in ihrer fliessenden bzw. aufbauenden, drängenden wirkung nicht ohne 
die entsprechenden Metren Daktylus (Amphibrachys) bzw. Trochäus denkbar. Da es sich um einen Achtsilber handelt, kanr. nur der Trochäus oder Daktylus rein auftreten, während der Amphibrachys jeweils mit dem Trochäus, in seltenen Fällen auch mit dem Jambus verbunden sein wird. An welcher Stelle dieser dann steht, auch das verleint dem Rhythmus wieder eine besondere Wirkung.

Dieser enge Zusammenhang zwischen Metrum und Rhy thmus bedingt den massgebenden Anteil des Bhythmus am Aufbau der Spiewy.

\section{3) Wortschatz, Syntax und rhetorische Figuren}

Die historischen Lieder und Dumen lassen auf einen verhältnismässig grossen Wortschatz des Autors schliessen. Aber immer bleiben die Worte in der nüchternen Sphäre des aufkärerischen Sprachgebrauchs. Trotz der Vielheit der dem Autor zur Verfügung stehenden Worte gelingt es nicht, sie so abzutänen, dass sie auch einen gewissen stimmungswert erhalten und über die sachliche Aussage hinaus zur Schaffung einer bestimmten Atmosphäre beitragen. Es sind immer die gleichen Worte, ob sie nun von Piast oder fast tausend Jahre später von Zamoyski gesprochen werden. Sehr deutlich ist das an den grösstenteils charakterisierenden Adjektiven zu beobachten: syn pierwotny 'erstgeborener Sohn' (Wlad.Warn.), puklerze staliste 'stählerne Schilde', obce narody 'fremde Völker' (Kaz.Jag.12), ciemny wąwbz 'finstere Schlucht' (Jan Albrycht 12) u.a.m. Selten sind die formelhaft verwendeten wie skarby drogie 'teure Schätze' (Boleslaw Chrobry 13,Kaz. Mnich 7), jezioro czyste (Piast 2). Für Lieder, die die einzelnen Epochen der Geschichte charakterisieren sollen, ist der Gebrauch der Adjektiva in den Spiewy verhältnismässig gering. Dafür treten aber gewisse Adjektiva immer wieder au:, 
sowohl in Verbindung mit bestimmten Substantiva als auch in Verbindung mit den verschiedenartigsten Begriffen. Dazu gehört in erster Linie dzielny - tapfer, das in allen nur möglichen Zusammenstellungen erscheint: dzielny koh 'tapferes Pferd', dzielny rotmistrz, dzielny wojownik '-Krieger', dzielny rycerz '-Ritter', dzielny hetman und dzielny narbd '-Volk'. Aber auch die Hand, die Siege, der Sturm auf die Festung, die Waffen, die taten und die Fugend werden mit diesem Epitheton bedacht. Angefangen von Piast gibt es wohl kaum ein lied, in dem dieses Wort nicht wenigstens einmal vorkäme. Fast ebenso oft ist das Wörtchen swietny 'glänzend! rünlich' anzutreffen, gleichfalls mit den verschiedensten Begriffen verbunden: Swietna korona (Piast 23), swietne gody '-Feste' (Wlad. Warn.2, Wlad.IV. 1), Gwietne poselstwo '-Gesandtschaft' (Raz. Jag. 12), Gwietne pole '-Feld' (Jan Zamoyski 6), swietne dzieła bzw. czyny '-Taten' (Bolesław Choobry 13 bzw. Stefan Batory 8). Um den Eindruck bei den Lesern zu vertiefen und vor allem auch mit Rucksicht auf das Volk bedient sich Niemcewicz vorzugsweise starker Bpitheta. Der häufige Gebrauch der Wörter okropny 'schrecklich' und okrutny 'grausam' kann als Beweis dafür angesehen werden. Auch diese beiden wörter erscheinen in vielerlei Zusammenstellungen: okropne klęski '-Unglucke' (Wlad. Warn 10) Jan Albrycht 13), okropne straty '-Verluste' (Karol Chodkiewicz 18), okropne poźogi '-Brände' (Wlad. IV. 5i, okropne mordy '-Morde' (Zawisza Czamy 7, Zygmunt III. 9), okropna bitwa '-Schlacht' (Wlad. Eokietek 2), okropne niezgody '-Zwietracht' (Aleksander 2), okropny cieh '-Schatten', okropny przykład '-Beispiel' (Glihski 1,17), okropne krzyki '-Schreie' (Zygmunt III. 2); okrutny los '-Schicksal' (ZOZkiewski 1), okrutne zdzierstwa '-Schindereien' (Kaz.Mnich 3). Zu dieser Kategorie sind auch wspanialy 'herrlich, grossartig' oder srogi 'grausam' zu rechnen: wspaniaze gmachy '-Gebäude' (Kaz. Wielki 7), wspaniała stolica '-Hauptstadt' ('Wad. Warn. 7), wspaniale poselstwo '-Gesandtschaft' (eben- 
da 8), wspaniały czyn '-Tat' (Gliński 15); srogie okowy '-Fesseln' (Ostrogski 5), srogie Tatary (ebenda 8), sroga zima '-Winter' (Tarnowski 1, Jan Kaz. 10), srogie przygody '-Abenteuer' (Michał Korybut 8). Durch den ständigen Gebrauch derart starker Epitheta ist aber eher das Gegenteil erreicht worden, d.h. eine gewisse Abwertung des Bedeutungsgehaltes durch Uberbeanspruchung.

Darüber hinaus ist eine Tendenz zu beobachten, bestimmte Substantiva immer mit bestimmten Adjektiva $z$ verbinden: Schlachten und Kämpfe werden immer als blutig dargestellt: krwawy bog (Bolesław Krzywousty 6, Stefan Potock1 10), krwawe bitwy (Leszek Biały.5, Wlad. Jag. 7, Kaz. Jag. 5). Für die Landschaften gitt es nur das Kennzeichen der Pruchtbarke1t: zyzne Morawy, zyzna Rus (Bolesław Chrobry 5 u. 6), Podola zyzne niwy (Potocki 2). Alle Begriffe, die mit der Kirche zusammenhängen, sind heilig, Trauer und Schmerz sind schwer, die Schilde stäblern und die Grenzpfähle stets eisern. Eine gewissermassen hypnotische Wirkung liegt in der Charakterisierung des polnischen Volkes, seiner Männer und Krieger, die in der Vergangenheit stets bewaffnet, mutig und tapfer waren und es auch in der Gegenwart und Zukunft sein solien. Auch die Erbfeinde Polens werden in dieser Weise charakterisiert, auch von ihnen schafft Niemcewicz eine feststehende Vorstellung: Turken und Tataren sind wild, roh und grausam, während die Rus', die Cechen und der Ritterorden als verräterisch gekennzeichnet werden. Auch die Adjektiva, mit deren Hilfe die wenigen Frauengestalten geschildert werden, sind immer die gleichen, ob es sich nun um die Frau von Piast, die Hofdamen der Königin Bona, die Gefangenen des Chmel 'nyc'kyj oder Elisabeth, die Geliebte Stefan Potockis, handelt. Die Epitheta, die der Königin Hedwig beigegeben sind, heben diese über die anderen Frauen hinaus: von thr heisst es nicht, dass sie hübsch war, sondern schön und hold. In der Charakterisierung der 
Könige kann man Niemcewicz's Herrscherideal erblicken. Er erwartet von einem polnischen König, dass er gerecht und kühn (Leszek Biały), gerecht und gut (Bolesław Chrobry), mächtig und kuihn (Wad. Warn.) ist. Auch Polen und sein Volk haben inre festen Epitheta: tapfere Polen, das tapfere Geschlecht Lechs oder aber das Geschlecht des Mars. Die interessanteste Gruppe der Adjektiva sind zweifellos die Farbvorstellungen. Sie zeigen, dass Niemcewicz dem Pseudoklassizismus doch schon entwachsen war, denn dessen Zeitgenossen hatten noch kein Empfinden weder für Licht und Schatten noch für Farben. In den Spiewy herrschen die Farben schwarz und weiss vor, dann folgen gold, grün und blau. Rot als solches erscheint nur einmal in der Verbindung mit weiss: die weiss und roten Fähnchen (Poniatowski 2), sonst nur indirekt als blutig. Auch in diesem Bereich macht sich der Hang Niemcewicz's zur Typisierung bemerkbar: wenn die Farbe von Kleidern überhaupt erwähnt wird, dann sind sie immer weiss: białe szaty '_Gewänder' (Piast 14), sniezne szaty 'schneeige Gewänder' (Wlad. Jag. 2), sniezne ubiory '-Kleider' (Wlad. Eokietek 10). Ist von einer Frauenstirn oder -brust die Rede, dann wird sie als schneeweiss bezeichnet: snieżne łono (Stefan Batory 6), sniezne czoło (Hedwig 22). Diese Typisierung gewisser Begriffe und Vorstellungen und nicht zuletzt auch der Gestalten, die durch die immer wiederkehrenden Epitheta erreicht wird, deutet auf (bewusste oder unbewusste?) Anlehnung an die Volksdichtung, deren Wesen durch einen gewissen Formelschatz geprägt wird. Wie wenig es Niemcewicz lag, seinen Gefühlen Ausdruck zu verleihen, kann daraus ersehen werden, dass in den Śpiewy keine Deminutiva vorkommen, die ja "meist nicht die Kleinheit des Gegenstandes bezeichnen, sondern in erster Linie den Gefühlsanteil des Sprechenden"l, in diesem Falle also den des Autors.

1 Kayser, Wolfgang, Das sprachliche Kunstwerk. Bern 1948 , S. 109 . 
Zum Wortschatz als solchem ist zu sagen, dass Niemcewicz viele Ausdrücke und Redewendungen aus dem Sprachgebrauch der Bewohner der ehemals litauischen, seit 1386 mit Polen vereinigten Gebiete verwendet. ${ }^{2}$ Seine Tendenz in dem Tagebuch uber seine Reisen durch die polnischen Lande, in den Bewohnern der Ukraine, Litauens und Rotrusslands das Bewusstsein wachzuhalten, dass sie trotz der Abtrennung dennoch $z u$ Polen gehören, könnte ihn zum bewussten Gebrauch polnischlitauischer Worte und Formen veranlasst haben. Eine besondere künstlerische Wirkung hat Niemcewicz damit kaum erzielen wollen, denn in der Alternative polnische/litauischpolnische Form ist kein künstlerisches System zu erkennen. Das Primäre dürfte in diesem Falle die Herkunft Niemcewicz's aus den genannten Gebieten sein.

In diese Kategorie gehören: pohaniec, poganiec, pogahcy: Klęskamie pohahcow rady poruszone (Kaz.Mnich. 8), gmachy pogah́ski (Wlad.Jag. I). Ob die Form "pohahcy" eventuell zu den Archaismen gehört, da sie von Kochanowski viel gebraucht wurde, ist schwer zu entscheiden. Recht zahlreich treten bohater/bohatyr auf, in manchen Liedern sogar beide Varianten gleichzeitig: powitat bohatera und juz swita promieh bohatyrskiej sławy (Karol Chodkiewicz 1 u. 2); zona, czcząc bohatyra.. und oglądat pragnie bohatera (Stefan Czarniecki 5 u. 6). Es überwiegt die Form bohatyr.

Aus dem polnisch-litauischen Sprachgebrauch stamm auch die von Niemcewicz angewandte Bedeutung von Wörtern, die im Polnischen uberhaupt nicht mehr gebraucht wurden oder einen Bedeutungswandel erfahren haben. Uber diese Wörter wird im Zusammenhang mit den Archaismen noch zu sprechen sein. Wo im Polnischen zwei Ausdrucke zur Verfügung stehen, ein spezifisch polnischer und ein gemeinslavischer, zieht Niemcewicz letzteren vor, wie ein Vergleich des Gebrauches von obłok - chmura zeigt: obłok: Jan III.Sobieski 9, Stefan

2 Siehe dazu auch G8rski, Konrad, I.c. S.207 ff. 
Potocki 11, Władysław Łokietek 2; chmura: Krסl Aleksander 5.

Soweit es bei den sich ständig wiederholenden Erscheinungen der polnischen Geschichte möglich ist, hat Niemcewicz versucht, durch Anwendung von Synonyma den Stil vor Eintönigkeit zu bewahren. Wie aber schon an Hand der Adjektiva gezeigt werden konnte, ist ihm das insofern nicht gelungen, als er ja offensichtlich andrerseits auch die Absicht hatte, feste Begriffe und Vorstellungen in seinen Lesern hervorzurufen und zu verankern. Dadurch war er gezwungen, in denselben Situationen wieder und wieder dieselben Begriffe zu verwenden. Wenn es sich dagegen um nebensächliche Erscheinungen handelte, hat er in grösserem Masse auf Synonyma zurückgegriffen, ohne jedoch damit eine feinere Bedeutungsdifferenzierung $z u$ verbinden. Es handelt sich in den meisten Fällen um eine Zweigliedrigkeit des Ausdrucks. In “einigen Liedern aber finden sich auch Beispiele für eine gewollte Synonymik, die eine Verstärkung des Ausdrucks herbeifuhren sollte: "Jako przed swoim $i$ krblem $i$ panem ...lennicy bili kolanem" (Die Lehensleute neigten die Knie vor ihm als ihrem König und Herrn. Whad. Warn. 7); "kt6rych by 1 niegdys duma i ozdoba" (deren Schmuck und Zierde er einst war. Poniatowski 4); "ze chrztem odbierał swiatłboi zbawienie" (mit der Taufe empfing es Erleuchtung, und Erlösung. Wlad. Jag. 1). In dem Vers aus Bolesław Smiały haben wir es sogar mit einer dreigliedrigen Form zu tun: "Wszędy płacz, trwoga i smutek niezmierny" (überall Weinen, Schmerz und masslose Trauer).

Eine Vorrangstellung nehmen die Verba in den Śpiewy ein. Zur Veranschaulichung, in wie weitgehendem Masse sie verwendet werden, soll die vierzehnte Strophe des Liedes von Piast dienen:

"Postat ich niebian mieszkahc6w wskazuje: Od bark6w snieżne skrzydła się podnoszą, Białe ich szaty do ziemi zstępują, A ciemne włosy woh lubą roznoszą" 
(Ihre Gestalt weist auf Bewohner des Himmels hin: von ihren Schultern ragen schneeige Flügel empor, ihre weissen Gewänder steigen bis zur Erde hinunter, und die dunklen Haare verbreiten einen holden Duft.)

An diesen Zeilen wird deutlich, welche Bedeutung der Autor den Verba zumisst, verständlich insofern, als das Geschehen die eigentliche Substanzschicht dieser Lieder ist. Als Bestätigung dafür kann das fast völlige Fehlen des Konditionals angesehen werden. Niemcewicz verwendet ihn nur dann, wenn er seinen eigenen Reflexionen freien Lauf lässt, z.B. was aus Polen hätte werden können, wenn Stefan Batory nicht so früh gestorben wäre (Stefan Batory 16).

Der Wunsch, nicht nur von den gebildeten Magnatenfamilien, sondern auch und vor allem vom Volk - dazu ist in dieser Zeit vor allem auch die wenig oder gar nicht gebildete Szlachta zu zählen - verstanden zu werden, hat unseren Autor offenbar veranlasst, sich eines leicht fasslichen und einfachen Satzbaus zu bedienen. Die kurzen nebengeordneten Sätze herrschen vor. Stellen, an denen man durch zu viel untergeordnete Sätze gezwungen wäre, erst einmal zu konstruieren, um die Art der Bezüglichkeit zu erfassen, sind sehr selten. Man darf sich auch durch die unmotivierte Interpunktion des Autors nicht zu der Annahme verleiten lassen, dass ein Satz, nur weil ein Komma oder Apostroph folgt, noch nicht zu Ende wäre. Diese nebengeordneten Sätze sind ein Zeichen mehr für den volkstümlichen Stil Niemcewicz's und für seinen inneren Abstand zu den Ereignissen. Aus dem ganzen Satzbau ist Eine Tendenz zur Ordnung zu ersehen, die klar erfiasten Sachverhalte bauen sich regelmässig aus Subjekt, Prädikat und einer adverbiellen Bestimmung auf. Aber auch die wenigen langen, untergeordneten Sätze, deren Sinn sich über mehrere Zeilen erstreckt - für die Ohren der Pseudoklassizisten eine Qual, da so die Verse zur monotonen Prosa wirden - sind verständlich und klar. Mit ihrer Hilfe gewann Niemcewicz eine Möglichkeit, mehrere Ereig- 
nisse und Bezogenheiten auf engstem Raum zusammenzudrängen und ausserdem dem Ablauf des Geschehens einen wesentlich dynamischeren Verlauf zu geben:

"A gdy po ojcu berło odziedziczył, Henryk, co w Niemczech panował, Yewien, ze tłumem najętych orszak $6 w$ Zastraszy dzielnych Polakbw, Nie znając, jak nam ohydną zniewaga, od Polski hołdu wymaga."

(Und als er vom Vater das Szepter ererbte, verlangte Heinrich, der in Deutschland herrschte, gewiss, dass er mit den Scharen der Söldner die Polen erschreckt, nicht wissend, wie schändlich für uns Beleidigungen sind, von Polen die Huldigung.) (Bolesław Krzywousty 4)

Die geschlossenen kurzen Sätze sind auch ein Merkmal für den Standort des Erzählers, sie sind gewissermassen das Ergebnis einer Erfahrung. Dieser Eindruck wird in den Spłewy noch durch das häufig verwand te Präsens historicum unterstrichen. Die meisten Lieder beginnen mit dem Präteritum, um dann plötzlich in das Präsens uberzugehen. Ein derartiger Ubergang ins Präsens historicum, der nie von langer Dauer ist, wirkt ausserordentlich belebend auf die sonst ziemlich eintönige Erzählung.

Das wirksamste Mittel in der Anwendung der Syntax liegt in der Voranstellung des Genitivs, die übrigens auch der polnischen Prosa und der Umgangssprache eigen ist. Die Bedeutung des Wortes (im Genitiv) wird eindringlicher und eigenwertiger als in der glatten Fügung der ublichen Stellung, wo das betreffende Wort gleichsam im Schatten des dazugehörigen Substantivs bleibt. Diese intensivierende Wirkung führt genau genommen sogar zu einer kleinen Bedeutungsverschiebung; das nachgestellte Genitivobjekt gibt die Bezie- 
hung zwischen den beiden Substantiva an, während sie, vorangestellt, zugleich räumliche Herkunft angibt. In der Nachstellung funktioniert sie nur logisch, in der Voranstellung dagegen trägt sie zur Schaffung einer bildhaften Gegenständlichkeit bei. 3 Diese Bedeutungsverstärkung bei Niemcewicz als den alleinigen Grund für die häufige (ca. $60 \%$ ) Voranstellung des Genitivs anzusehen, hiesse die rein künstlerischen Bemühungen des Autors überschätzen. Dem Rationalisten lag die praktische Seite des Problems mindestens genauso am Herzen, in diesem Falle also der Endreim. Diese Erwägung dürfte für Niemcewicz bei der Syntax ausschlaggebend gewesen sein. Umso besser, wenn diese praktischen tberlegungen ausserdem noch, eine künstlerische Wirkung zeitigten. Eine andere, in den Spiewy sehr häufig zu beobachtende besondere Wortstellung dagegen ist offensichtlich weniger vom Reimzwang als von kinstlerischen Gesichtspunkten bestimmt: die Umstellung, d.h. die Trennung von Subjekt und Pronomen bzw. Adjektiv. Besonders zahlreich sind diese Umstellungen in den Elfsilbern, in denen die Zäsur streng eingehalten und auf diese Weise - wenn also das Pronomen oder Adjektiv vor der Zäsur, das Hauptwort aber am Schluss der Zeile steht - die Zäsur auch gleichzeitig zu einem Bindeglied wird: òstatnig będzie/ uczczony posiuga (wad. Jag. 12); ale najtkliwsze/wznieciło wspomnienia (Zawisza Czarny 8); okropnym zostax/Polakom przykładem (Glifski 17). Bei allen diesen Beispielen könnten sowohl der Reim wie auch die Zäsur nach der fünten Silbe eingehalten werden, so dass der Autor demnach hier nach rein künstlerischen Gesichtspunkten verfahren ist. In erster Iinie kommen dafür rhythmische Überlegungen in Betracht. Anders verhält es sich aber in den folgenden Zeilen: w nieladzie sniezne/spadały mu włosy (Glihski 2); Tatarzyn bystre/rospusciwszy konie (Ostrogski 16); chwałą się polskie/okryły rycerze (Zygmunt August 4). Hier verlangt die Teilung des polnischen Elfsilbers in einen füfsilbigen Anvers und einen sechssilbi-

3 Siehe dazu Wolfgang Kayser, 1.c. S. 134 
gen Abvers unbedingt nach dieser Umstellung. Andere Wortstellungen wären in diesen (und noch vielen anderen) Versen nicht möglich. Aber auch die Rücksichtnahme auf den Reim hat Niemcewicz zur Trennung von Stubstantiv und Pronomen brw. Adjektiv veranlasst: dla lepszej $w$ walce/dzisiejszej usługi (Wład. Jag. 4); w jakimże, Krסlu/oglądam cię bycie (Kaz. Jag.7); i straszna smierci/zbliza się godzina (Glihski 14). Jedoch sind dafür nur wenig Beispiele zu finden. Der polnischen Syntax entsprechend ist auch die umgekehrte Wortstellung möglich und sogar sehr gebräuchlich, d.h. die Nachstellung des Adjektivs; folglich ist auch in diesen Fällen eine Wortumstellung möglich, die ich aber nur mit Rücksicht auf die einzuhaltende Zäsur nach der fünften Silbe angetroffen habe: za nimi widok/przybliżył się srogi (Wład. Jag. 11); jak się rycerze/potykali butni (Ostrogski 23); jak tylko boje/ukohczył zawziete (Stefan Batory 13). Nur in einem Falle hat diese Umstellung rein künstlerische Motivierung: proszą, by miejsca/ chcieli zasiąst swoje (Piast 10). Dass auch beide Erwägungen gut miteinander zu vereinbaren sind, wird an den Umstellungen offensichtlich, in denen die Adjektiva aus dem Bereich der Licht- und Farbvorstellungen stammen. Hier wird durch die Trennung eine wirksame Intensivierung erreicht: na łono cbrki Sniezna spadła głowa (Glihski 18); już czarne smierci/okryłay ją cienie (ebenda). Ausschliesslich der bedeutsamen Auffüllung des Adjektivs dienen die Umstellungen, die unabhängig von der Zäsur vorkommen: nie dosyt jemu/własnej bronit ziemi (Tamowski 3); zwolna idące/czarne ujrzal mary (ebenda 5); Własna dał mu synowice (Zan:oyski 5). Darúber hinaus hat diese Wortstellung nicht nur stilistische, sondern auch rhythmische Bedeutung. Dagegen dienen Trennungen von Worten, die sich über mehrere Zeilen ausdehnen, der Auflockerung des Strophenbaus: na dworze Bony lube $z$ swej urody/ hozych panien widat grono (Zygmunt I. 8), aber gleichfalls auch der Realisierung des Reims. 
Infolge der häufigen Anwendung der direkten Rede sind die Imperative zahlreich vertreten: "zaklinam, chciejciez rolnictwa szanowat!" (Ich beschwöre Euch, wollet den Ackerbau achten. Piast 24); "w kraju obronie użyj jedynie tych znamion rycerza, niech ołuż̨ chwale nie dumie" (zur Verteidigung des Landes allein verwende diese Kennzeichen des Ritterstandes, mögen sie dem Ruhm, nicht dem Stolze dienen. Bolesław Krzywousty 2.); "przyjm, Ksiq̨że, ludu ofiary, panuj, kiedy lud clę wzywa!" (nimm, oh.'Fürst, das Angebot des Volkes an, herrsche, wenn das Volk Dich ruft! Leszek Biały 8). Fast in jedem Lied finden sich ein oder mehrere Imperative, die alle eine deutliche Lehre aussprechen und demnach auf die Gegenwart bzw. Zukunft bezogen sind. Die Interpunktion in den Liedern ${ }^{4}$ ist der Ausdruck für Niemcewicz's Bemühungen, die Strophen rein äusserlich als eine Einheit erscheinen zu lassen. Denn nur sehr selten setzt der Autor innerhalb einer Strophe einen Punkt. Obwohl es sich in den meisten Fällen um abgeschlossene, selbständige Sätze handelt, verwendet er Kommata oder, wo ein Punkt unerlässlich scheint, behilft er sich mit einem Semikolon bzw. Doppelpunkt. Das ist nicht nur in den vierzeiligen Strophen zu beobachten, sondern auch in den sechszeiligen und sogar in den achtzeiligen strophen, bei denen allerdings auch eine Zweiteilung anzutreffen ist. Merikwïdigerweise vermeidet Niemcewicz in diesen langen Strophen den Doppelpunkt gerade dort, wo er durchaus zu vertreten wäre: vor der direkten Rede, und setzt statt dessen einen Punkt. Mit Ausnahme der oben erwähnten Erscheinung - keine Punkte innerhalb der Strophen - kann von einem System oder gar von einer Wertung der Interpunktion als Stilmittel nicht die Rede sein.

Sowohl die einzelnen Sätze wie auch die Strophen sind miteinander verknüpft, am häufigsten durch die Wiederholung einer Vorstellung. Wenn auch nicht immer mit Hilfe von

4 Niemcewicz, J.U. Spiewy historyczne. Paryz 1868. 
Synonyma, so geschieht das doch mit Worten, die in die gleiche Begriffsspäre gehören. Zur Veranschaulichung seien zwei Strophen aus dem Liede von Piast zitiert: "Narbd ...zebral się w pięknych równinach Kruszwicy" (1) "Stały nad Gopłem Słowiany rozliczne....zamku Popielow wieke niebotyczne odbijały się o jezioro czyste." (2) "Gdzie wielkie mndtwo, cięzko szukak zgody" (3). Dem Subjekt der ersten Strophe 'Volk' entspricht das der zweiten Strophe 'Slaven'. Aber auch auf den Ort der Handlung wird in der zweiten Strophe hingewiesen: zu Kruschwitz gehört der Goplo-See. Die dritte Strophe nimmt dann Bezug auf einen Charakterzug des Leitbegriffes der ersten beiden Strophen, auf die zahlreichen Slaven: 'wo eine grosse Vielzahl..'. Auf die an diesem Beispiel gezeigte Weise sind alle Strophen des Liedes miteinander verbunden. Das gilt auch für die anderen lieder, besonders dann, wenn sie nur ein Geschehen beinhalten. In den Liedern aber, in denen mehrsträngige Fabeln uberhaupt nur eine Aneinanderreihung von Ereignissen den Inhalt ausmachen, war auch die Schaffung eines ubersatzmässigen Zusammenhanges nicht mehr möglich. Wo er aber vorhanden und sinngemäss berechtigt ist, zeigt sich gewissermassen die Unselbständigkeit eines jeden einzelnen Satzes. Damit wäre in diesen Fällen die erwähnte Interpunktion des Autors Vermeidung von Punkten innerhalb einer Strophe - durchaus gerechtfertigt.

Das Streben Niemcewicz's nach "Volkstümlichkeit", nach einer gewissen Vertrautheit mit seinen Lesern, ist aus Anspielungen erkennbar, die nur einem bestimmten Leserkreis verständlich sein können. Z.B. wird die Bezeichnung "Rewera' nur einem Polen etwas sagen, nur er wird den Zusammenhang dieses Beinamens des Fürsten Ostrogski mit dem Liede verstehen können. Ebenso verhält es sich bei der Nennung Chmel'nyc'kyjs nur mit seinem Vornamen Bohdan, noch dazu in der ukrainischen Form (Potocki 1l). Ab und zu jedoch rïkt j! 
Niemcewicz, gewiss ganz gegen seine Absicht und gewissermassen unter dem Einfluss der Umgebung, in eine höhere Sphäre, wenn er Anspielungen aus der antiken Geschichte einflicht: der Vergleich des Rokosz von Zebrzydowski mit Pharsalos im Liede von Zygmunt III.; der Vergleich des Warnensers mit dem Neffen des Augustus, Marcellus, oder Zawisza Crarnys mit Achill and Ajax. Solche Vergleiche waren nicht dazu geeignet, den Kontakt mit dem Volke enger zu gestalten, da diese Begriffe ja nicht zum Bildungsgut des Volkes gehörten.

Der vorwiegend rhetorischen Haltung entsprechend lassen sich viele Beispiele für Reihung, syndetische sowohl als auch asyndetische, feststellen: Białę, Drohobuź, Kaługę z Możaj skiem.. (Wlad. IV. 7); na przepych zbroi, i pereł 1 złota (Wlad. IV. Il); przepych, wspaniałost, przechodniow zdziwiący, zręcznost rycerstwa, turnieje, zawody i hozych dziewic wdzięki ujmujące (Wład. IV. 15); dziedziniec, bramy 1 wieze zewsząd okrył lud.. (Stefan Potocki 10); zaszedi.droge senat wierny, kapłani, wdowy, pafstwa urzędnicy 1 pospblstwa tzum niezmierny (Kaz. Mnich 12): Auch die symmetrischen Steigerungen sind in grossem Masse vertreten: gdzie mieczem błysnọł, tam przed nim leciały postrach, okropne rany i smierb blada (Wlad. Warn. 15); przembgł Rzym i głos chrzebcijahskich pan6w, przemogła sława (ebenda 14); do chlubnych czyn6w otworzy wam pole, da wam zwycięstwa, chwał̨ $i$ swobody. (Piast 16); waleczny hetman...na czele swoich naciera, dowodzi, walczy, w wycieczkach szczęsliwych przewazne tłumy odpiera (ebenda 16); rzuca się z koniem wpław, rzekę przebywa, uderza, pole trupami okrywa (Zarniecki 7); Lubomirskiemu buławę oddaje, sciska za rękę i kona (Chodkiewicz 16). Diese eigentlich lakonische Art der Verwendung der Klimax vor allem in den beiden letzten Beispielen weist bereits auf die Volksdichtung hin. Ebenso auch die gar nicht seltenen Paralielismen, die von ausdruckssteigernder Wirkung sind, wie aus den folgenden Zitaten zu ersehen ist: "Dla mojego wnuka niechaj 
ten koh się zachowa, niechaj rycerskiej sławy na nim szuka, niechaj pamięta te słowa" (Czarniecki 17); "przysięgam, ze cię na głowę nie włożę, aż nieprzyjacibł krwią mego nie zmyję, aź cieniom wodza ofiary nie złoźz i pbl cecorskich trupem nie okryję" ( $26 ł k i e w s k i$ 18); "Wilhelm rakuski kładł nadzieje pewne w bogatych szatach, w utrefionych włosach; w tym, ze od dziecihstwa znał jeszcze krblewnę" (Hedwig 5); "nikt go nie wstrzymał i nikt go nie strwożył" (Wad. Jag. 8): Den hier angefuhrten Beispielen ist g?eichzeitig auch noch die ausdruckssteigernde Dreiheit eigen.

Sehr stark vertreten ist Antithese und Chiasmus: drżal nieprzyjaciel, narbd go szanował (Wlad. IV. 6); wspomnial na młodost szczęsliwą i na wiek swoj nieuźyty (Potocki 3); czcząc bohaty-ra, o męża truchleje (Czarniecki 5); czest rzecze - męznym, hatba zniewiesciałym (Ostrogski 20); ujrzysz rodak6w.. mnie złorzeczacych,lecz tobie żczliwych (Glikski 16); niech kraje, bronią zajęte, uszczęsliwią prawa swięte (Kaz.Wielki 3). Mit Vorliebe baut Niemcewicz auch die Sentenzen antithetisch auf. Alle antithetisch aufgebauten Bilder in den Spiewy schliessen mit einer Sentenz ab. Als Beispiel für eine Sentenz innerhalb eines Liedes sollen die Worte des Kanzlers Zamoyski an Maximilian von Habsburg gelten, der bei dem Versuch, seine Wahl zum König von Polen mit Heeresmacht gegen die Partei des schwedischen Anwärters durchzusetzen, von Zamoyski gefangengenommen wurde:

"Herr, sprach der Hetman, unser Volk weiss die Bräuche der Vorfahren zu schätzen, wenn jemand mit Gewalt über uns herrschen will, lässt es ihn die Macht s'einer Gefühle spüren; ängstige Dich nicht: der Pole, obwohl furchterregend für die Kecken, weiss zu den Unglücklichen hochherzig zu sein. Du bist mein Gefangener, so hat es der Himmel gewollt, klage nicht über die Unfreiheit: Du wirst erkennen, 
wie der hochherzige Sinn der Polen Deine Gefangenschaft versuissen wird.

Wir wollen den Nachbarn kein Land entreissen, aber wir wissen die Unglücklichen zu stützen."

Zamoyski 10,11 .

Ein Beispiel für eine Sentenz als Abschluss:

"Nach vier Jahren erkannte er im frühen Tod, dass das Gluick selten auf dem Thron zu finden ist."

Michal Korybut 9.

Am eindrucksvollsten sind die mit Hilfe entsprechender Eigenschaftsworte dargestellten Gegensätze von Licht und Schatten bzw. Dunkelheit. Die Pseudoklassizisten hatten für die künstlerischen Möglichkeiten, die diese Vorstellungen bieten, kein Empfinden. Niemcewicz aber verbindet schon mit jeder Darstellung eines Gefängnisses z.B. den Eindruck der Dunkelheit und stellt diese dem Licht des Tages gegenuber, dem Strahl der Sonne; ist aber mit dem Gefängnis das Grab gemeint, so verbindet Niemcewicz damit das Mondlicht. Die Erwähnung der Helligkeit erfolgt fast nur im Zusammenhang mit der entsprechenden Antithese:

"Als der Abend herankam, sass Piast,

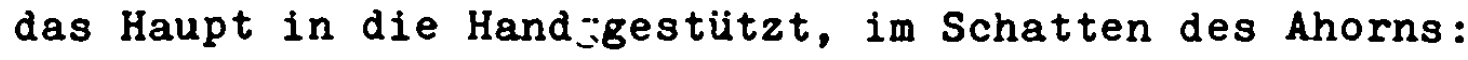
Wieder kamen dieselben Jïnglinge vor sein Haus, umbüllt von hellem Licht." Piast 13

"Schon hat die Nacht ihre traurigen Schatten ausgebreitet,

Hier und dort die lodernden Flammen der Lagerfeuer." Wlad. Eok. I

In der ersten Strophe der Duma von Michal Gliński sind gleich zwei derartige Gegenüberstellungen enthalten:

"In der entsetzlichen Finsterheit unterirdischer Höhlen, wo kein Sonnenstrahl hinkommt, wo die Pechpfanne, in der Mitte der düsteren Gewölbe hängend, fahlen Schein verbreitet..." 
Dem finsteren unterirdischen Gefingnis stellt der Autor die Schörheit der Tochter Glihskis und die Morgenröte inres Lebens gegenuber ( 3 ), dem Grab und der Finsternis - den Schein von Sonne und Sternen (4). Ausser dem Reim cieniewięzienie enthält dann die letzte Strophe noch den Gegensatz des schneeweissen kopfes des Alten zu den schwarzen jchatten des Todes. Auch in dem Liede von 0strogski wird die Finsternis des Gefängnisses - czarne więzienie - durch . die Erwähnung des holden Tageslichtes unterstrichen. In der Dur. $z$ von Stefan Potocki ist neben der Vorstellung vom stillen Schatten der Bäume und freundlichen Mondlicht auch noch eine Gegenüberstellung von Farben enthalten: der goldne Helm auf schwarzen Locken und das Grab im grünen Eichenwald, an dem die Rüstung an der blutbefleckten weissen Schleife hängt. Hier wie auch in der vorletzten Strophe des Liedes von Wadysław Jagiełło soll das Blut offensichtlich die Vorstellung von roter Farbe vermitteln.

Im Zusammenhang mit diesen Farbadjektiva stösst man des öfteren auf eine Verwendung im übertragenen Sinne, wenn es $2 . B$. heisst: blasser Tod (Wlad. Warn. 15); dunkle Stille (0strogski 9); schwarzer Kummer (Hedwig 17); bleicher Schrecken (Wład. IV. 3) u.ä. Diese Vorstellungen entsprechen fast alle auch dem volkstümlichen Sprachgebrauch, so dass wohl mit Recht angenommen werden kann, dass Niemcewicz sich dieser Formulierungen weniger zur Erzielung künstlerischer Effekte bedient hat als zur Anlehnung seiner Sprache an die Sprache des Volkes. Das dürfte auch auf die in den Śptewy anzutreffenden Synästhesien anzuwenden sein, die im $\mathrm{Zu}-$ sammenhang mit Niemcewicz insofern aufschlussreich sind, als sie schon auf die Romantik vorausweisen: süsser Gesang (Ostrogski 9); traurige Glocken (Henryk Waleziusz 1); stiller Schatten (Potocki 15); silberne Töne (Poniatowski 8) und viele andere.' Auch die von Niemcewicz verwendeten Metonymien sind sowohl in der Umgangssprache als auch in der Volksdichtung anzutreffen. Die Vorstellung rom Tode als dem ewigen 
Schlaf (Potocki 12) oder vom Kriege als blutigem Treffen (Czarniecki 3), die katholische Kirche durch Rom verkörpert sind allgemein verbreitet. Die Sprache der -Spiewy, so nüchtern sie im grossen und ganzen auch ist, hat doch auch einige Kennzeichen der dichterischen Bildhaftigkeit aufzuweisen. Bilder bzw. epische Vergleiche hat Niemcewicz in elf Liedern eingebaut. Einer der eindrucksvollsten Vergleiche ist der des Königs Bolesław Chrobry mit einem verwundeten Löwen: "Wie sich ein verwundeter Löwe, die blutunterlaufenen Pupillen rollend, auf ein dreistes Tier stürzt, so kämpfte Chrobry..(4). Ein lyrischer Vergleich findet sich in der sechsten Strophe des Liedes von Kazimierz Wielki: "Wie an einem Maientage, wenn der warme Regen den Acker durchdringt, die schlafenden Pflanzen weckt, die fruchtbaren Felder ergrünen lässt, so erbluihte Polen unter der Herrschaft, die von Klugheit gelenkt war." Als durchaus selbständiges Bild können auch die folgenden Zeilen angesehen werden: "Die Zwietracht entfacht ihre Fackeln und ristet zum Blutbad und zu schrecklichen Verbrechent: (Henryk Waleziusz 3); "Der Mai hatte eben Bäume und Blumen sich entfalten lassen, der Mond, in der Nacht in vollem Lichte erstrahlend, spiegelte sich in den silbernen Flügeln und im Helm, aber der Ritter seufzte, von Trauer bedrükt." (Źbłkiewski 2). In dem lied von Jan III. Sobieski werden die polnischen Heerscharen mit einem Adler verglichen, der sich in steilem Flug aus den Wolken auf sein Opfer stürzt, und der König selbst in seiner Bedeutung für Polen mit der untergehenden Sonne: "Und wie die Sonne beim Untergang die Erde mit hellerem Schein bestrahlt, so hat auch er tapferer den Ruhm des Volkes erhoben, bevor Polen sich mit den Schatten des Todes bedeckte." Mit diesem Vergleich sollten die lieder ursprünglich abgeschlossen werden. Denn das Trauerlied aus Anlass der Beisetzung des Fürsten Poniatowski ist, wie Płoszewski nachweist ${ }^{5}$ erst später

5 Leon Płoszweski, 1.c. 
entstanden und gehört nicht zur eigentlichen Konzeption. Zwär nicht als echte Bilder, aber doch als bildhafte Sprache könnte man die folgenden Verse bezeichnen "Ein süsser Wohlgeruch verbreitete sich in der Luft, wie der Duft von Veilchen nach einem warmen Regen." (Piast 2l); "Wie der Schatten der schwarzen Nacht begannen die Horden der Tataren Litauen in Schwärmen zu überfallen." (Aleksander 5). $\mathrm{Zu}$ den schönsten Versen können die folgenden, aus dem Trauerlied für den Fürsten Poniatowski gezählt werden: "Ihr wehmütigen Trompeten, klagenden Flöten, ihr silbernen Töne der wehenden Adler, schweigt still!"

Gemessen an dem Umfang der Sammlung sind diese Beispiele dichterischer Sprache aber nur als Ausnahmen $z u$ werten. Das völlige Fehlen von Metaphern in den Siewy unterstreicht die sachliche Sprache.

Bemerkenswert ist weiterhin noch der Hang des Autors zu archaischen Formen. Płoszewski bertchtet, dass Niemcewicz sogar alte Werke studiert und sich archaische Worte und Redewendungen notiert habe (in dem bereits genannten Album befinden sich Auszlige von Texten aus der Bibel mit französischen Entsprechungen!). Die in den Liedern auftretenden alten Worte beziehen sich in erster Linie auf Waffen, Geräte und Kleidungsstücke sowie auf Begriffe aus dem ritterlichen Lebenskreis: bachmat - tatarisches Kriegspferd, bułyt türkisches Pferd, buhczuk - tatarisches Fähnchen, kolczuga Kettenpanzer, spahy - türkische Kavallerie, surma - Kriegstrommel, wici - ein Bündel Schnüre, Symbol der Strafe für Nichterscheinen, das mit dem Befehl des Königs zur Gestellung zum Krieg übersandt wurde, u.ä. Alle diese Worte werden aber wahllos verwendet; ohne Rücksicht auf ihren Ausdruckswert, sie dienen eigentlich eher dem Bestreben nach Abwechslung als der Erzielung historischen Kolorits. Dieselbe Handhabung kann auch in bezug auf die archaischen Formen beobachtet werden, von denen der alte Instrumental Pluralis der masculinen o-Stämme (bzw. jo-Stämme) am häufigsten anzutreffen ist. Er kann als Privileg der poetischen 
Sprache überhaupt angesehen werden. Etwa die Hälfte ajlcr in den Spiewy enthaltenen Instr.pl. haben die alte Form, sie stehen fast alle unter Reimzwang oder wurden mit Rücksicht auf die Silbenzahl verwandt: "Szedł do Wisniowca, gdzie Tatarzyn dziki...i straszliwymi odzywał sie krzyki" (Ostrogski 17); "wzięty plon obfity...kraj nasz kohskimi zdeptany kopyty" (ebenda 18). Analog zu diesen Masculina bildet Niemcewicz aber auch dieselbe Form fïr die femininen a- und i-Stämme, eine Form, die es nie gegeben hat: "słodkimi swobody ... waziękbw i urody" (Glinski 3) oder "stepy nieuzyte ludnymi włosci okrywa" (Zamoyski 14). Die dreimalige Verwendung des Wortes piers im Instr.pl. zeigt die rein technischen Beweggründe für den Gebrauch dieser pseudoarchaischen Form: "broti go twymi piersiami" (Potocki 5), aber "on piersi swymi ojczyznę zasłonił" (Zołkiewski 16) und "z gołymi piersi wpadz pierwszy na wały" (Czarniecki 4 ). Sehr häufig bildet Niemcewicz auch noch den alten Acc.Pl. der masc. o- und jo-stämme für männliche Personen. Auch hierbei handelt es sich in erster Iinie um Rücksichtnahme auf Reim und Silbenzahl: "srogie pogromił Tatary...pełen zniewagi z bezwstydnej niewiary" (Ostrogski 8), "z dobranymi szyki...do poddahstwa wraca buntowniki" (Hedwig 22). Die richtige und die veraltete Form zusammen in einer strophe lassen die rein technische Funktion eindeutig erkennen: ".. z cesarzem Sluby kojarzy; wzywa na weselne gody / czterech potęznych mocarzy,/ kr618w, ksiazat z Niemiec całych.." (Kaz. Wialki 1l). Nur in einem Falle hätte auch mit der richtigen Form sowohl der Reim als auch die Silbenzahl eingehalten werden können: "Kiedy Władysław korzy dumne cary,... po dwakrob gromi Turki i Tatary" (Wlad. IV. 9). Offenbar von Krasicki übernommen ist die Verwendung des alten Acc.pl. der masc. o- und jo-stämme auf $-y$ in der Funktion des Nom.pl.: "juz się zebrały...swięte kapłany" (Zygmunt August 1), "bojary wysłane pędzą torem drogi" (Ostrogsiki 11). Diese Form ist aus keinem altpolnischen Nominativ pl. abzuleiten, ist 
also formal als eine absichtliche Neuschöpfung zur Erzielung eines archaischen Anstriches anzusehen. 6 Die Nachahmer Krasickis aber haben sie offenbar als echten Archaismus ubernommen. Im Gegensatz zu Krasicki, der diesen pseudoarchaischen Nominativ vorwiegend im Reim verwendet hat, hat Niemcewicz ihn wahllos eingesetzt, da seine Anwendung keinen Einfluss, weder auf den Reim noch auf die Silbenzahl ausibt.

Wie Płoszewski in einem Vergleich der ersten, im Pamiętnik Warszawski erschienenen Fassung der Spiewy mit der Erstausgabe der ganzen Sammlung im Jahre 1816 festgestellt hat, enthielt die erste Redaktion noch wesentlich mehr archaische Formen, die aber wohl auf Anraten Kokmians z.T. gestrichen und z.T. modernisiert worden sind. An dieser Stelle muss auch eine gewisse archaische Verwendung von Worten erwähnt werden, die in der heutigen Sprache eine andere Bedeutung haben. Bei dieser Kategorie von Worten ist es schwer zu entscheiden, ob es sich um beabsichtigte Archaismen handelt oder aber um einen gleichsam angeborenen Archaismus der Sprache des Dichters. Zunächst sollen einige Beispiele angefuinrt werden: wast - Bauerndorf, Linde bringt nur Beispiele aus dem 16. und 17. Jahrhundert (Kaz. Wielki 8, zokietek 6), zawołany - berïhnt, bei Linde für das 16. Jahrhundert bis zum Anfang des 18. Jahrhunders belegt (Zawisza

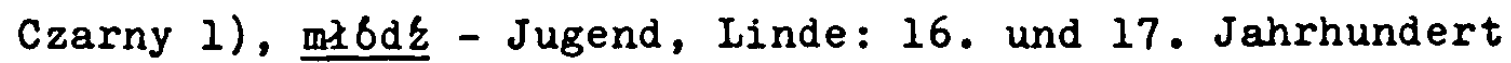
(Jan Kazim. 3, Jan Albrycht 11). Die oben angefürten Worte gehören zu der Gruppe, die in der modernen Sprache nicht mehr verwendet werden. Ihr Sinn ist aber in den meisten Fällen noch bekannt. Anders ist es mit den Worten, deren Bedeutung sich in der neueren Sprache geändert hat, während die Dichter, in diesem Falle also Niemcewicz, die Worte noch in ihrer alten Bedeutung gebrauchen. Hierher gehört der Gebrauch von Scisnąt - ht. 'umarmen, einklemmen', bei Niemceiㅗㄷㅡ

6 Obrębska-Jabłohska, J. Od Archaizmu do Nowej Formy Jezykowej Stylistyka Teoretyczna w Polsce. Warszawa 1946. 
wicz im Sinne von 'bedrücken, zum Äussersten treiben': scisniony glodem (Stefan Czarniecki 6), mir - ht. 'Nimbus', altpoln. Bedeutung 'Frieden', wie es in den ostslavischen Sprachen jetzt noch heisst (Chodkiewicz 23, Aleksander 3), przewaźnie - ht. 'vorwiegend', bei Niemcewicz in der Bedeutung 'ernstlich, schwer'(Bolesław Chrobry 9, Zawisza Czarny 7), przytomny - ht. 'bewusst', hier im Sinne von 'anwesend' (Leszek Biały 1l), nędzny - ht. 'erbärmlich', hier mitleiderregend', ohne pejorativ zu sein (Jan Albrycht 15), cieh - ht. 'Schatten', hier 'lichtloser Platz' (Glifski l), więzieh 'der Kriegsgefangene', Linde fürt nur ein Beispiel dafür aus dem 16. Jahrhundert und eins bei Kochanowski an (Wład. Eokietek). Da in den Spiewy. diese alten Worte nicht in erster Iinie in Reden litauischer Gestalten erscheinen, sie also nicht als Mittel $z$ deren Charakterisierung dienen, sind sie demnach auch nicht als Stilmittel anzusehen, sondern vielmehr als Ausdruck der sprachlichen Tradition der Heimat des Dichters. Auch Mickiewicz, der wie Niemcewicz aus den litauischen Gebieten stammte, hat alte und neue Formen abwechselnd verwendet, je nach Anforderung von Reim und Rhythmus, wie Konrad Gorski festgestellt hat. 7 Was Gorski als eine der Ursachen für den grossen Anteil des Altpolnischen bei Mickiewicz anführt, hat auch für den Autor der Spiewy Gültigkeit, die Konservierung von Relikten der altpolnischen Sprache, vor allem aus dem Adelsleben, in den litauischen Gebieten. Was in den Augen der anderen Provinzialismen waren, hatte für Mickiewicz und auch Niemcewicz altpolnische Legitimität, war "arką przymierza między dawnymi i młodszymi laty" (Bundeslade zwischen den alten und jungen Jahren).

Diese Untersuchungen sollten zeigen, dass von einem eigenen Stil der Śpiewy keine Rede sein kann, dagegen waren einige sprachliche Merkmale so ausgeprägt, dass sie für alle Lieder bestimmend waren. Diese Merkmale kann man in drei Kate-

7 Gorski, Konrad, Staropolszczyzna w Jezzyku Adama Mickiewicza. Pamiętnik Literacki, Rocznik XLVI. Warszawa 1955. S. $157 \mathrm{ff}$. 
gorien einordnen: in rhetorische, didaktisch-moralisierende und volkstüliche. Das Rhetorische als solches zelgt sich besonders in negativen Zügen: völliges Fehlen von Metaphern, nur sehr vereingeltes Auftreten von Formen des uneigentlichen Sprechens überhaupt. Eng verbunden mit dem Rhetorischen ist das Moralisierende, das sich z.B. in der Bevorzugung der charakterisierenden Epitheta ausdrückt, vor allem aber in den antithetisoh aufgebauten Sentenzen innerhalb oder am Schluss der einzelnen lieder. Auch die Antithese selbst steht zum grossen Teil im Dienste der moralisierenden Bestrebungen des Autors. Den interessantesten, wenn auch nicht grössten Teil machen die $Z$ üge aus, die schon auf eine gewisse Vollistümlichkeit und damit also auf die Romantik hinweisen. In erster Linie ist der formelhafte Gebrauch der Adjektiva zu nennen, weiterhin Parallelismen und Steigerungen. Dazu gehören aber auch die kurzen, nebengeordneten Sätze, die in den Spiewy bei weitem in der Uberzahl sind. Auf die Romantik weist nicht nur die wirksame Anwendung von licht- und Farbvorstellungen; auch die Rolle der Natur in den Liedern ist bereits dem Pseudoklassizismus entwachsen. Die Natur wird nicht mehr nur als Kulisse in Form von Parks und Grotten dargestellt, sondern wir finden die wirkliche Natur, und sie ist ausschlaggebend an der Schaffung einer Stimmun beteiligt (Władysław Łokietek 1-2, Kazimierz Jagiellohczyk 5, Jan Albrycht 8, Ostrogski 9, Stefan Potocki 11, um nur die wichtigsten herauszugreifen). Und schliesslich die $\mathrm{Be}-$ sonderheiten der Sprache, teils wirkliche Archaismen, teils "Provinzialismen", die vor allem in ihrer besonderen Punktion als Bindeglied von Vergangenheit und Gegenwart zwischen Polen und den abgetrennten Gebieten bedeutsam sind. 
4) Der Aufbau der Śpiewy historyczne

Der äussere Aufbau der ganzen Sammlung in Lieder und dieser wiederum in Stróphen mit verschiedener Zeilen- und Silbenzahl wie auch die Auswahl des Stoffes sind einzig und allein von dem Bemühen des Autors um Abwechslung und damit Vermeidung von Eintönigkeit bestimmt. Das sichtbar Gemeinsame aller Lieder besteht darin, dass jedes von ihnen aus gleichmässigen Strophen besteht und zum Vertonen geeignet ist, entsprechend der Forderung des Towarzystwo Przyjaci 61 Nauk. Auch hat Niemcewicz versucht, nicht nur chronologisch, sondern auch inhaltsmässig den Zusammenhang zu wahren, d.h. er hat entweder in den letzten Strophen eines Liedes bereits auf das nächste Lied vorausgewiesen oder aber am Beginn eines Liedes auf den Inhalt des vorhergegangenen zurückgegriffen. Das geschieht in Form von kurzen Erwähnungen von Namen der gerade dargestellten Herrscher oder als Anspielung oder Hinweis auf die Taten von Vorgängern und Nachfolgern: "Gut ist es Polen unter Chrobry ergangen", damit beginnt die Darstellung des nächsten Königs, Kazimierz Mnich, unter Weglassung des direkten Nachfolgers von Bolesław Chrobry, Miecysław. die sich anschliessenden Lieder berichten abor über Ereignisse, die sich weder chronologisch noch mit technischen Mitteln verbinden liessen, da es sich um Zeitabstände von etwa hundert Jahren handelt (von Leszeks Tod 1227 bis zum Regierungsantritt Eokieteks 1306). Obwohl von Łokietek an die chronologische Folge beachtet und mit Hilfe der eingefügten Lebensbilder grosser polnischer Heerfürer die historische Basis sogar noch erheblich erweitert worden ist, finden wir immer wieder Verbindungen und tberleitungen, entweder in Form von kurzen Namenserwähnungen oder als Anspielungen und Hinweise auf die Taten von Vorgängern und Nachfolgern. Diese Hinweise haben in einigen Fällen auch eine Funktion für den inneren Aufbau, indem sie nämiich eine ganze Gruppe von Liedern unté einen bestimmten Aspekt stellen. Das gilt z.B. 
für den Hinweis auf die politischen Möglichkeiten, die für Folen in einer Verbindung mit litauen liegen und die bereits in dem Liede von Madysław Eokietek unterstrichen werden. Dieser Aspekt wird in allen Liedern aus der Jagiellonen-Zeit mehr oder weniger deutlich betont. Der Schluss der Schilderung Łokieteks aber hebt die besonderen Merkmale hervor, unter denen die Regierungszeit Kazimierz Wielki's stehen wird: "Ich musste kämpfen, Du aber ziehe den Nutzen aus dem. Krieg und lass Polen im Frieden erbluhen". Diese beiden eben angefühten Beispiele sind die wirksamsten Verbindungen zwischen einzelnen Liedern, in den übrigen Fällen beschränkt sich der Autor auf die Wiederholung von Namen: "So war der letzte Piast" schliesst das Lied von Kazimierz Wielki, und das Lied von Hedwig beginnt: "Als der Lebensfaden der Piasten abriss...". Um die durch die Einfügung des Lebensbildes von Zawisza Czarny unterbrochene Verbindung wiederherzustellen, greift Niemcewicz bei Władysław Warnehczyk auf dessen Geburt als Sohn des Jagiełıo zuruck: "Das war ein grosser Tag, in ganz Polen bekannt, als Jagiełło der erste Sohn geboren wurde". Auch bel der Schilderung der Zeiten Kazimierz Jagiellohczyks schafft der Autor gleich in der ersten Zeile die Verbindung: "Władysław war gefallen". Manche lieder sind eng miteinander verflochten, wie das Beispiel Glihskis zeigt, auf dessen Taten und Untaten schon im Liede von König Alexander hingewiesen wird, während dann das lied von Zygmunt I. nochmals eine Erwähnung von Glihski enthält. In diesem lied deutet der Autor dann anbh schon manches Ereignis an, das erst in späteren Liedern seine Darstellung findet. Dazu gehören einmal die Nennungen berühmter Nameq, denen eigene Lieder gewidmet sind: Ostrogski, Tarnowski, und Sieniavsk1, der in der Duma von $861 k i$ ewski die Rolle des Erzählers erhalten hat. Die neunte Strophe spielt bereits auf die Treulosigkeit des Herzogs von Preussen an: "Als Zygmunt das Leben des reichen preussischen Landes an Albert vergab, sah man die Undankbarkeit nicht voraus, auch nicht, dass sich der Lehensmann gegen den Herrn empören wird." Die letzte Strophe 
aber greift noch weiter in die Zukunft hinaus:

"Das Volk, dass die Angreifer leicht hätte vernichten führte mit dem eigenen König streit. Nicht kämpfen, sondern zu Haufen beraten wollte es, versäumte die Gunst der Stunde. Nicht wissend, wo es die Grenze der Freiheit setzen sollte, warf es auf ein so ruhmreiches Zeitalter einen dunklen

Fleck."

Hierin ist auch eine deutliche Anspielung auf die Gegenwart enthalten. Die Rückschau auf den Tod des letzten Jagielionen bildet dann die Einleitung zu der Beschreibung der ersten KöniEswahl. Von Heinrich von Valois zu dem zweiten Wahlkönig, Stefan Batory, führt in den Spiewy keine Verbindung, aber von letzterem zu seinem Kanzler und Vertrauten Jan Zamoyski, der wiederum die Brücke zu dem nächsten König, Zygmunt III., schlägt. Die Eingliederung des Liedes von Karol Chodkiewicz erfolgt durch die Erwähnung eines kleinen Zwischenfalles, der sich beim Auszug Stefan Batorys gezen die Moskowiter ereignet haben soll: "Wer ist dieser Knappe, fragt König Stefan,von solch schöner, kühner Gestalt?.....Das war Chodkiewicz". Die Nennung von Żłkiewski und Chodkiewicz als Lehrmeister des junzen Prinzen Władysław leitet zum liede von König Władysław IV. über. Auch in der Duma von Z $6 ł k i e w s k i$ war der Kronprinz schon erwähnt worden, als neuer Zar von Moskau. Ohne Ubergang folgt dann das Lied von Jan Kazimierz, verbunden nur durch die Kosakenfrage mit dem Liede Zygmunts I. durch die Erwähnung des ersten Kosakenhetmans Ostafi. Die Mahnung $\dot{a} \geq s$ abdankenden Königs deutet wiederum auf die traurigen Ereignisse der Zukunft hin und soll die Verbindung zur jünsten Vergangenheit bzw. Gegenwart schaffen. Ein allen Liedern gemeinsames Kennzeichen des inneren Aufbaus ist die Erzählhaltung. Sie wird bestimmt durch die Perspektive des Autors, der über die Erlebnisse der Helden und Könige 
und die Geschicke des polnischen Staates z.T. reflektierend berichtet. In einigen Liedern und Dumen verlegt der Autor die Perspektive in eine Nebengestalt. Für die innere Struktur hat er auf diese Weise eine belebende Mehrschichtigkeit gewonnen, die in anderen Liedern mit Hilfe langer Monologe der Hauptperson erreicht wird, wie z.B. in der Duma von Michal Glihski oder in dem Liede von Zygmunt August. Auch die Dialoge dienen diesem Zweck. Da die meisten von innen keine echten $Z$ wiegespräche sind, können sie auch keinen dramatischen Effekt erzielen. Wir spüren in allen liedern nur den Standpunkt des Erzählers, obier nun, wie schon gezeigt, durch den Mund einer Nebenfigur, durch den Helden oder eine mit diesem in engem Zusammenhang stehende Figur oder aber durch den Dichter selbst mehr oder weniger offensichtlich kundgetan wird. Wenn der Erzähler dabei das "wir" bevorzugt und sein Ich dahinter versteckt, erreicht er damit eine stärkere Verbindung mit dem Publikum, das so neben ihm steht und gleichsam mitverantwortlich ist. Dennoch ist der standpunkt des Autors in den Spiewy immer ein höherer als der seiner Leser, aber Niemcewicz bleibt stets bemiht, durch sein Streben nach möglichst enger Vertrautheit mit dem Leser diesem und damit also dem Volk verbunden zu bleiben. Der höhere Standpunkt wird an der kritischen Stellungnahme des Erzählers zu einzelnen Erscheinungen der Geschichte, besonders aber an seiner moralisierenden Art deutlich, die immer wieder zum Durchbruch kommt und als Kennzeichen der sentimentalen Dichtung anzusehen ist und deren Einfluss wir schon bei der Untersuchung der Stilzüge kennengelernt haben. Aber sie tritt auch als Kompositionsmerkmal auf, wie das Lied von Wladysław Jagiel 10 zeigt, in dem Niemcewicz durch die Zusammendrängung der Ereignisse die Entfesselung des Krieges durch den Orden auf den Zeitpunkt der Taufe des litauischen Volkes verlegt und den Fluch dieser bösen Tat durch den Tod des Hochmeisters und die Niederlage des Ordens symbolisiert., Dasselbe Prinzip ist für den Aufbau des Liedes von Bolesław Smiały kennzeichnend, 
dessen Verbannung aus Polen Niemcewicz auf den frevelhaften Mord an dem Bischof Stanisław glaubt zurückfüren zu müssen. Auch die Geschichte Leszeks des Weissen gehört hierher. In diesem Falle aber wird am Schluss des Liedes noch einmal in der Manier der sentimentalen Erzählung die moralische Schlussfolgerung gezogen: "Der Himmel hat soviel Tapferkeit und diesen Edelmut reichlich belohnt". Der innere Aufbau entspricht in keiner Weise dem äusseren. Nach den Titeln der Lieder zu schliessen, misste man die strukturelle Fihrung in den Personen erwarten, tatsächlich aber liegt sie im Geschehen, das hauptsächlich und in erster Linie nach dem Kompositionsprinzip der Reihung von Einzelheiten dargestellt wird. Der Autor bedient sich dabei in fast jedem Lied auch des Gespräches. Besonders zur Erzielung einer stimmung eignet sich der damit gestaltete Beginn eines Liedes. Niemcewicz hat aber nur zweimal von dieser Möglichkeit Gebrauch gemacht: das Lied von Jan Tarnowski wird mit der Zwiesprache des Ritters mit seinem toten Hetman eingeleitet, die Duma von Stefan Potocki mit einem Aufruf des Dichters an seine jungen Leser. Das sind die elnzigen, unkonventionelien, von echtem Gefül getragenen Liedanfänge. Ein grosser Teil der übrigen Lieder beginnt mit einer Ortsbestimmung: "Inmitten der Karpathen" (Zawisza Czarny), "in der schrecklichen Finsternis der unterirdischen Höhlen" (Glihski), "in dem hohen Gebäude" (Zygmunt August), "jenseits des rauschenden Dniestr" (Zołkiewski), "in edlem Hause" (Stefan Czarniecki). Einige Male wird auch das Wörtchen juz 'schon' an den Beginn eines Liedes gestellt (Władysław Eokietek, Jan Albrycht, Henryk Waleziusz), aber noch in viel grösserem Masse an den Anfang einer Strophe, - fast in jedem Lied eine -, von den vielen Zeilenanfängen mit juź gar nicht $z u$ reden. Der Ruickgriff auf die Vergangenheit bzw. den Inhalt des vorhergegangenen liedes erfolgt in vielen Fällen durch eine Konjunktion: "Als Popiel" (Piast), "als die Tage der Piasten" (Hedwig), oder aber durch eine Präposition: "Nach schweren Stürmen" (Zygmunt I.), "durch drei Jahrhunderte hindurch" 
(Kazimierz Wielki). Ähnliche Verhältnisse lassen sich bei den Strophenanfängen konstatieren. Auch hier herrschen die ortbestimmungen und das Wörtchen już vor. Hinzu kommt noch die 3. Sing. Praesens historicum oder Praeteritum: "Es war ein ausgedehnter Wald" (Jan Albrycht 5), "Es ist hinter der Hauptstadt ein Dorf" (Michał Korybut 2), "es war ein Mann zur Zeit Zygmunts" (Ostrogski 3). Auch ein lied fängt so an: "es war ein grosser Tag" (Władysław Warn.)

Der Schluss der Lieder wird of von Betrachtungen des Erzählers geprägt, wie u.a. in den letzten Strophen des Liedes von Stefan Batory über den frühen Tod dieses grossen Königs und die sich daraus für Polen ergebenden ungünstigen Folgen. Mit einem der Fehler des polnischen Volkes setzt sich Niemcewicz am Ende des Liedes von Zygmunt $I$. auseinander. Die am meisten vertretene Art des Liedschlusses besteht in einer zusammenfassenden Beurteilung des Helden bzw. seiner Zeit: "Das war ein guter König, nur im Kampfe grimmig, er war gerecht und bestrafte den Mutwillen, unter inm pflugte auch der arme Bauer in Sicherheit sein Feld" (Bolesław Chrobry), ebenso die Lieder von Władysław Warnehczyk, Jan Zamoyski. Zygmunt III., Jan III. Sobieski. Ein Teil der Lieder schliesst auch mit einem summarischen Bericht uber die letzten Jahre bzw. das weitere Schicksal der geschilderten Gestalten, etwa in der Form, wie das Lied von Michal Korybut:

"Aber umsonst; dieser König erfuhr bei der besten Absicht Behinderung von den Grossen;

der Türke nimmt Kamieniec und Podolien, zettelt eine Verschwörung gegen ihn an. Nach vier Jahren erfuhr er in schnellem Tod, dass selten das Glück auf dem Throne weilt."

Dieselbe Art finden wir in den Liedern von Kazimierz Mnich, Bolesław Śmiały, Leszek Biały, Kazimierz Wielki, Hedwig. Aber auch die Ansprache benutzt Niemcewicz in mehreren Fällen, um die Hauptperson des jeweiligen Liedes am Schluss noch 
einmal zu Wort kommen $z u$ lassen. Jan Kazimierz ermahnt bei seiner Abdankung noch einmal sein Volk, das Vaterland mit allen Mitteln zu verteidigen:

"Lebt wohl, Kinder! Ich beschwöre Euch

bei der Erinnerung an die Vorfahren, bei meinem Alter, schuizt das geliebte Vaterland

mit der Waffe, stätzt es mit Ratschlägen."

Auch das Lied von Piast schliesst mit einer Ansprache des inthronisierten Königs und seinem Appell, den Ackerbau zu achten. Die gleiche Form des Abschlusses weisen die Lieder von Władysław Łokietek (Ermahnung an seinon Sohn), Wiadys\aw Jagiełło, Zygmunt August, Heinrich von Valois und Stefan Czarniecki auf. Die Duma von Stefan Potocki wird mit einem Anruf des Dichters abgeschlossen, genau so wie sie begonnen natte.

Zur Auflockerung oder auch Dramatislerung der sonst allzu eintönigen Berichte hat Niemcewicz aber auch in den Spiewy selbst, also nicht nur am Anfang und Schluss, das Gespräch in Porm von Monologen und Dialogen eingebaut. Die so entstehenden Szenen aber bleiben rein epische Formen, denn auch sie enthalten in erster Linie Beschreibungen und $\mathrm{Be}-$ richte, und die direkte Rede verdeckt auch in den Liedern, in denen sie vorherrschend ist, nicht die Tatsache, dass in diesen epischen Szenen alles vom Erzähler gestaltet ist, dass die Szene erzählt und nicht, wie im echten Drama, dargestellt wird. Das wird durch das Lied von Kazimierz Wielki veranschaulicht, in dem der König dem in Wislica versammelten volk seine Statuten ubergibt:

"...Nicht Krieg fordere ich heute von Euch, Polen!

Es ist Zeit, dass Inr in Frieden lebt, sowohl Ritter als auch Bauern!

Mögen die mit der Waffe eroberten Lande

durch Gesetze glücklich werden."

lít diesen forten nahm er die geschriebenen Gesetze aus den Händen Mielsztyns entgegen; 
Das Siegel hing an der Schleife.

"Dieses Gesetz - sagt er - enthält

den Keim für eine glückliche Zukunft,

Eure Ganzheit und Freiheit.

Es genügt nicht, fremde völker zu besiegen,

es ist an der Zeit, zu Hause glücklich zu sein;

die freche Übermacht zu bändigen,

damit sie niemandem Schaden zufügt.

Ho streng die Obrigkeit des Gerichtes,

weint die arme Witwe nicht."

Die direkte Rede enthält hier eine allgemeingültige Lehre, wie sie der Autor in fast keinem Liede auszudrücken versäumt. Die Wirkung dieser Lehren auf den Leser wird noch erhöht durch die Form der Ansprache, durch die der Leser in einen beinahe direkten Kontakt mit der dichterischen Wirklichkeit gelangt. Wieder ein Beweis dafür, dass Niemcewicz die Kunst nur als Mittel zum Zweck betrachtet, um mit ihrer Hilfe die gewinschte Wirkung bei seinem Publikum zu erzielen und seine politischen Ideen kundzugeben. In den meisten Fällen bilden diese Szenen eine Art Höhepunkt, sie enthalten in gedrängter Form den eigentlichen Sinn des Liedes, wie an dem gerade zitierten Beispiel festzustellen ist. Ebenso verhält es sich in dem liede von Bolesław Krzywousty, der auf die Forderung des deutschen Kaisers, die Oberhoheit des Reiches anzuerkennen, ausruft:

"Ich soll huldigen? - rief Bolesław, Ich, solch eine Beleidigung ertragen!

Der Pole neigt nicht vor Fremden die Stirn, solange er eine Waffe, Mut hat! Ach, hundertmal will ich in blutigem Kampf die Krone, das Leben verlieren, ehe ich die Schmach des Volkes ertrage und gemeinen Tribut leiste." 
Nicht immer aber gelingt es dem Autor, aus Berichten, Beschreibungen, Bildern und Gesprächen eine Einheit zu schaffen. In den meisten Fällen sind die verschiedenen Formen der Komposition nur lose nebeneinander gestellt, um die Gefahr der Eintönigkeit $z u$ bannen. In den Liedern von Boleslaw Smiały, Zawisza Czarny, Kazimierz Jagiellohczyk, Konstanty Ostrogski, Jan Zamoyski, Z6łkiewski, Jan Kazimierz und Stefan Czarniecki sind wohl kleine Szenen enthalten, aber sie stehen nur gleichwertig neben den anderen Strukturelementen, sie haben nicht genügend Gestaltungskraft, um eine grössere Einheit zu schaffen. Stehen in einem Lied sogar mehrere Szenen nebeneinander, wie z.B. im Liede von Zawisza Czarny, so vermindern sie gegenseitig ihre Wirkung. Dieses Nebeneinander ist Folge bzw. Ausdruck für das Nebeneinander der Handlungsreihen in den betreffenden liedern. In dergestalt komponierten Liedern herrschen Bericht und Beschreibung vor, wie in dem Liede von Bolesław Chrobry, das überhaupt nur ein einziger langer Bericht ist. Diese vorherrschende Stellung des Berichtes entspricht dem Geschehen als eigentlicher Substanzschicht der Lieder. Beschreibungen sind in vielen Liedern anzutreffen, aber es ist Niemcewicz nioht gelungen, sie zu einem wirklich plastischen Bild zu verdichten. Wesentlich mehr liegt inm die Reflexion, die nicht nur eingestreut als kurzer Satz in Erscheinung tritt, sondern durchaus strukturellen Wert hat. Da sie sehr oft in die Form der direkten Rede gefasst ist, trägt sie zur Gestaltung der epischen Szene mit bei. Letztere ist eine der hervorstechendsten Formen des Aufbaus der historischen Lieder. Niemcewicz bedient sich ihrer stets dann, wenn ein Geschehen im Mittelpunkt eines thedes steht, wie es z.B. bei dem Lebensbild Bolesław Krzywoustys der Fall ist, als dessen wichtigstes Kennzeichen der Kampf um die Unabhängigkeit Polens von Kaiser und Reich dargestellt wird. Ahnlich verhält es sich bei Kazimierz Wielki, wo das ganze lied auf das Statut von 'Wislica abgestellt ist. Das Lied von Leszek Biały be- 
steht ibberhaupt nur aus zwei grossen Szenen, verbunden durch eine kurze Uberleitung und abgeschlossen mit einer moralischen Folgerung des Autors, wie er sie in seinen Fabeln und Märchen zu ziehen pflegt. Auch "Hedwig" ist nach diesem Kompositionsschema aufgebaut: die Werbung,Jagiełłos und seine Krönung mit dem Aufruf der jungen Königin. Diese Szenen sind, trotz der dazwischen liegenden bzw. vorausgehenden Berichte doch stark genug, um das ganze Lied zu beherrschen. . Nur in einer einzigen Szene ist das Wirken Wladysław Jagieztos zusammengefasst: in der Schlacht be1 Tannenberg. Die direkte Rede ist zwar nur auf drei von dreizehn Strophen beschränkt, die dafür aber umso bedeutungsschwerer sind. Ausserdem zeichnet sich gerade diese Darstellung durch grosse Geschlossenheit aus. Eine epische Szene par excellence ist die Duma von Michał Glifski: die Einheit von Zeit und Raum bewirkt eine auch äusserlich in Eræcheinung tretende Geschlossenheit; das kurze Gespräch Glifskis mit seiner Tochter am Anfang lässt fast den Eindruck eines zu erwartenden Dramas entstehen. Der lange Monolog Glifskis, der den Hauptteil der Duma ausmacht, hebt diesen Eindruck wieder auf und fuhrt das Geschehen ganz in den Bereich des Epischen zurilck. Als weitere Beispiele für diese Form des Aufbaus sind noch die Lieder von Zygmunt August, in dessen Mittelpunkt der Reichstag von Lublin 1569 mit der Union Polen-Litauen-Preussen steht, von Heinrich von Valois zu nennen, dessen Flucht Niemcewicz zum Anlass nahm, die Hingabe der Polen an ihren König und die Vorzüge Polens überhaupt mit Hilfe einer fast dramatisch zu nennenden Szene darzustellen; endlich noch das lied von Michał Korybut, in dem die Wahl zum König und die Huldigung seiner Mutter szenisch aufgebaut sind und das Kernstluck des Liedes ausmachen.

Ein deutlicher Unterschied im Aufbau ist im Vergleich zu den anderen in den Liedern von Jan Tarnowski und Stefan Potocki festzustellen. In beiden tritt das volkstümliche Element hervor. Man könnte sie sich von einem blinden ukrainischen Bettelsänger vorgetragen denken. Das lied von Jan Tarnowski 
hat auch einen Untertitel, der schon etwas Besonderes anzeigt: die Trauer des Ritters über den Tod seines Hetman. Am Anfang beider Lieder steht ein Anruf des Erzählers.man könnte es "liedhaftes Sprechen" nennen - der den Leser in die vom Dichter beabsichtigte lyrische Gestimmtheit versetzt. Aber nur in der Duma bleibt Niemcewicz diesem Beginn entsprechend konsequent und setzt auch an den Schluss wieder ein liedhaftes Sprechen: "Höret, ihr jungen Ritter" "Schlafe, oh Ritter", während im Liede von Tarnowski diese Stimmung durch die folgenden Aufzählungen der Taten des Hetman, denen jede Spannung und vor allem auch ein Höhepunkt fehlen, vollkommen verloren geht. Dasselbe Schicksal erleiden auch die vielen Ansätze einer Dramatisierung. Sie werden stets von der Masse des berichteten Stoffes in Form von Aufzählungen und Aneinanderreihungen gleichsam erstickt. Viele Lieder, die einen vielversprechenden Anfang haben, werden dadurch, dass der Autor die Dramatisierung nicht bis zum Ende durchgeführt hat, verdorben. Auf diese Weise erhält die ganze Sammlung die Note einer gereimten Chronik. Die eigentlichen Kompositionsmerkmale der Ballade sind nur in der Duma von Michal Gliński verwirklicht worden. Sie enthält sowohl stimmung wie die in eine Szene "zusammengepresste Handlung von dramatischem Pulsschlag". I Die Stimmung wird durch den Hintergrund der "von fahlem Licht erhellten unterirdischen Höhlen" erzeugt, die ganze Handlung ist in die Sterbestunde Glifskis verlegt, der mit seiner Erzählung die Vergangenheit enthüllt. Niencewicz hat noch in anderen Liedern diese Technik versucht. Aber der Vorrang, den er den "unpoetischen Ereignissen" auf Kosten des Gefühlsmässigen Eeben zu müssen glaubte, nahm ihnen ein wesentliches Kennzeichen der Ballade: die Stimmung. Er hat versucht, sie in zwei iiedern durch Einfügung sentimentaler Szenen zu schaffen, mit. denen er an die Vorstellungswelt des Volkes appellierte: in "Leszek Biały" ist es die arme ivitwe, die das Los ihres vater-

1 Kleiner, Juliusz, Przyczynki do dziejow romantizmu w Polsc:e. Pamiętnik Literacki, Rocznik XIX, S. 21. 
losen Kindes beweint, und in "Michał Korybut" die liebende Mutter, die als erste inrem Sohne, dem jungen König, huldigt und inre Segenswünsche auf seinen schweren Weg mitgibt. Diese Szenen aber sind naiv und sentimental und keine echte, von tiefem Gefühl getragene Stimmung. Man darf dabei aber nicht übersehen, dass sich dem Gedächtnis des einfachen Menschen derartige Vorstellungen, die an sein Gemüt rühren, viel besser einprägen. Und das war ja einzig und allein der Wunsch des Autors.

Durch die ursprünglich nicht beabsichtigte Einfügung des Trauergesanges zum Gedenken des Füsten Poniatowski hat die ganze Sammlung einen von echtem Gefühl geprägten Abschluss erhalten. Dieser Trauergesang ist wohl das lyrischste der Lieder zu nennen. Die darin enthaltenen Beschreibungen und Reden bzw. Apostrophen sind durch das starke Gefühl der Trauer gewissermassen "lyrisiert" worden. Das lied ist eine Verbindung von lyrischen Elementen und realistischen Einzelheiten, Berichte wechseln ab mit Anrufen des Dichters an die traurigen Trompeten und die wehmuitigen Flöten, die auf diese Weise personifiziert werden, an ein "Du", das wohl das Volk als Einheit verkörpern soll, und an den Toten selbst. Das Lied schliesst ab mit einem Bild, das zum Sinnbild der Unsterblichkeit des gefallenen Helden wird: am Grabe Poniatowskis schärft ein Soldat, voll ritterlichen Kampfeswillens, die Waffe an dem Schilde des Toten, um durch diese symbolische Handlung die Tapferkeit des Totén auf die kommenden Generationen zu übertragen.

Die Gestaltung der Personen in den Liedern und Dumen ist, vom literarischen Standpunkt aus gesehen, wohl die schwächste Seite des Autors überhaupt, weil es inm nicht gelungen ist, aus den Königen und Helden einmalige Persönlichkeiten zu schaffen. Ihre Perspektive ist auch die des Dichters. Ihr Stil ist der des Erzählers, ihre Sprache die des Adels des 18. Jahrhunderts. Die Gestal ten leben auch nicht, durch die vielen aneinandergereihten Ereignisse werden sie gewis- 
sermassen erdrückt. Auch die Psyche der Menschen in den verschiedenen Zeitaltern hat Niemcewicz nicht erfült bzw. nicht erfühlen können. Die Nebenfiguren sind überhaupt nur ganz schematisch dargestellt, obwohl gerade sie bei der Schaffung eines charakteristischen Milieus hätten mitwirken können. Dieser Personenkreis muss sich mit kurzen Beschreibungen bzw. Urteilen zufriedengeben: der träge Mieczysław (Kaz. Mnich), der junge und kühne ziemowit, der aufbrausende Ziemowit (Hedwig) u.s.w. Von allen Personen lernen wir in erster Linie ihr Äusseres kennen, ihre Kleidung. Aber auch dieses Bild ist selten plastisch, nur dann, wenn der Autor sich malerischer Epitheta bedient, wie z.B. bei der Beschreibung der Engel im Liede vom Piast: schneeige Flügel, weisse Gewänder, dunkles Haar. Die Figuren können auch gar nicht eigenwertig sein, da ja die strukturelle Fihrung in diesen Liedern und Dumen eindeutig beim Geschehen liegt. Bei der Darstellung der Helden ist bemerkenswert, dass sie so oftals als weinend gezeigt werden: Kazimierz Mnich, Wladysław Jagiełło, Zawisza Czarny, Glifski Zygmunt I., Heinrich von Valois, Z6łkiewski und Jan Kazimierz, aio alle vergissen bittere Tränen. Diese Darstellungsweise ist charakteristiscn fur den Sentimentalismus, aber auch für die Volksdichtung, die seelische Vorgänge durch die Angabe der äusserlichen Reaktion darstellt. Auch das Volk weint in den Spiewy, seiner Freude aber gibt es singend Ausdruck. Ebenso ist die schematische Darstellung der Helden ein Kennzeichen der Volksdichtung, die nicht nur die Situationen typisiert, sondern auch Personen.

Bei der Kritik der vielen Mängel künstlerischer Art aber darf nicht vergessen werden, dass die Spiewy zur didaktischen Dichtung gehören und somit "als zweckbestimmte und also nicht mehr autonome Literatur ausserhalb der eigentlichen Dichtung stehen". 2

2 Kayser, WolfEang, Das literarische Kunstwerk, Bern 1948.

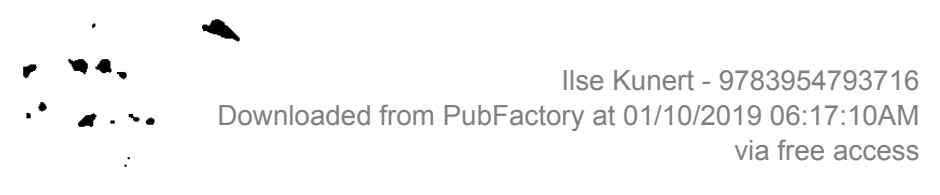


Das Wesentliche an den historischen Liedern und dem Gesamtwerk von Niemcewicz uberhaupt ist nicht die Kunstfertigkeit, die äussere Form, sondern der Inhalt und vor allem der Geist, der diesen Inhalt formt: die uneingeschränkte und durch nichts wandelbare Liebe des Autors zu seinem Vaterland. Und dieser Geist war auf die Zeitgenossen umso wirksamer, als Niemcewicz selbst seinem Ideal nie untreu geworden ist und es dem Publikum gleichsam vorgelebt hat. Darauf beruht zu einem gewissen Teil auch seine geschichtliche Autorität, die nicht nur bei den zeitgenössischen Lesern der mittleren und auch höheren Schichten, sondern in den späteren Jahren auch beim Volk wirksam war und blieb. 
(n)

25if Hof

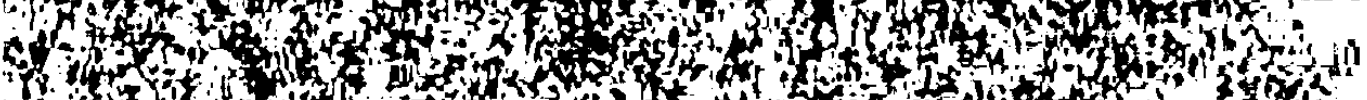

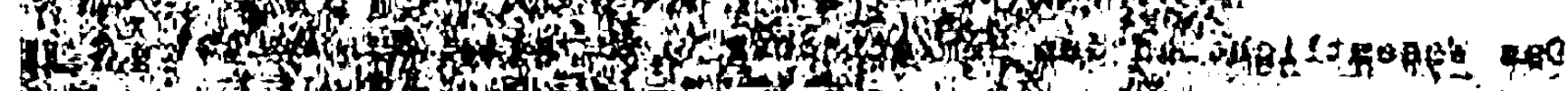

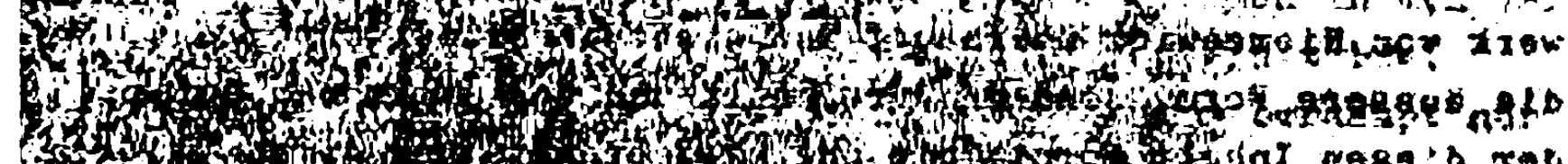
sive

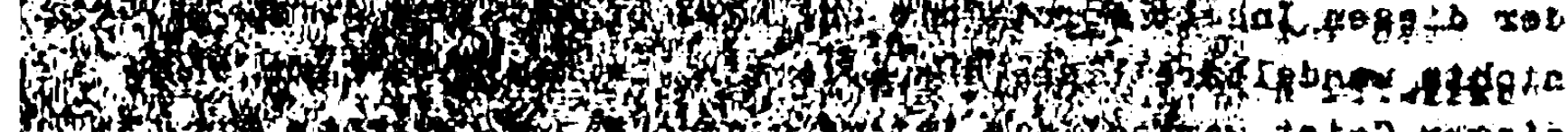
Mo of Went Fon

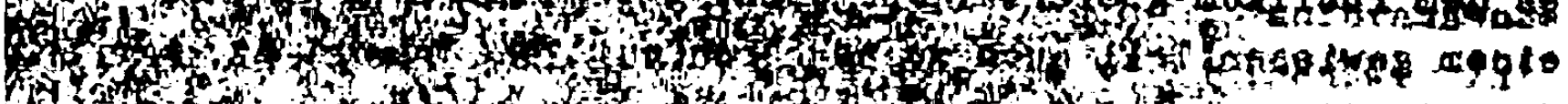
(5) (4)

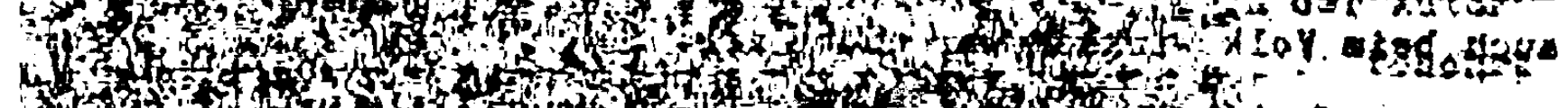

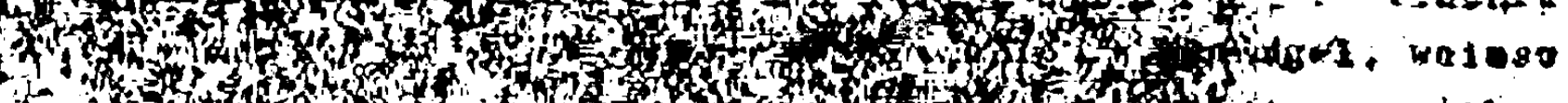

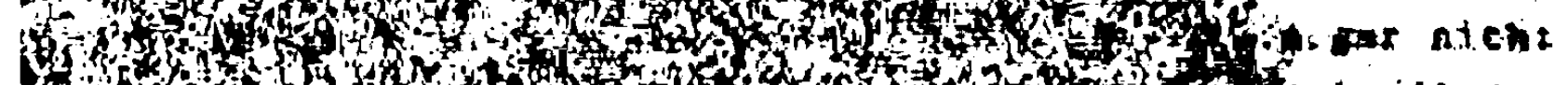

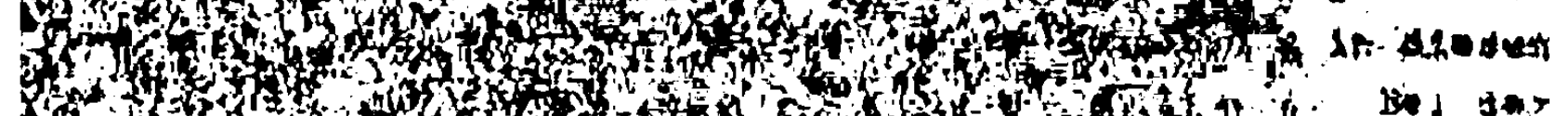

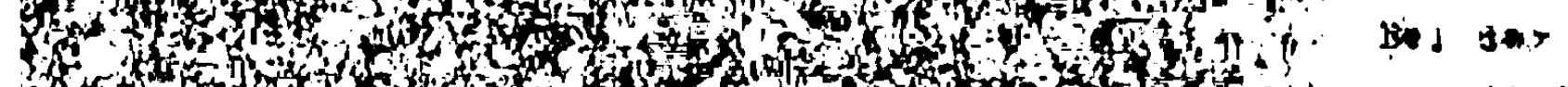

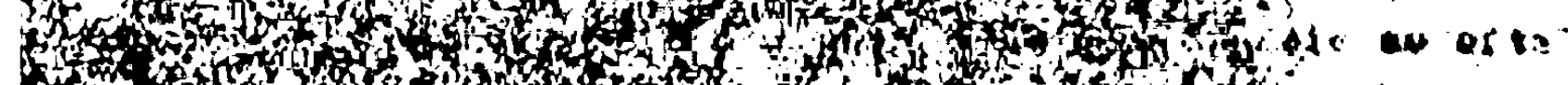
Hof (1)

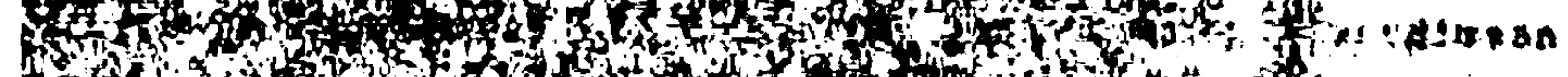

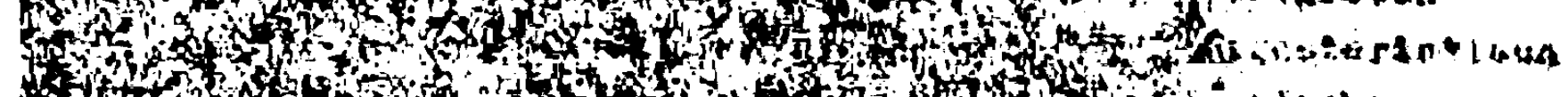

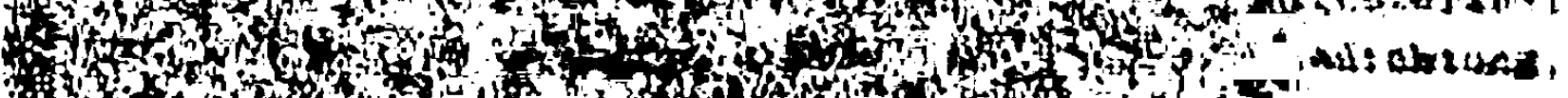

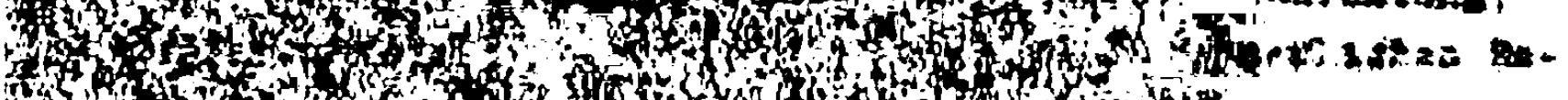

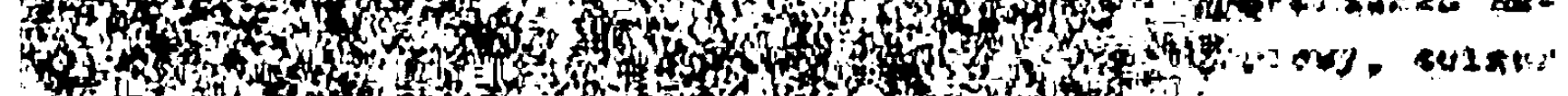
rat sond

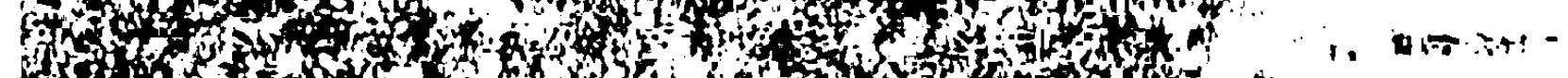
H. 3 ind

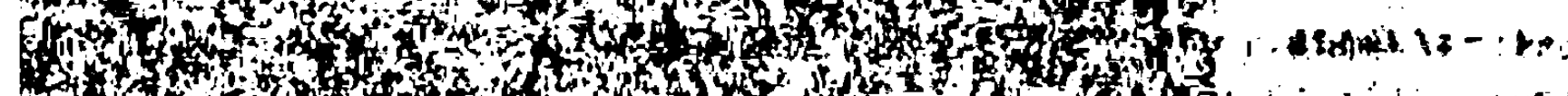

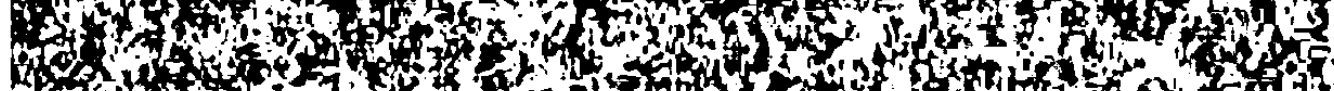

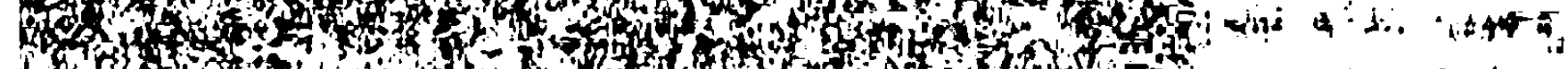

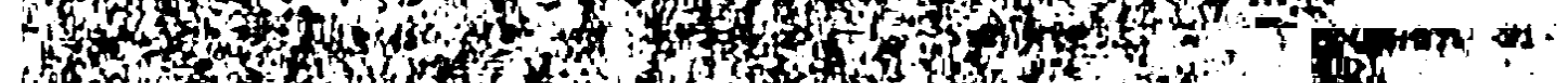

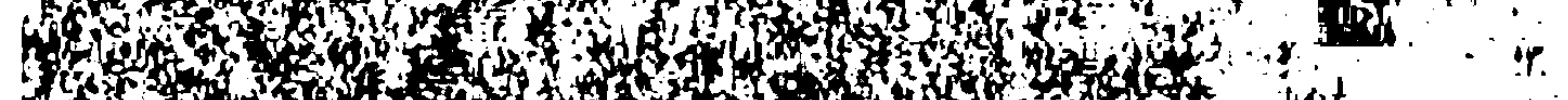

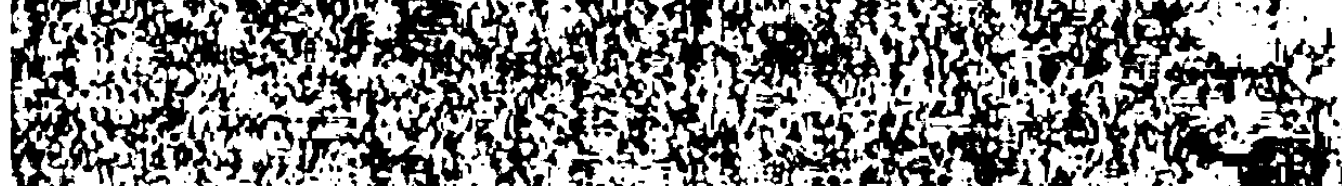

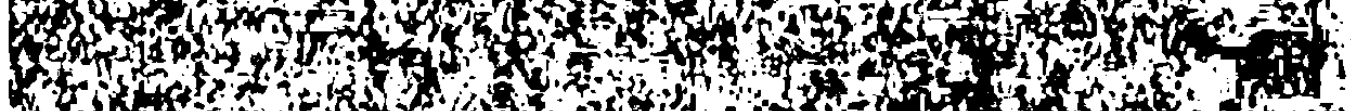

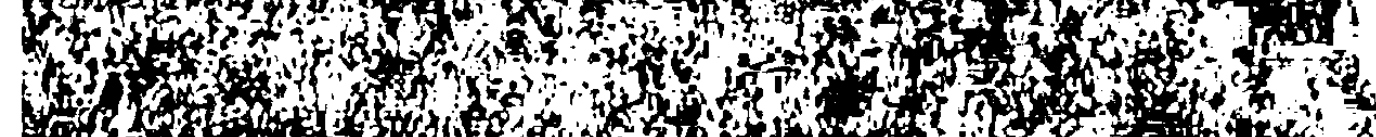

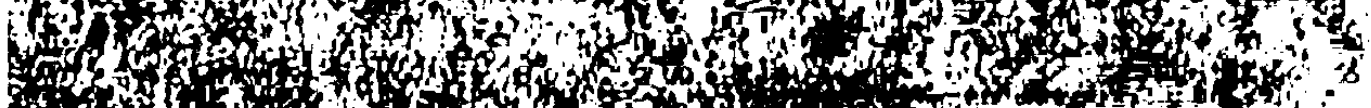

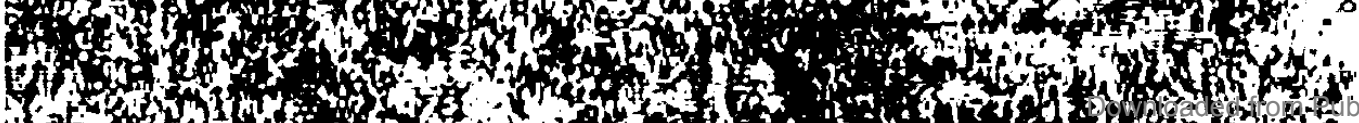

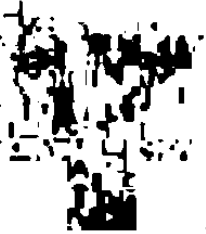

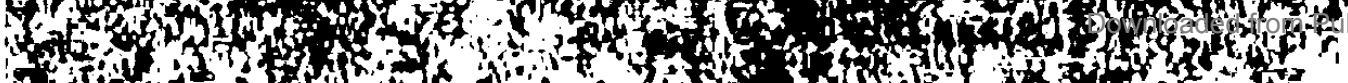




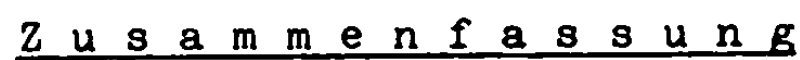

Die von Niemcewicz auf diese Art und Weise dargestellte Geschichte des polnischen Staates entspricht durchaus nicht dem in der Einleitung von inm selbst gesteckten Ziel: der wahrheitsgetreuen Berichterstattung von den ".bedeutendsten Taten des polnischen Volkes". Wohl scheint sich der Autor an die Uberlieferung der Chronisten zu halten. Er bringt auch keine wirklichen Fälschungen. Aber seinem anderen Leitsatz entsprechend, die "beruhmtesten Epochen" darzustellen, hat er sich, von wenigen Ausnahmen abgesehen, bemüht, die weniger ruhmreichen Ereignisse aus dem polnischen Geschehen wegzulassen oder aber nur am Rande zu erwähnen, so dass sie gewissermassen im Schatten der glänzenderen Taten stehen. Musterbeispiel für diese Taktik ist der Schluss des Liedes von Zygmunt III.: "Wenn auch ohne Nutzen, so waren die Zeiten Zygmunts doch voller Ruhm". Nur ein einziges Mal hören wir auch aus dem Munde unseres Dichters eine harte Kritik an seinem eigenen Volk, und zwar in bezug auf die Behandlung der Kosaken: "Unsre Habgier und unmenschlichen Strafen empörten das tapfere Volk der Kosaken". (Jan Kazimierz 2).

Zur Eerklärung und bis zu einem gewissen Grade auch zur Entschuldigung dieser idealisierten Geschichtsdarstellung muss wiederum auf die eigenen Worte des Autors verwiesen werden: "Die Jugend an die Taten ihrer Vorfahren zu erinnern, sie mit den ruhmreichsten Epochen des Volkes bekanntzumachen, Vaterlandsliebe mit den ersten Eindrucken zu verbinden, ist ein unfehlbarer Weg, im Volke'eine starke Verbundenheit zur Heimat zu erwecken". 1 Diese Aussage ist für die Auswahl des Stoffes massgebender als die Stellen, an denen Niemcewicz von der wahrheitsgetreuen tberlieferung spricht (der Dichter-Historiker schreibt nur das, was war). Diese Ausfïhrungen des Autors sollen eigentlich nur die von den

I J.U. Niemcewicz, Śpiewy Historyczne, Paryż 1868. S. I. 
Balladen und Romanzen abweichende Form der historischen Lieder motivieren.

Niemcewicz war ja schliesslich und endich kein Historiker, er wollte es auch gar nicht sein. Darum sah er die Geschichte und ihre Probleme auch mit anderen Augen an. Für ihn als Publizisten und erst recht als Menschen der Aufklärung war die Historie nur ein Hilfsmittel, mit dem er das Volk aus seiner Lethargie zu neuen grossen Heldentaten, ihrer Ahnen würdig, erwecken wollte.

Niemcewicz selbst hat in der Vorrede $z u$ seiner historischen Erzählung "Jan z Tęczyna" definiert, was er unter Geschichtsschreibung (im Gegensatz zum historischen Roman) versteht: "Die Geschichte stellt die wichtigsten Ereignisse der Königreiche heraus, zeichnet die Befehle der Monarchen auf, die Taten der vortrefflichsten Ratgeber und Fuhrer, die Bewegungen an den Höfen der Monarchen; immer auf dem Gipfel der Höhe, sinkt sie nicht in die privaten Gesellschaftsschichten hinab, tritt sie nie in die niedrigen Lehmhutten des Volkes". Auch aus den weiteren Erläuterungen, die Niemcewicz uber das Wesen des historischen Romans gibt, geht seine Einstellung zur Geschichte hervor. Niemcewicz betont, dass in einem solchen Werk der Schriftsteller Einzelheiten darstellt, die für den Historiker zu gering sind, wie z.B. Menschen aller Stände, ihre Sprache und ihr Tun, an Hand derer man die Gesellschaft, die politische Situation eines Landes, Bildung, die Leidenschaften und sogar die Vorurtelle erkennt. Der historische Roman ist also "wenn ich so sagen darf, die drklärende Ergänzung der strengen und ernsten Geschehnisse". Diese Auffassung aber hat Niemcewicz offensichtlich von Bodin ubernommen, denn Czarnik fuhrt die Zeitschrift "Astra", IV, 3-13 aus dem Jahre 1823 an, in der eine Ubersetzung des Artikels von Felix Bodin aus der Pariser "Revue Encyclopédique" rom

2 J.U. Niemcewicz, Jan z Tęczyna; zitiert bei Bronisław Czarnik, Spor Literacki o nJana z Tęczyna". Pamiętnik Literacki Rocznik IV, S. 208. 
Februar 1823 erschienen war unter dem Titel "Bemerkungen zur romantischen Literatur und inrer Anpassung an Geschichte, Altertum und Volksbräuchen. Caarnik stellt fest, dass Niemcewicz diese Ausführungen z.T. Wörtlich wiederholt hat. Czarnik berichtet des weiteren ausfuhrlich von dem Streit, der sich zwischen Dzieduszewski, der die Geschichtsauffassung Niemcewicz's mit Schillerschen Argumenten angreift, und Chłędowski entwickelt hatte. Chłędowski weist in sei- . ner Verteidigung darauf hin, dass Niemcewicz ja nicht die Menschheitsgeschichte, sondern die Nationalgeschichte meint und dass in dieser die "wichtigsten Ereignisse der Königreiche, die vortrefflichsten Taten und Befehl der Monarchen und inrer Berater" ersten und unmittelbaren Einfluss auf die Schicksale der völker haben. Czarnik kommentiert diese Motivierung als nicht sehr logisch, zieht aber die Möglichkeit in Erwägung, dass die Auffassung Herders in den IIdeen zur Philosophie der Geschichte der Menschheit" (1784-1791), dass nämlich jedes Volk allein, wie die ganze Menschheit, nach der Erlangung des grösstmöglichen Grades von Humanität strebt, die Einstellung Niemcewicz's beeinflusst haben könnte. In jedem Pall aber stimmt die in der Einleitung zu der historischen Erzählụng "Jan 2 Tęczyna" geäusserte Auffassung mit der in den Siewy praktisch angewandten uberein. In der Vorrede $z u$ den Liedern teilt Niemcewicz seinen Vorsatz mit, die "bedeutendsten Taten" zu schildern. Die in den Splewy enthaltenen Berichte scheinen diesem Vorsatz zu widersprechen. In Wirklichkeit aber kommt es auch hier wiederum nur auf den Aspekt an, unter dem man diese Darstellungen bzw. ihre Wichtigkeit betrachtet. Geht man davon aus, was in den Augen des Volkes wichtig ist, so hat der Autor richtig ausgewählt. Denn er hat offensichtlich danach seine Wahl getroffen, was das Gemút eines einfachen Menschen am meisten und am bleibendsten beeindruckt. Die langanhaltende Nachwirkung seiner Lieder in den unteren Schichten, von der Bystroh sagt, wie schon erwähnt, dass sie noch bis in die 
Jahre vor dem ersten Weltkrieg zu spüren war, hat dem psychologischen Fingerspitzengefül des Publizisten Niemcewicz durchaus recht gegeben. Noch ein zweites Moment aber ist bei Niemcewicz̀ ohne Frage für die Zusammenstellung der geschichtlichen Ereignisse massgebend gewesen: die Uberlegung, wie weit sich die friheren Geschehnisse auch auf die Gegenwart oder jüngste Vergangenhe1t beziehen lassen. Diese Aktualität ist in allen seinen Werken zu spüren, in einigen, wie dem Drama von Kazimierz Wielki, ist es sogar zum Kompositionsprinzip geworden; sie ist auch hervorstechendste Ursache für den erstaunlichen Publikumserfolg der Śpiewy. Und wenn man die Lieder nur aus dieser Perspektive heraus noch einmal liest, ist man fast versucht, diese Gegenwartsbezogenheit direkt als strukturelles Element zu bezeichnen. Damit wäre auch die Wirkung auf die höchsten Schichten der polnischen Gesellschaft der damaligen Zeit erklärt, die Niemcewicz ganz bewusst mit diesem Mittel zu erzielen verstand. Dieses bewusste Streben nach Wirkung, das sich in der persönlich-menschlichen Sphäre des Autors in oftmals kleinlicher und aufdringlicher Effekthascherei in der Manier eines Mannes, dem öffentliche politische Tätıgkeit versagt geblieben war, äusserte, fand in seinen Werken und ganz besonjers in den Spiewy, geläutert durch den reinen patriotischen Geist, seinen sinnvollen Niederschlag.

Die Untersuchung des Inhalts und seiner Darstellung, der Form und der künstlerischen Mittel hat die verschiedenartigsten Aspekte der Spiewy historyczne aufgezeigt. Viele davon würden dazu berechtigen, Niemcewicz und dieses Werk der Ära des Pseudoklassizismus zuzuordnen. Für diese Annahme spräche als wichtigstes Argument der didaktische Charakter der Lieder. "Die Menschheit zu bilden" war ein pädagogisches Schlagwort der Aufklärung. Aber vor allem in der Behandlung der Geschichte und in ihrer Darstellung finden sich viele Elemente, die ihren Ursprung in der Aufklärung hatten. Wenn Friedrich Meinecke in der "Entstehung des Historismus" der Aufklärungshistoriographie den Vorwurf macht, dass sie nicht 
die gewohnten Vorstellungen der eignen Zeit in sich unterdrückt hat, um die eigene Vergangenheit richtig sehen zu können, so gilt das auch für Niemcewicz. Auch er erliegt dem naiven Hang, mit den eigenen Erkenntnismitteln die Uberlieferung gewissermassen zu überfliegen, $d . h$. sich uber sie hinwegzusetzen. Bei Niemcewicz kam noch das Bestreben hinzu, zeitbezogen und aktuall zu sein. Grundsätzlich war eine oft voreilige Vereinfachung der Geschichte die Folge, besonders was die lösung geschichtlicher Rätsel anbelangt. Als weiteres Merkmal dieser Position ist noch die Neigung des Autors zu nennen, in den meisten Fällen die geschichtlichen Ereignisse in ihrer Vollendung darzustellen, ohne deren Entwicklung aufzuzeigen, was durchaus dem Perfektionsgedanken der Aufklärung entsprach. Auch die Betrachtung der Geschichte als ein Nebeneinander von Einzelerscheinungen, charakteristisch für die Śpiewy, ist dem Ideengut der Aufklärung entnommen; Die Stoffansammlung, die den kilnstlerischen Wert der Spiewy so nachteilig beeinflusst, ist ein Zeichen des ausgeprägten utilitaristischen Geistes. Von der künstlerischen Seite gesehen, ist die Zeichnung der Personen, vor allem der Helden, noch ganz im klassizistischen Geist verhaftet. Die Menschen in den historischen Liedern sind Menschen im allgemeinen, manchmal vielleicht auch Polen im allgemeinen, und zwar so, wie sie zu allen Zeiten waren, ohne dass sie sich in ihren historischen und lofalen Besonderheiten von einander abheben wiurden. Die eincelnen Könige und Heerführer bleiben isoliert, ohne innere Verbindung zu der Gesellschaft, in der sie leben. Aber abgesehen von dieser Gestaltung der Hauptpersonen und der allgegenwärtigen Tendenz oder, besser gesagt, dem lehrhaften und moralisierenden Geist, den die ganze Sammlung ausstrahlt, sind die eben genannten Symptome auf den ersten Blick gar nicht erkenntlich. Offensichtlicher dagegen sind die Merkmale, die Niemcewicz von den Pseudoklassizisten, zu denen er ja dem Alter nach gehören müsste, unterscheiden. 
In erster Iinie fällt seine wenig sorgfälțige Arbeitsweise auf, deren deutliche Zeichen auch an den Spiewy sichtbar werden, obwohl sich Niemcewicz in diesem Palle, wie pioszewski nachweisen konnte, doch noch zu etlichen Verbesserungen bereit gefunden hat, aber erst nach Aufforderung durch die Kritiker aus den Reihen der Gesellschaft der Freunde der Wissenschaften. Den vornehmen Stil, wie ihn die Klassizisten prlegten, hat Niemcewicz schon in der Einleitung unter dem Hinweis auf den besonderen Charakter der Iidder abgelehnt, d.h. er glaubte, der stil durfe weder zu niedrig noch zu gehoben sein. 3 Das gleiche ist von dem mythologischen Stil zu sagen, uber den der Autor sich zwar nicht geäussert hat, von dem aber nur geringe Spuren in den Liedern zu finden sind.

Die grösste Bedeutung komgt den Elementen zu, die schon auf die grossen Umwälzungen vorausweisen, die nicht nur in der Iiteratur, sondern in der ganzen Geisteshaltung der nächsten Generation vor sich gehen werden. Dazu sind die Stilzuge zu rechnen, die im vorangehenden Kapitel nachgewiesen werden konnten, u.a. die Verwendung von Iicht- und Farbeffekten, die Rolle der Natur. Und wenn Niemcewicz in den Liedern von Hedwig und Stefan Batory das Heldentum der Frauen besingt, so ist aurh dieses Thema neu für die polnische Iiteratur, von besonderem Reiz noch dadurch, dass diese Motive und Ereignisse nicht erdacht, sondern geschichtilch $2 u$ belegen sind. Einen wesentlichen Faktor auf diesem Wege zur Romantik hatten wir im Gebrauch des Syllabotonismus kennengelernt. Und last not least die äussere Form der Iieder, angelehnt andile alte Volksballade. Die genaue Untersuchung der Lieder hat ergeben, wie wenig wirklich balladeske Züge in ihnen enthalten sind. Dafür zeigen sich umeo mehr Elemente, die der polnischen Volksdichtung eigen sind, wie z.B. der Syllabotonismus oder verschiedene sprachliche Erscheinungen, die nur zu einem Teil

3 Niemcewicz,J.U. Spiewy historyczne. Paryz 1868. S. IV. 
Archaismen sind, zum anderen aber landschaftlich bedingte Relikte des Altpolnischen. Hinzu kommen noch die vielen Merkmale, die für alle Volksdichtung charakteristisch sind, wie die formelhaften Epitheta, Parallelismen oder die Neigung zur schablonenhaften Darstellung der Personen. Alle diese Symptome zusammen ergeben ein etwas anderes Bild von den Absichten Niemcewicz's in Bezug auf die Einflihrung dieser neuen Form in die polnische literatur. Er wollte nämlich mit den historischen Dumen und Liedern nicht nur die Geschichte Polens in den Herzen des Volkes und der Jugend wachhalten, sondern. mit ihnen auch die seiner Meinung nach nur unterbrochene Tradition der patriotischen Volkslieder. wieder aufleben lassen. Typisch aufklärerisch noch seine Meinung, mit Hilfe von Kunstliedern den schöpferischen Mangel in der Volksdichtung ausgleichen zu können, schon romantisch, zumindest aber vorromantisch, dagegen die angewandten Mittel. Typisch auch die Anschauung, die schon von einem gewissen Traditionalismus (im Gegensatz zum Historismus), Ansätzen zu induktiver Methode und vor allem der Propagierung eines Staptsideals geprägt ist, das aus der Sehnsucht nach der idealisierten Vergangenheit geboren ist. Auch die von Niemcewicz selbst in der Vorrede zu der Brzählung "Jan z Tęczyna" geäusserte Auffassung von der Geschichte die sich aus anschaulichen, nach geschichtlichen Gemeinschaften bestimmten Entwicklungen zusammensetzt, d.h. aus Nationalgeschichten, muss in diesem Zusammenhang noch einmal erwähnt werden. Alle diese züge sind geboren aus dem hervorbrechenden Patriotismus. Fur echte volkstüliche Dichtung war die Zeit in Polen noch nicht reif und auch Niemcewicz seinem Wesen und seiner ganzen Erziehung nach nicht in der Lage. Seine historischen Lieder tragen den deutlichen Stempel der tbergangszelt. Da sie also zwischen zwei literarischen und geistesgeschichtlichen Epochen stehen, muissen sie auch gewisse Merkmale beider in sich vereinigen. Niemcewicz selbst ist das Verbindungsglied zwischen der Epoche 
Stanisław August's und der Romantik, deren Ankïndigung in seinen Werken und besonders in den Spiewy schon so deutlich zu erkennen ist, dass man sie zur Vorromantik zählen kann. Diese vorbereitende Periode stellt im Gegensatz zur Romantik weniger "un ensemble logique et lie" dar als vielmehr "une collection d'efforts isoles" 4 , von denen ein grosser Teil schon bei Niemcewicz anzutreffen ist. Fir inn gilt auch, was Julian Krzyżanowski als kennzeichnend für die polnische Vorromantik nennt: die Anschauung, dass die Hauptaufgabe des Schriftstellers die Verbindung des Schönen mit dem Nützlichen sei, d.h. die Belehrung, von Schönem zur Abwehhslung unterbrochen "zdrową dat naukę $i$ młodym i starym, co pierwszy ma byc zawsze poety zamiarem". 5

Niemcewicz's Stellung in der allgemeinen Literaturgeschichte wird wohl am besten von der Feststellung Juliusz Kleiners umrissen, dass bei Niemcewicz, dem grössten Vertreter dieser vorromantischen Epoche, der Grundzug der Epoche, die Rezeptivität, am deutlichsten wird. Zugleich bewahrt Niemcewicz aber auch, im Vergleich zu seinen Zeitgenossen, die grösste Selbständigkeit.

Niemcewicz's Bedeutung für die Polen hat Stefan Witwicki, ${ }^{6}$ ein Freund Mickiwicz's, am schönsten ausgedrückt, wenn er sagt, dass nicht jedes Volk und dann auch nicht in jeder Epoche seines Daseins ähnliche Männer aufweisen kann, in denen steh so das ganze Leben dieses Volkes zusammenballt, dass sie wie zu einer Personifizierung dieses Volkes würden. Einer dieser Männer, mit denen die Vorsehung ein Volk segnet, sei Niemcewicz gewesen!

\footnotetext{
4 van Tieghem, Paul, Le Romantisme dans la litterature europeenne. Paris 1948, S. 24.

5 Krzyzanowski, Julian, Historia Literatury Polskiej. Warszawa 1953 , S. 441.

6 Zitiert bei Chrzanowski, Ignacz, 1.c. S. 575.
} 


\section{Literaturverzeichnis}

B $\circ \mathrm{h} \circ \mathrm{m} \circ \mathrm{l}$ e c, Franc. Zycie Jana Zamoyskiego. Bibl.Polska, Krak6w 1860.

B r u c h n a l s ki, Wilh. Mickiewicz-Niemcewicz.Pamiętnil Lit., Roczn.II, Lw6w 1903.

B u d z y k, Kaz.

Polski Sylabotonizm. Pamiętnik Iiter., Roczn.XIVI,Z.1. Warszaw, 1955.

B y 8 t $r \circ h$, Jan

Iiteraci i Grafomani z Czasbw Kr61.Kongr.1815-31. Iw6w 1913.

B y $8 t r \circ h$, Jan Polska Piesh ludowa. Lwbw 1925.

Cambridge History of Poland, the

Cambridge University Press 1951.

C hl e b o w s ki, Bron.

Ia fittêrature Polonaise au XIX siecle. Paris 1933.

$c h \circ d$ y $n$ i c k 1 , Karol

Poglądy na Zadania Historyi

w Epoce Stan.Aug.Prace histor.lit.Nr.15. Warszawa 1915.

C h r a n o w s ki, Ign. $\dot{C} w$ i $k$, waad.

Historya Literatury Niepodległej Polski. Warszawa $\mathbf{3 . a .}$

Wpływ "Ruin" Volneya na "Sybille" Horonicza. Pam.lit., Roczn.XII; Lw6w 1913.

Czz a r n i k, Bron.

Spor Iiteracki o "Jana 2 Tęczyna" Pam.Lit., Rocznik IV, Lw6w 1905.

C z a r t $\mathrm{r}$ y $8 \mathrm{k}$, Adam zywot J.U. Niemcewicza. Berlin- Posen 1860.

D \pm u s k a, Maria

Studja 2 Historil 1 Teorii Wersyfikacji Polskiej. I-II. Krak6w 1948.

D I u s k a, Maria

Prozodia Jezyka Polskiego. Krak8w 1947. 
$G 6 \times 8 k 1$, Ign.

G 6 r s k 1, Konrad

J a n k 0 w s k 1, Wlad.

J a r e c k 1, Kaz.

K a y s e $r$, Wolfg.

K I e I n e r, Juliusz

K I 1 d 1, Manfred

K r z y z a n 0 w $s$ k 1 ,Julian

$M 1 k$ u 1 s k 1, Tad.

N a r u s e wi c z, Adam

N 1 e m c e w 1 c z, J.U.
Historja Literatury Polskiej. Warszawa 1953.

Iiteratura 0bwiecenia.' In: O Sytuacj1. w Historil Ii teratury Polskiej. Krak6w 1953.

Ballada Polska przed Mickiewiczem.Yrace hist.-11t., ir .13 , Warszawa 1915.

Staropolszczyzna w Języku A. Mickiewicza.Pam.Lit.Roczn.XIVI, Z.1. Warszawa 1955.

Geneza i Dzieje "Śpiewow Historycznych" Niemcewicza. Pam.lit. Rocznik IX, Lw6w 1911.

Idee historyozoficzne Woronicza a mesyanizm polski. Pam.Lit. Rocznik III, Lw6w 1905.

Das sprachliche Kunstwerk. Bern 1948.

Kleine deutscine Verslehre. Bern 1949.

Przyczynki do dziejow romantyzmu w Polsce. Pam.Lit. Roczn.XIX. Lw6w 1921.

Die polnische Iiteratur. Hdb.d. Lit.-Wis8.: Ii teratur d. slav. volker. (1929)

Iiteratura Polska Wieku XIX,I, Warszawa 1930.

Zywot J.K.Chodkiewicza. Krakbw 1858. Spiewy Historyczne. Paris 1868. Spiewy Hiatoryczne. Warsz.1947

Dwaj Panowie Sieciechowie. Wrockaw 1950.

Dzieje Panowania Zygmunta III. Krakau 1860.
Dzie1a.I-V. Krakau 1883-1880. 
O b $r$ \& $b \mathrm{~s} a-J a b \pm \circ h s k a$, Antonia

8d Archaizmu do Nowej Pormy Je zykowej.Stylistyka teoretyczna w Polsce. Warszawa 1946.

P 10 s z e w s k 1 , Leo

T a $r$ n 0 w $s$ i, Stan.

$\mathrm{T} \pm \mathrm{e} \mathrm{g} \mathrm{h}$ e $\mathrm{m}$, Paul van

U jejski, Jbzef

$W$ a $z \mathrm{y} k$, Adam

Z
Pierwsza Redakcja"Śpiewbw hist." Niemcewicza.Pam.Iit. Rocz.XV, Iwow 1916.

Historya Iiteratury Polskiej. III-IV, Krak6w 1904.

Le Romantisme Dans La Iittérature Europeenne. Paris 1948.

Dzieje Polskiego Mesjanizmu do Powstania Listopadowego włącznie. Lw6w 1931.

Mickiewicz i Wersyfikacja Narodowa. Warszawa 1951.

Polen, Gotha 1916. 